UNIVERSIDADE DE SÃO PAULO

ESCOLA DE ENGENHARIA DE SÃO CARLOS

DEPARTAMENTO DE ENGENHARIA MECÂNICA

Estudo do comportamento das deformações em flanges obtidos pelo processo de estampagem incremental através de elementos finitos $e$ projeto de um suporte modular

\author{
MICHAEL FURLANETTI
}


MICHAEL FURLANETTI, Engenheiro Mecânico.

\section{Estudo do comportamento das deformações em flanges obtidos pelo processo de estampagem incremental através de elementos finitos e projeto de um suporte modular}

Dissertação apresentada à Escola de Engenharia de São Carlos, Universidade de São Paulo, como parte dos requisitos para obtenção do título de Mestre em Engenharia Mecânica.

Área de Concentração: Processos de Manufatura e Projeto Mecânico

Orientadora Profa. Dra. Luciana Montanari

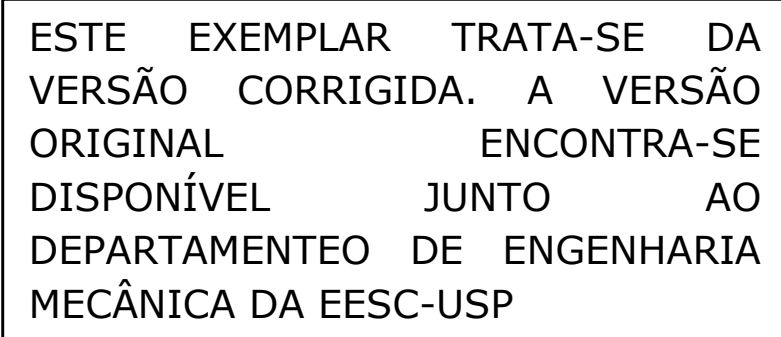

São Carlos

2014 
AUTORIZO A REPRODUÇÃO TOTAL OU PARCIAL DESTE TRABALHO, POR QUALQUER MEIO CONVENCIONAL OU ELETRÔNICO, PARA FINS DE ESTUDO E PESQUISA, DESDE QUE CITADA A FONTE.

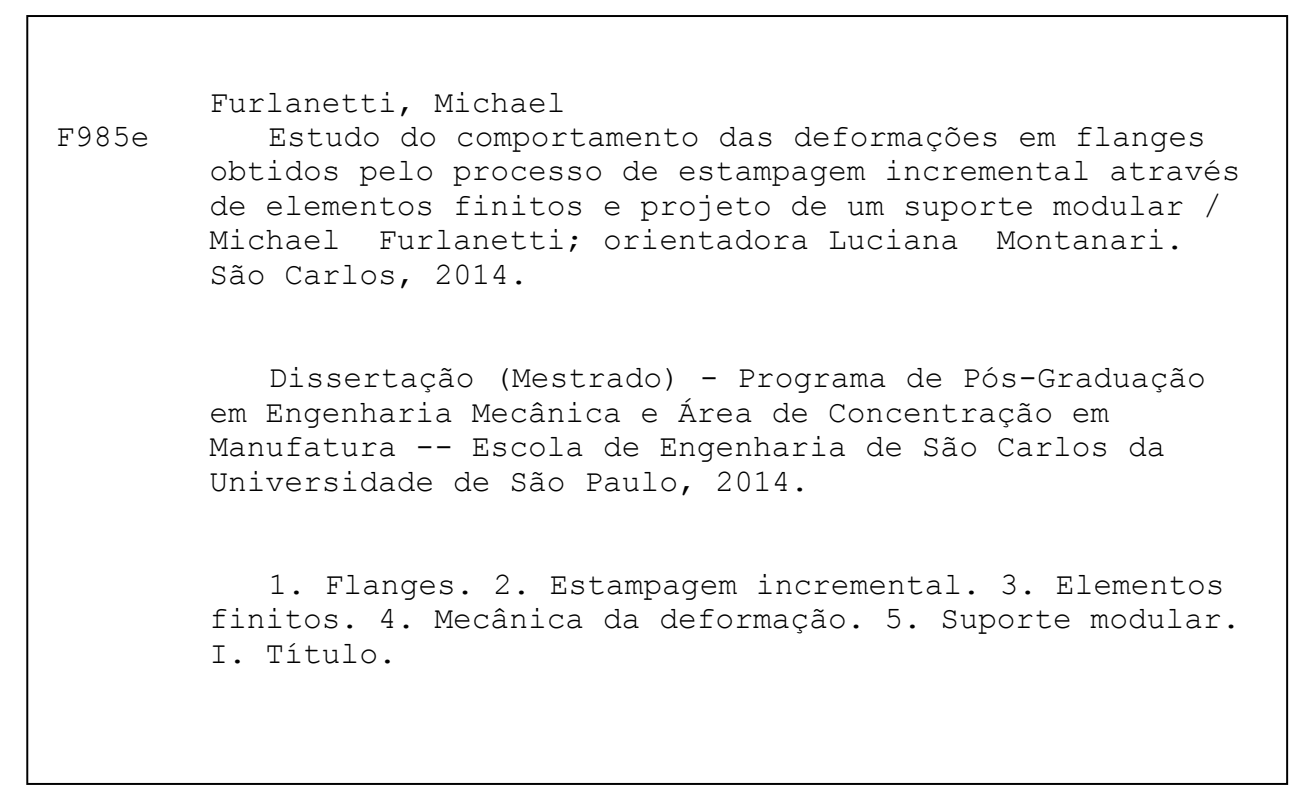




\section{FOLHA DE JULGAMENTO}

Candidato: Engenheiro MICHAEL MIGUEL FURLANETTI.

Título da dissertação: "Estudo do comportamento das deformações em flanges obtidos pelo processo de estampagem incremental através de elementos finitos e projeto de um suporte modular".

Data da defesa: 08/10/2014

Comissão Julgadora:

Profa. Dra. Luciana Montanari (Orientadora)

(Escola de Engenharia de São Carlos/EESC)

Prof. Dr. Sergio Henrique Evangelista

(Universidade Federal de São Carlos/UFSCar)

Prof. Dr. Sergio Tonini Button

(Universidade Estadual de Campinas/UNICAMP)
Resultado:

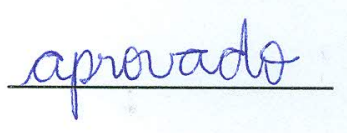

APROVADO

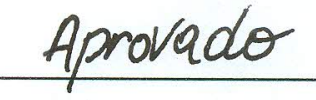

Coordenador do Programa de Pós-Graduação em Engenheira Mecânica:

Prof. Associado Marcelo Areias Trindade

Presidente da Comissão de Pós-Graduação:

Prof. Associado Paulo César Lima Segantine 
Aos meus pais Maurilio e Eliana 


\section{AGRADECIMENTOS}

A Prof.a Dra. Luciana Montanari, pela orientação, estimulo, paciência e confiança durante todas as etapas deste trabalho.

Ao Prof. Dr. Sergio Henrique Evangelista pelo apoio técnico na elaboração das simulações em elementos finitos apresentadas.

Ao Prof. Dr. Ernesto Massaroppi pela paciência na avaliação das simulações iniciais em elementos finitos.

Ao Prof. Dr. Jaime Gilberto Duduch, pelas discussões das quais resultaram as avaliações de projeto do suporte apresentado.

Aos Técnicos do Laboratório que contribuíram no projeto do suporte modular com sugestões baseadas nos vários anos de experiência que possuem.

A meus pais Maurilio e Eliana e minha irmã Milena, por propiciarem condições, me encorajarem e me apoiarem durante a execução deste trabalho. 


\section{RESUMO}

FURLANETTI, M. M. Estudo do comportamento das deformações em flanges obtidos pelo processo de estampagem incremental através de elementos finitos e projeto de um suporte modular. 2014. $107 \mathrm{f}$. Dissertação (Mestrado) Escola de Engenharia de São Carlos, Universidade de São Paulo, São Paulo, 2014.

A estampagem incremental é um processo de deformação incremental de chapa que pode ser classificado em três modos distintos: estampagem incremental sem matriz, estampagem incremental com matriz parcial e estampagem com matriz total. A deformação ocorre devido ao contato entre a ferramenta e a chapa, localmente e progressivamente, ao longo de uma trajetória pré-definida. A chapa permanece presa a suportes que fixam as suas extremidades de maneira a impedir os deslocamentos provocados pela passagem da ferramenta. A primeira parte deste trabalho compreende estudos em elementos finitos, usando o software LS-Dyna ${ }^{\mathrm{TM}}$, sobre a trajetória das deformações na estampagem incremental para a fabricação de flanges em chapas previamente furadas de liga de alumínio AA1050. Foram realizados testes de contato e de linha que permitiram definir parâmetros da simulação. Os resultados para as deformações foram confrontados com os resultados obtidos experimentalmente por outros autores e permitiram verificar o comportamento das deformações nos flanges. As deformações crescem montonicamente até os valores máximos. Este resultado confirma a teoria de que na estampagem incremental de chapas a fratura ocorre sem o prévio aparecimento da estriç̧ão. A segunda parte deste trabalho trata do desenvolvimento de um suporte modular aplicável aa estampagem incremental, tanto na sua variante sem matriz quanto com matriz, com o intuito de aumentar a flexibilidade do processo com relação à geometria da peça a ser deformada. Foi empregada a técnica de análise de valor objetivando alcançar a melhor funcionalidade do sistema. Como resultado foi obtido um suporte modular que atende os requisitos de rigidez, flexibilidade, modularidade, agilidade na troca da chapa a ser deformada e simplicidade construtiva.

Palavras-chave: Flanges, estampagem incremental, elementos finitos, mecânica da deformação, suporte modular. 


\begin{abstract}
FURLANETTI, M. M. Study of the behavior of deformations in hole-flanging produced by incremental sheet forming using finite elements and design of a modular rig. 2014. 107 f. Dissertação (Mestrado) - Escola de Engenharia de São Carlos, Universidade de São Paulo, São Paulo, 2014.
\end{abstract}

The sheet incremental forming can be classified into three basic configurations, depending on the number of contact points between the sheet, tool and die (when present). Single incremental forming (absence of specific dies) and two point incremental forming (presence of a partial or full die) can be distinguished. The process makes use of a simple, low-cost, hemispherical tipped tool to precisely and progressively shape a blank into a metal sheet along a predefined tool path. The sheet is fixed onto the rig to prevent lateral displacements caused by tool movement. The first part of this work includes studies about finite elements, using the LS-Dyna ${ }^{\mathrm{TM}}$ software, applied to deformation path in hole-flanging produced by incremental sheet forming. The investigation was carried out using aluminum alloy AA1050. Contact and line numerical results support simulation parameters choices. The results from the strains were compared with empirical ones obtained by other authors. The results showed the deformation mechanics behavior of the hole-flanging. The strain paths of hole-flanging produced by incremental sheet forming grew linearly and monotonically from the origin to the maximum achievable strains. This result confirms the absence of local necking along plane strain directions. The second part of this work deals with the development of a modular rig that can be applied to dieless, partial or total die single point incremental forming in order to increase the flexibility of the process concerning the geometry of the part to be deformed. The result was a modular rig with constructive simplicity and requirements of stiffness, flexibility and modularity when exchanging sheets.

Keywords: Hole-flanging, incremental sheet forming, finite elements, deformation mechanics, modular rig. 


\section{Sumário}

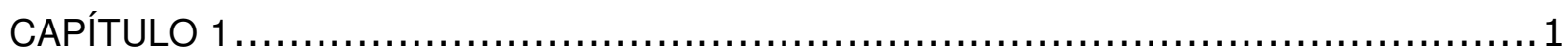

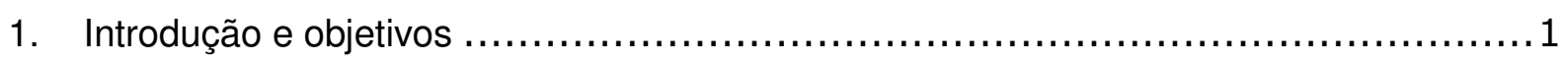

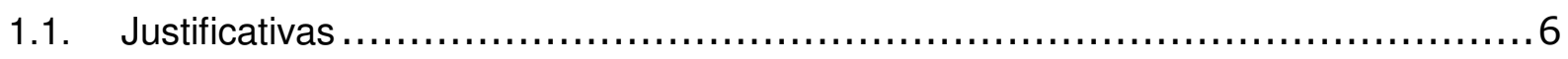

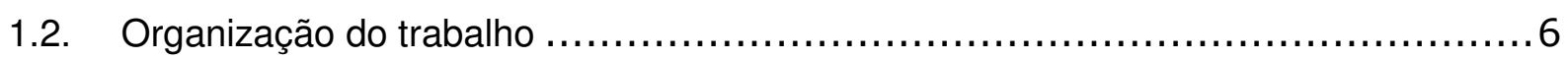

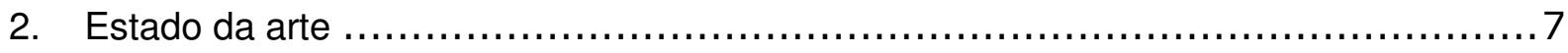

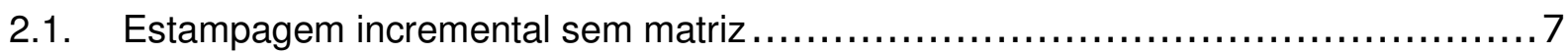

2.2. Estampagem incremental com ferramenta auxiliar $\ldots \ldots \ldots \ldots \ldots \ldots \ldots \ldots \ldots \ldots \ldots \ldots$

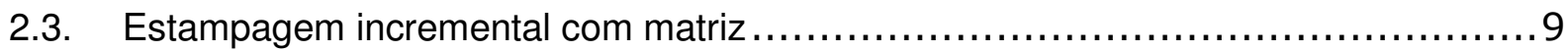

2.4. Vantagens e desvantagens da estampagem incremental $\ldots \ldots \ldots \ldots \ldots \ldots \ldots \ldots \ldots \ldots \ldots \ldots \ldots \ldots \ldots$

2.5. Parâmetros da estampagem incremental .................................. 12

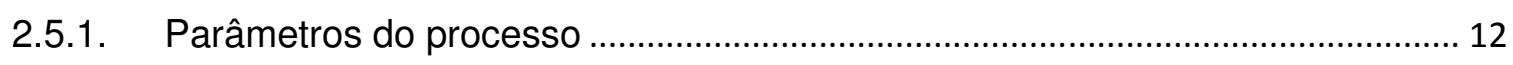

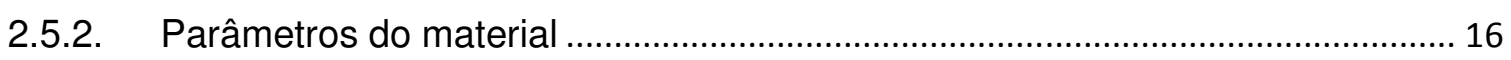

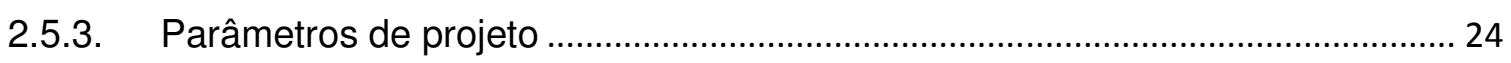

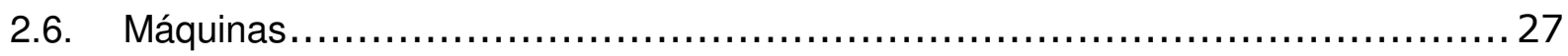

2.7. Outras abordagens da estampagem incremental ............................ 28

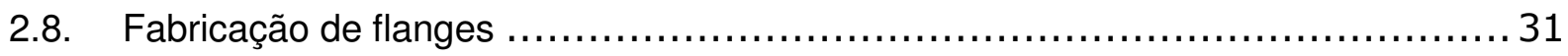

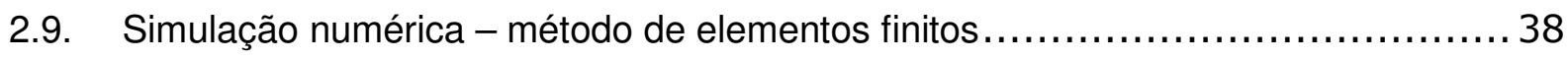

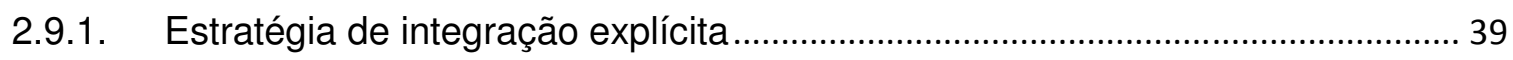

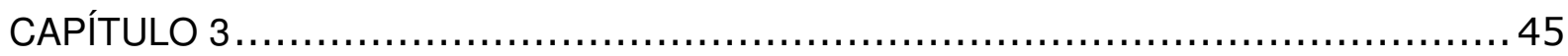

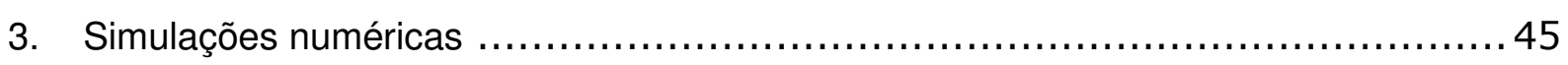

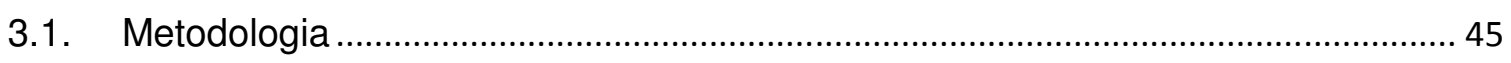

3.1.1. Definição do sistema e construção do modelo e geometria .................................. 46

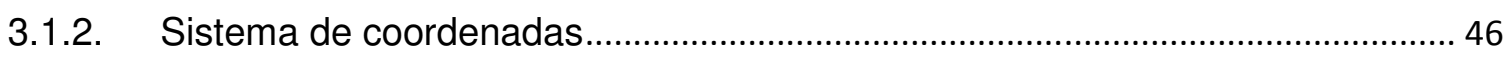

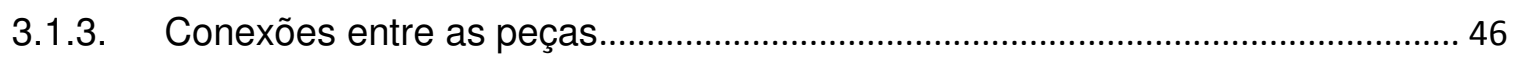

3.1.4. Tipo de elemento usado na simulação ............................................................. 47

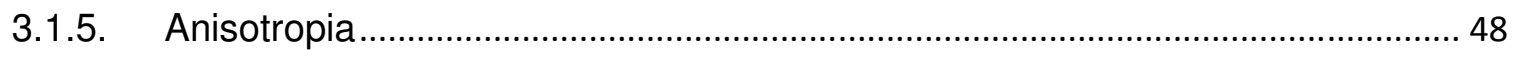

3.2. Execução das simulações............................................... 51

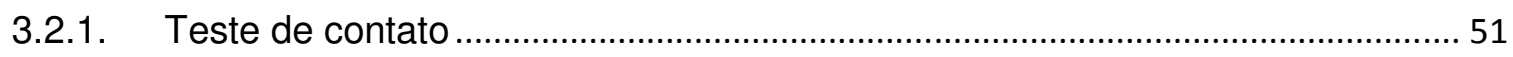

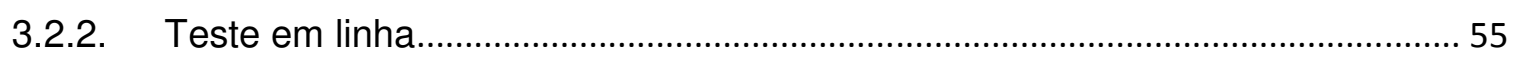

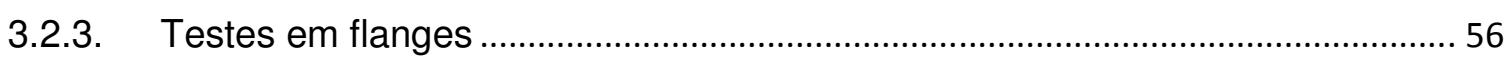




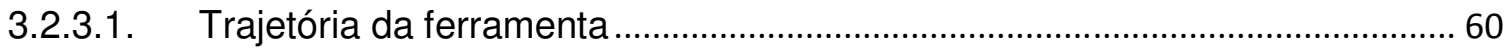

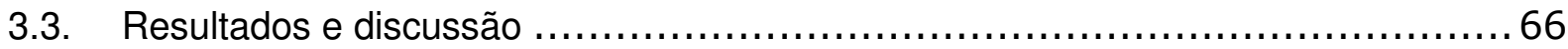

3.3.1. Estudo da trajetória das deformações................................... 66

3.3.2. Redução da espessura da chapa ...................................... 74

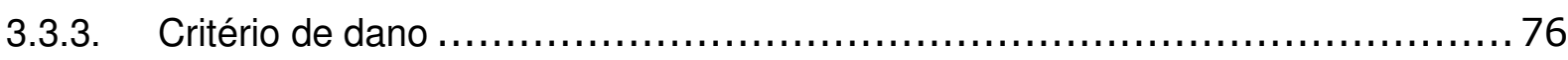

3.3.3.1 Determinação das tensões atuantes................................. 79

3.3.3.2 Determinação das tensões hidrostáticas ............................... 81

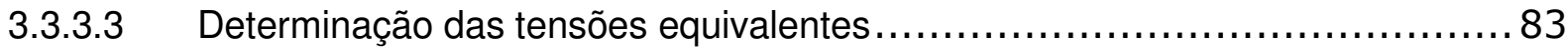

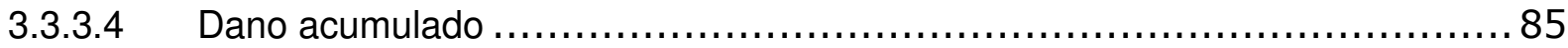

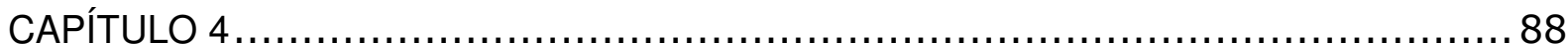

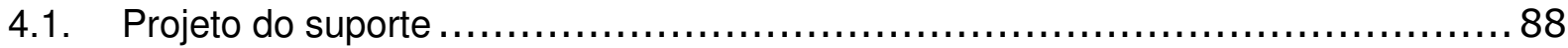

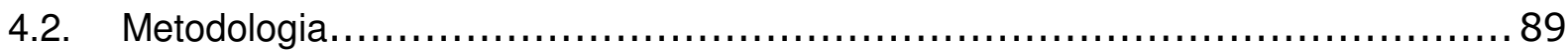

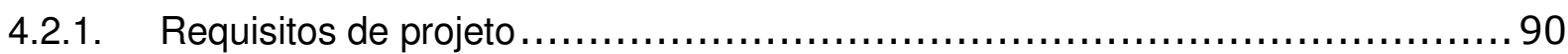

4.3. Etapas do Projeto e suas Características ................................... 91

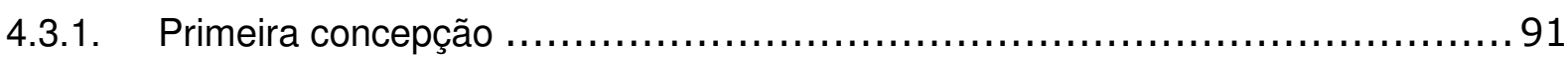

4.3.2. Segunda concepção................................................... 92

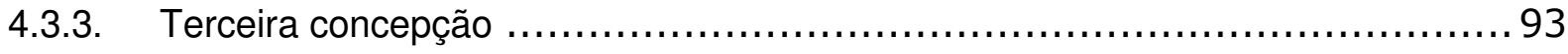

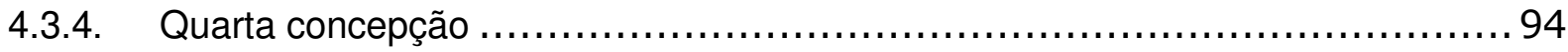

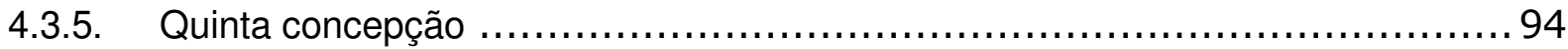

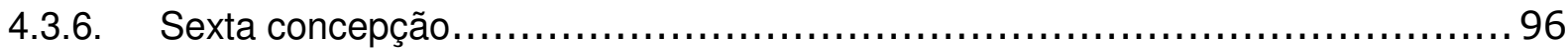

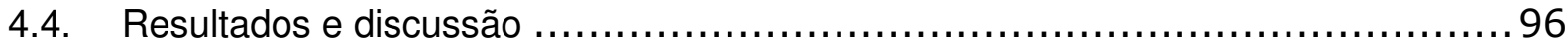

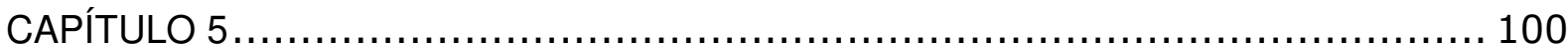

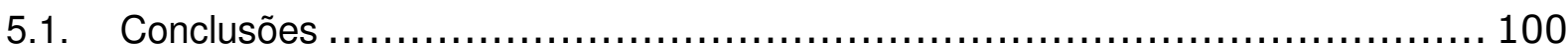

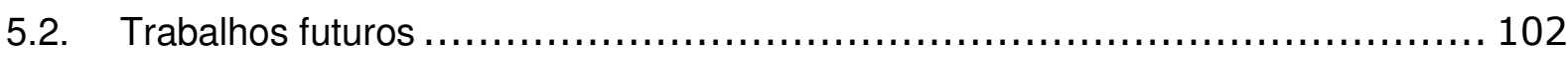

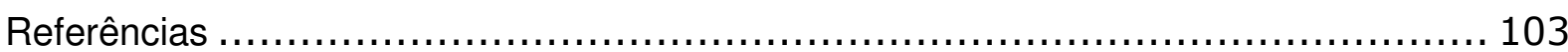




\section{CAPÍTULO 1}

\section{Introdução e objetivos}

A estampagem incremental, um dos vários processos de deformação plástica incremental, tem sido desenvolvido e amplamente investigado ao longo da última década, devido à sua capacidade de substituir as operações de estampagem convencional na fabricação de pequenas séries ou séries unitárias (JESWIET et al., 2005a; ECHRIF; HRAIRI, 2011a).

Nesse processo a superfície da chapa permanece livre, somente as bordas permanecem presas a um dispositivo para evitar que se desloque durante 0 processo de deformação, como mostra a Figura 1. A deformação plástica ocorre pelo contato entre a ferramenta e a superfície da chapa, localmente e progressivamente (FRATINI et al., 2004 e EMMENS e BOOGAARD, 2009).

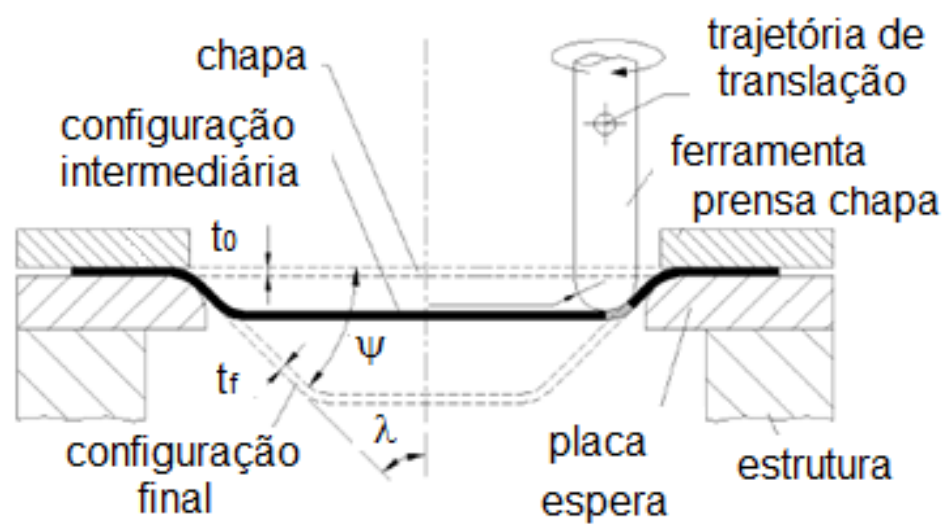

Figura 1 - Representação esquemática da estampagem incremental sem matriz. Adaptado de Silva et al. (2008a).

A estampagem incremental de chapas pode ser classificada em três formas distintas, sendo elas a estampagem incremental sem matriz, estampagem incremental com o emprego de uma ferramenta auxiliar do lado oposto da chapa e a estampagem incremental com matriz (parcial ou total), como apresentado na Figura 2. 


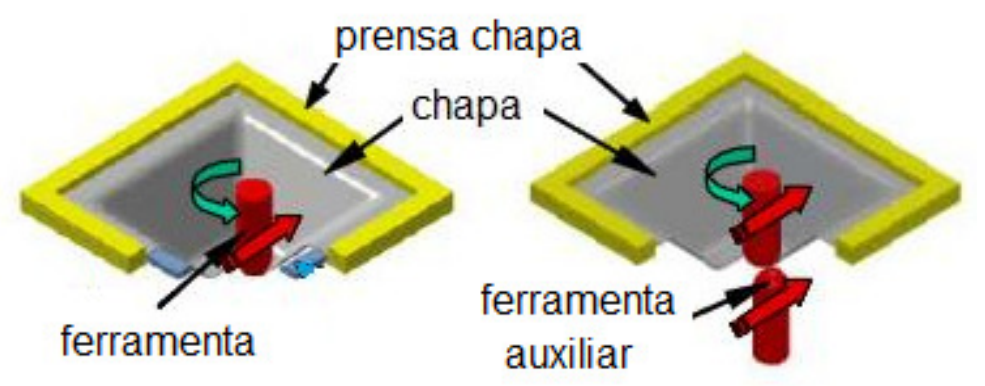

(a)

(b)

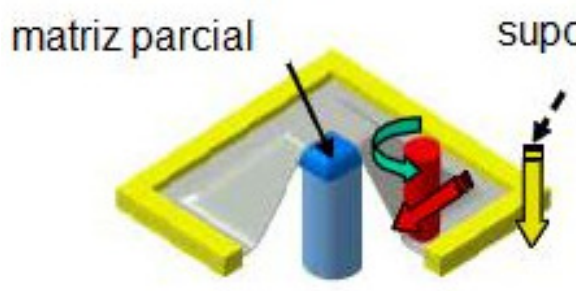

(c)

uporte móvel matriz total

Figura 2 - Configurações que caracterizam a estampagem incremental. (a) sem matriz, (b) com ferramenta auxiliar, (c) com matriz parcial, (d) com matriz total. Adaptado de Jeswiet et al. (2005a).

A estampagem incremental com ferramenta auxiliar é muito semelhante a estampagem incremental sem matriz (Figura 2(a) e (b)). A principal diferença reside no fato da utilização de uma ferramenta auxiliar do lado oposto da chapa que pode ter ou não a mesma trajetória que a ferramenta principal (Figura 2(b), dependendo da complexidade da geometria a ser obtida). Neste caso, o movimento da ferramenta auxiliar requer controle independente, que pode ser fornecido por meio de uma máquina específica ou através de um mecanismo de acionamento auxiliar. Essa forma é empregada quando há máquinas exclusivamente projetadas para esta técnica de deformação incremental (Alwood et al., 2005) e/ou quando se emprega braços robóticos.

Já a estampagem incremental com matriz apresenta duas variantes, sendo elas a estampagem incremental com matriz parcial e a estampagem incremental com matriz total, cujas representações esquemáticas podem ser observadas na Figura 2(c) e (d), respectivamente.

$\mathrm{Na}$ estampagem incremental com matriz parcial, a matriz suporta apenas determinadas áreas da chapa (ver Figura 2(c)). Por outro lado, uma vez que a matriz 
é apenas parcial, não apresenta uma geometria específica, possibilita a sua utilização na produção de peças com geometrias diversas. Deste modo, esta variante do processo é mais versátil e flexível que a estampagem incremental com matriz total (Figura 2(d)).

Além das máquinas exclusivamente projetadas para deformar incrementalmente as chapas, é comum o emprego de centros de usinagem com comando numérico computadorizado (CNC). Exceto para a configuração com ferramenta auxiliar (Figura 2(b)), pode-se adaptar um dispositivo para a fixação da chapa ao centro de usinagem (JESWIET et al., 2005a). Há variações no dispositivo quando se trata da estampagem incremental sem matriz e com matriz. Para a variante de estampagem incremental sem matriz emprega-se uma estrutura fixa (Figura 2(a)) e na variante de estampagem incremental com matriz, parcial ou total, emprega-se uma estrutura móvel (Figura 2 (c) e (d)). A mobilidade da estrutura está na parte superior, onde a chapa está fixada, possibilitando movimento vertical, de modo a acompanhar o movimento da ferramenta que está acoplada ao eixo-árvore da máquina, contrariamente ao que se observa nas estruturas fixas.

É dentro desse contexto que surge um dos propósitos deste trabalho: projetar e fabricar um suporte adaptável ao centro de usinagem, que seja capaz de suportar as forças impostas sobre a chapa, tenha rigidez e área útil suficientes para a fabricação das peças com geometrias e dimensões diferentes, além de ser de fácil instalação e retirada da máquina, garantindo a flexibilidade do processo. $E$ também deve ser adaptável à estampagem incremental com matriz parcial e total.

A facilidade de adaptação a centros de usinagem e a flexibilidade do processo contribuem para a diminuição do tempo e dos custos de processamento de materiais, especialmente para a produção de protótipos, de pequenas séries ou séries unitárias, atraindo e incentivando as empresas para o emprego da técnica de estampagem incremental, sendo especialmente atrativo para indústrias automotivas, aeronáuticas e também da área médica (DUFLOU et al., 2005 e ARAÚJO et al., 2014). Sendo assim, muitas pesquisas estão voltadas para, por exemplo, desenvolver o processo, buscar a técnica para se obter novas geometrias, aplicar novos materiais ao processo e determinar os seus limites de conformação e simular o processo para aperfeiçoá-lo. 
Neste sentido há estudos direcionados ao processo de fabricação de flanges circulares em chapas previamente furadas (Figura 3(a)) (CENTENO et al., 2012; SILVA et al., 2013) pela estampagem incremental sem matriz, já que pela estampagem convencional a fabricação de flanges em chapas previamente furadas, aumenta drasticamente a complexidade do ferramental, seus custos e, consequentemente, os custos do produto final (PETEK; KUZMAN, 2012), especialmente quando se trata de peças, cujos flanges se localizam em lugares difíceis para executar a operação de estampagem convencional (Figura 3(b)).

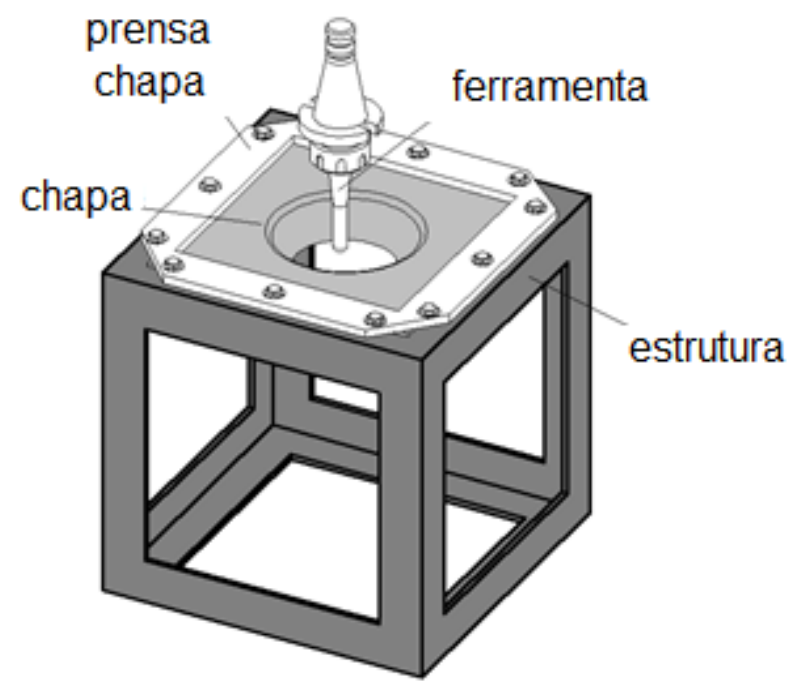

(a)

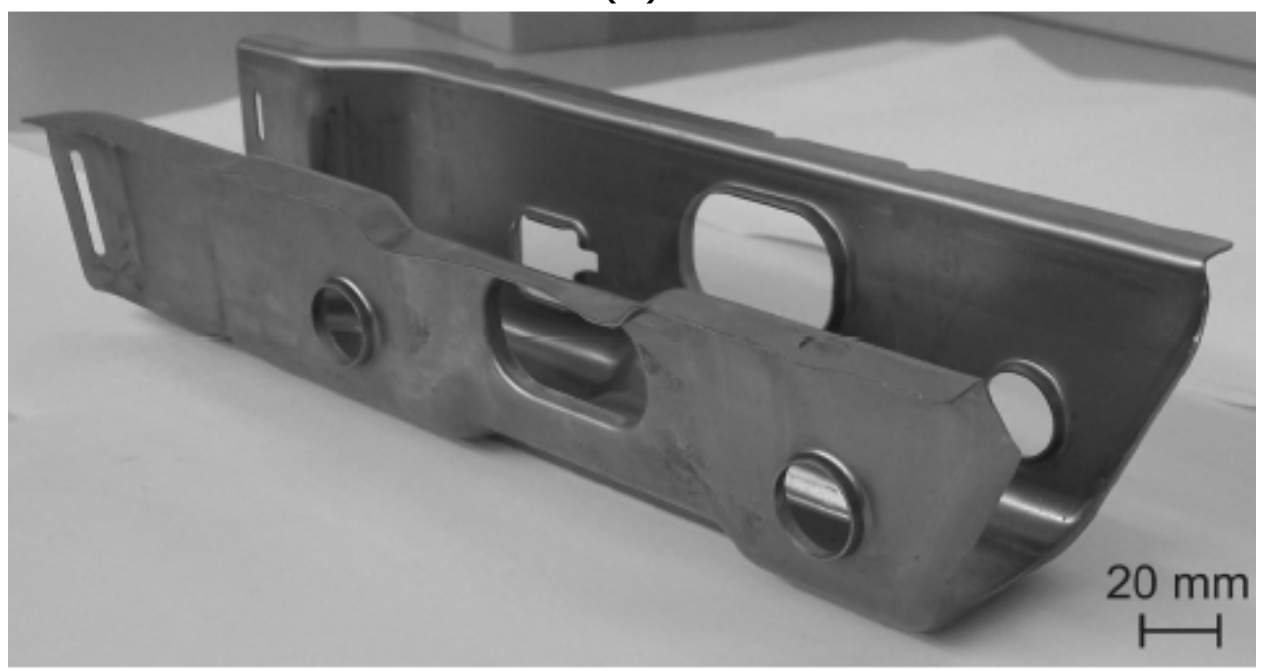

(b)

Figura 3 - Flanges circulares. (a) Fabricação pela estampagem incremental de chapas. Adaptado de Montanari et al. (2013). (b) Exemplo de aplicação de flanges (PETEK et al., 2011). 
O primeiro trabalho de pesquisa sobre fabricação de flanges circulares a partir de chapas previamente furadas por estampagem incremental foi realizado por Cui e Gao (2010), que estudaram a influência da trajetória da ferramenta e a sua implicação nos limites de conformação da liga de alumínio AA1060. Outros investigadores, tais como Petek, Hirt, Centeno, Silva e Martins, continuam as suas pesquisas sobre a estampagem incrementa e os seus mecanismos de deformação para a obtenção de flanges a partir de chapas previamente furadas.

Foi dentro desse contexto que Montanari et al. (2013) estudaram a trajetória das deformações e a fratura em flanges circulares obtidas pelos processos de estampagem com diferentes diâmetros de furos previamente cortados para a liga de alumínio AA1050 H111.

Os resultados de Montanari et al. (2013) foram obtidos a partir de trabalhos experimentais. Como forma de auxiliar a fabricação de flanges por estampagem incremental e comparar numericamente os experimentos realizados é providencial realizar estudos de simulação numérica, que é uma técnica de resolução de problemas, por meio da observação do comportamento de uma representação particular de um sistema em uma base de tempo.

Desse modo, esta dissertação de Mestrado tem dois objetivos gerais. Um deles é validar um modelo em elementos finitos para a fabricação de flanges em chapas previamente furadas pela estampagem incremental sem matriz, usando o software LS-DynaTM. Seu uso permitirá predizer o estado de deformações durante o processo e, consequentemente, prevenir possíveis falhas no processo. Os resultados da simulação serão comparados com os valores experimentais apresentados em Montanari et al. (2013) para as mesmas condições. Além disso, deseja-se prever a região onde, provavelmente, ocorrerá a falha por fratura. Essa análise será realizada pela redução de espessura em diversas regiões da parede dos flanges e usará o critério de dano de Rice e Tracey (1969). Os resultados encontrados serão comparados com os apresentados por Cristino et al. (2014).

O segundo objetivo deste trabalho é desenvolver um suporte modular que será empregado na estampagem incremental, tanto na sua variante sem matriz quanto com matriz. 


\subsection{Justificativas}

A estampagem incremental de chapas é uma tecnologia que ainda carece de maiores investigações científicas sobre a sua eficácia no processo, a sua viabilidade econômica e melhorias. $O$ emprego de simulação em elementos finitos neste estudo visa identificar o comportamento das deformações e, com isso, expandir o conhecimento a respeito da estampagem incremental que se mostra tão promissor, possibilitando prever o nível de deformação atingido e a região propícia à ocorrência de falha por fratura. Após a realização deste estudo, certamente a área de manufatura da Escola de Engenharia de São Carlos evoluirá.

\subsection{Organização do trabalho}

Além deste capítulo introdutório, a Dissertação de Mestrado conta com mais quatro capítulos.

No Capítulo 2 são abordados aspectos gerais sobre a estampagem incremental, as suas variantes, os parâmetros que influenciam o processo, a fabricação de flanges e, por fim, serão mostrados alguns trabalhos na área que utilizam o método de elementos finitos para validar algumas proposições.

O Capítulo 3 define uma metodologia para a simulação de flanges em chapas previamente furadas através do software LS-Dyna ${ }^{T M}$. E, na sequência, neste mesmo capítulo estão os resultados e as discussões sobre as simulações.

Já o Capítulo 4 apresenta o desenvolvimento do suporte modular que será adaptado ao centro de usinagem para a fabricação de peças pela estampagem incremental nas variantes com e sem matriz. Serão apresentados alguns conceitos do suporte e os seus princípios de funcionamento. Será realizada a tomada de decisão, a fim de obter o suporte modular mais adequado para a tarefa.

No Capítulo 5 são apresentadas as conclusões e as propostas para trabalhos futuros.

Ao final dessa dissertação encontram-se as referências usadas neste trabalho. 


\section{CAPÍTULO 2}

\section{Estado da arte}

Neste capítulo serão apresentados tópicos sobre estampagem incremental sem matriz, estampagem incremental com ferramenta auxiliar, estampagem com matriz (parcial e total), parâmetros que influenciam o processo, máquinas, desenvolvimentos da estampagem incremental, o processo de fabricação de flanges e aplicações do método de elementos finitos. A seguir está a descrição de cada um deles.

\subsection{Estampagem incremental sem matriz}

A estampagem incremental é um processo no qual a trajetória da ferramenta é prédefinida, e imprime deslocamentos graduais e localizados sobre a superfície de uma chapa. Um centro de usinagem pode ser adaptado para executar o processo. A adaptação consiste em ajustar uma ferramenta ao eixo-árvore e fixar um suporte na mesa de trabalho do centro de usinagem. A chapa permanece presa ao suporte por meio do prensa chapa, que fixa as suas extremidades de maneira a impedir deslocamentos (Figura 4). A ferramenta é de ponta esférica ou hemisférica e é acoplada ao eixo-árvore do centro de usinagem e sua trajetória é dada pelo CNC.

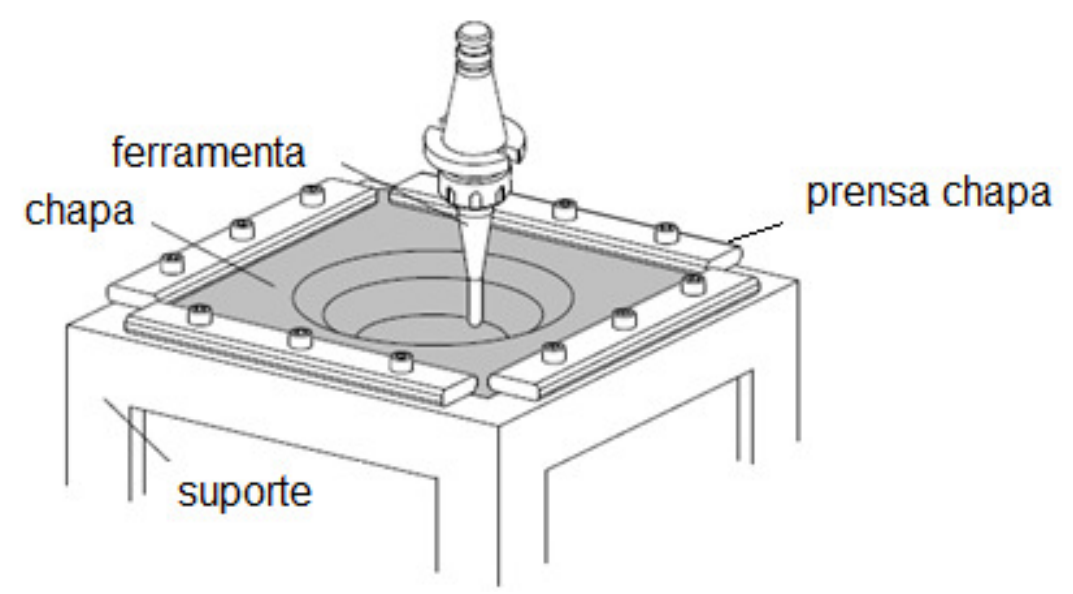

Figura 4 - Representação esquemática da estampagem incremental (CRISTINO e MARTINS, 2013). 


\subsection{Estampagem incremental com ferramenta auxiliar}

A estampagem incremental com ferramenta auxiliar é muito semelhante a estampagem incremental sem matriz. A principal diferença é o uso de um segundo ponto de contato sob a chapa, do lado oposto da ferramenta principal, que pode acompanhar a ferramenta principal, como na Figura 5, servindo assim como apoio local e assistindo localmente a deformação (MEIER et al., 2011; MEIER et al., 2009). Meier et al. (2009) mostram que o processo com uma ferramenta auxiliar resulta em uma região menor de abaulamento na periferia das peças conformadas.

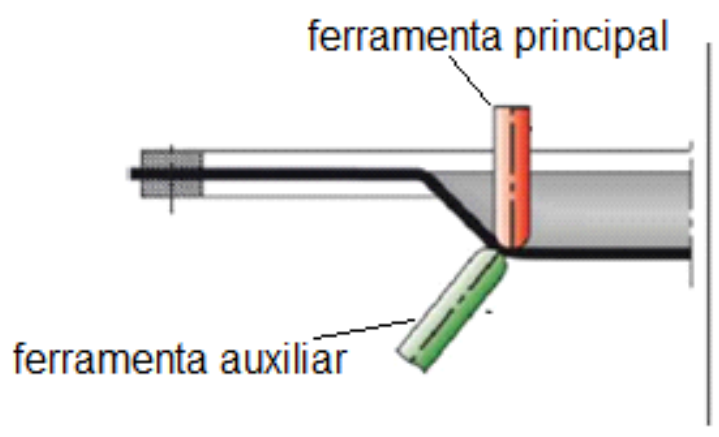

(a)

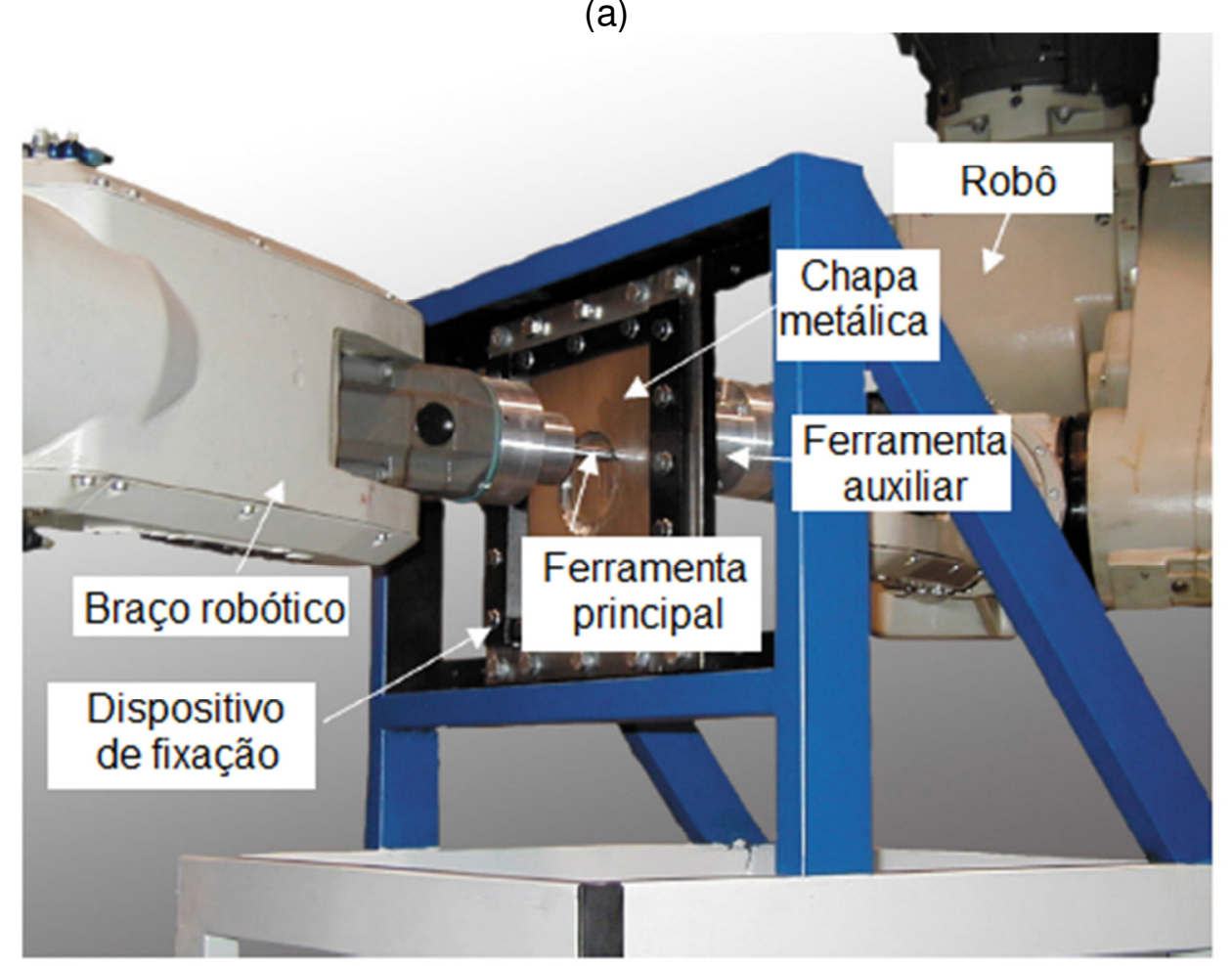

(b)

Figura 5 - (a) Estampagem incremental com ferramenta auxiliar. (b) Estampagem incremental com dois robôs Manutec r15. Adaptada de Meier et al., 2007. 
O movimento da ferramenta auxiliar requer controle independente, que poderá ser fornecido por meio de uma máquina específica (Figura 5(b)) ou através de um mecanismo de acionamento auxiliar. Essa forma é mais usual quando há máquinas específicas ou braços robóticos.

Os braços robóticos oferecem a possibilidade de trabalhar, simultaneamente os dois lados da peça, aumentando a flexibilidade do processo. O robô impulsiona a ferramenta sobre um lado da peça contra a ferramenta de apoio. Não é necessário o uso de placas de apoio ou matrizes dedicadas ou parciais. A chapa é deformada num processo gradual, ao longo de trajetórias programadas no plano $X Y$, sem ajustes da ferramenta de apoio na direção Z. No entanto, apresenta como desvantagens 0 alto custo do equipamento, a limitação do uso somente para esta finalidade e a falta de rigidez do sistema (JESWIET et al., 2005a). Isso pode ser compensado usando robôs com capacidade de carga elevada em comparação com as forças que ocorrem na estampagem incremental ou, ainda, usar estruturas robóticas paralelas. Desse modo, além de melhorar a rigidez do sistema, oferece melhor relação entre volume de trabalho/custo.

\subsection{Estampagem incremental com matriz}

Há duas variantes na estampagem incremental com matriz, matriz parcial e matriz total, como mostra esquematicamente a Figura 6. A ferramenta inicia no topo da geometria e caminha em direção às bordas. A matriz é usada para aumentar as possibilidades geométricas e melhorar a precisão das peças.

Não é necessário que a matriz seja fabricada em aço. Podem ser usados materiais com custo inferior ao do aço como, por exemplo, a madeira e a resina epóxi (ATTANASIO et al., 2008). A geometria da matriz pode ser côncava ou convexa. 


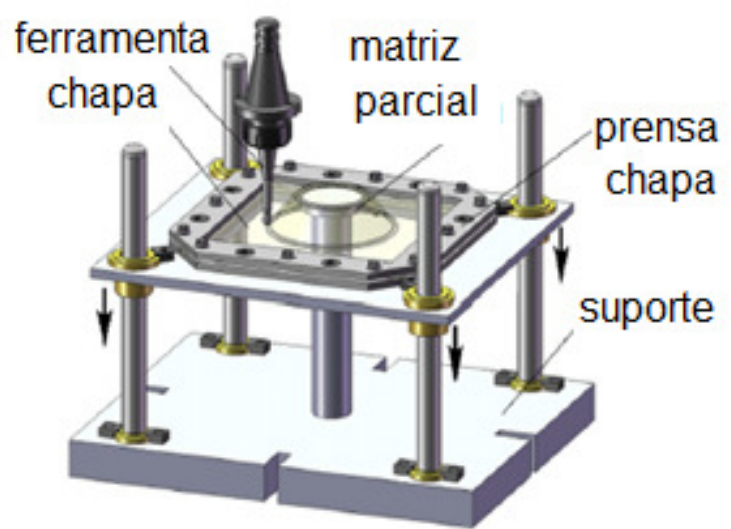

(a)

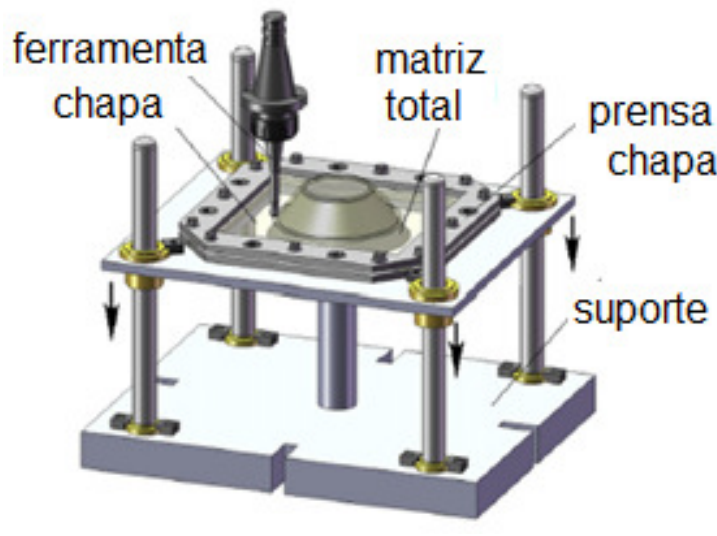

(b)

Figura 6 - Estampagem incremental com matriz. (a) parcial. (b) total. Adaptada de Silva e Martins, 2014.

A geometria da matriz parcial não é específica, pode ser somente um ponto de apoio. A precisão das peças é melhorada quando comparada a estampagem incremental sem matriz (JESWIET et al., 2005a). Já o processo com matriz total oferece maior precisão geométrica das peças, já que a chapa, durante a estampagem, é limitada pela ferramenta e pela matriz. Esta abordagem demanda um custo maior que as outras, já que os custos associados com o material da matriz e a sua fabricação são mais elevados. A principal desvantagem do processo é a pouca flexibilidade, pois para cada nova peça é necessário o projeto e fabricação de uma nova matriz.

\subsection{Vantagens e desvantagens da estampagem incremental}

A estampagem incremental vem ao encontro às necessidades das empresas que buscam processos inovadores e eficientes, com potencial para reduzir o tempo e o custo de desenvolvimento, permitindo o retorno mais rápido do investimento e garantindo meios mais eficientes de produção.

Algumas das vantagens da aplicação da estampagem incremental são (JESWIET et al., 2005a; AMBROGIO et al., 2007):

- O custo de set-up é praticamente nulo.

- O processo pode ser adaptado a um centro de usinagem. 
- O componente a ser produzido pode ser executado a partir de modelo CAD com o uso de apenas uma ferramenta.

- Alterações no projeto de peças podem ser facilmente adaptadas, conferindo flexibilidade ao processo, sendo que o lote mínimo para a fabricação é "um".

- Este processo dispensa o emprego de matriz específica.

- As tensões originadas na zona de mudança de ângulo podem ser corrigidas e controladas.

- O nível de deformação máximo de alguns materiais é elevado.

- A qualidade do acabamento dos componentes pode ser controlada pelos parâmetros do processo, por exemplo, usando a variante com matriz total ou parcial.

- O funcionamento e modos de operação são, relativamente, pouco ruidosos.

- O processo pode ser usado para criação de protótipo e também para reconstruir peças antigas, como, por exemplo, peças automotivas e até mesmo para obter próteses.

No entanto, há algumas limitações (JESWIET et al., 2005a; AMBROGIO et al., 2007):

- O tempo de processo para a fabricação do componente. Quanto mais profunda e complexa a geometria, maior o tempo.

- A utilização deste processo está limitada à produção de pequenos lotes de peças.

- Ocorre retorno elástico e acúmulo de tensões residuais, tornando necessário o desenvolvimento de algoritmos de correção.

- Ângulos de paredes próximos a 90 graus são obtidos pela realização de várias etapas intermediárias.

- Dependendo da geometria final, as bordas da chapa que estão presas ao prensa chapa durante o processo de deformação, não sofrem ação da ferramenta de estampagem e podem se deformar pela ação das tensões residuais após a liberação do prensa chapa, causando erros dimensionais (AMBROGIO et al., 2005; AMBROGIO et al., 2007). 
- As dimensões das peças são limitadas pelo tamanho do suporte de fixação das chapas.

\subsection{Parâmetros da estampagem incremental}

Há três grupos de parâmetros que afetam a mecânica da estampagem incremental: os parâmetros de processo, os parâmetros do material e os parâmetros de projeto.

\subsubsection{Parâmetros do processo}

Os principais parâmetros de processo que influenciam a estampagem incremental são o diâmetro da ferramenta, o avanço em $Z$, a velocidade de avanço, a velocidade de rotação da ferramenta e a lubrificação.

A ferramenta deve ser fabricada com material rígido e com propriedades tribológicas apropriadas, já que estará em contato com a chapa a ser deformada (DUFLOU et al., 2007a).

As ferramentas utilizadas na estampagem incremental podem ter as pontas hemisféricas ou esféricas, como mostra a Figura 7. O diâmetro da ponta da ferramenta pode variar e é parâmetro fundamental do processo, pois está diretamente relacionado com a força atuante e com a geometria a ser obtida (DUFLOU et al., 2007a). 


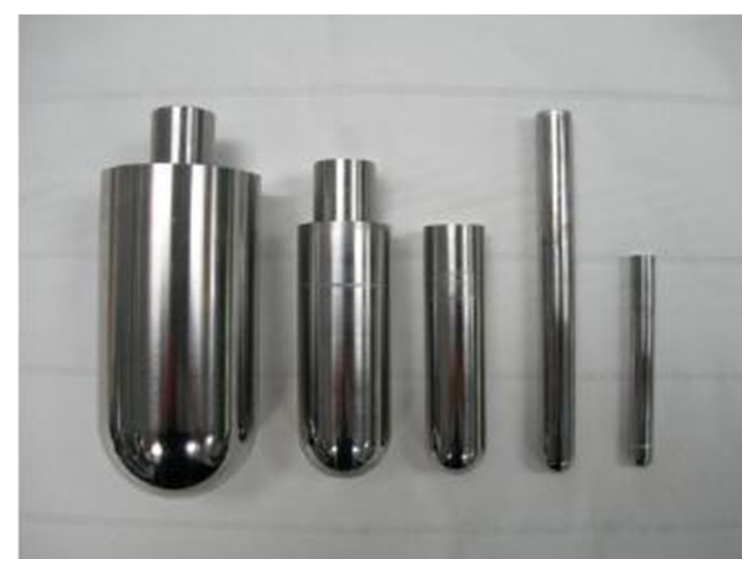

(a)

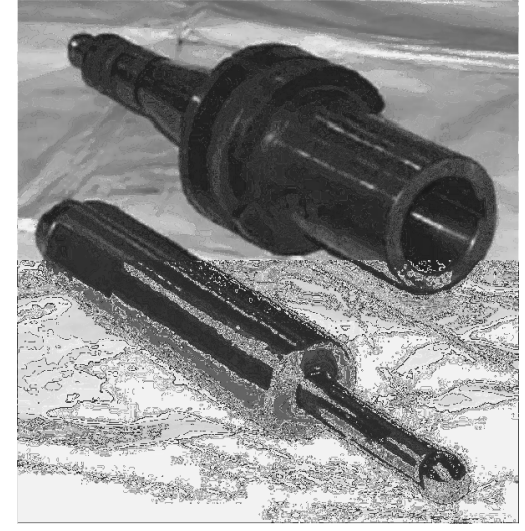

(b)

Figura 7 - Ferramentas usadas na estampagem incremental. (a) Ferramenta com ponta hemisférica (CÂMARA, 2009). (b) Ferramenta com ponta esférica (CERETTI et al., 2004).

O diâmetro da ferramenta também afeta o acabamento e o tempo de fabricação. Quanto maior for o diâmetro da ferramenta melhor será o acabamento da peça para um mesmo valor de avanço em Z. Além disso, quanto maior o diâmetro da esfera da ferramenta, maior a área de contato e, por sua vez, maior a zona de deformação e menor o nível de tensão (PARK; KIM, 2003). No entanto, o nível de deformação aumenta com a redução do diâmetro da ferramenta. Esta afirmação é ratificada por Silva et al. (2011) que também afirmam que a diminuição do raio da ferramenta também resulta na diminuição do razão de triaxialidade de tensões. A escolha do diâmetro da ferramenta deve estar de acordo com os detalhes da geometria da peça a ser fabricada.

$\mathrm{O}$ avanço em $\mathrm{Z}$ se dá segundo duas estratégias, a primeira consiste em fornecer incrementos em $Z$ no início de cada volta, ou seja, a ferramenta avança em profundidade depois de terminada uma volta (Figura 8(a)). Já a segunda estratégia o incremento em Z é variável (helicoidal) (Figura 8 (b)). 


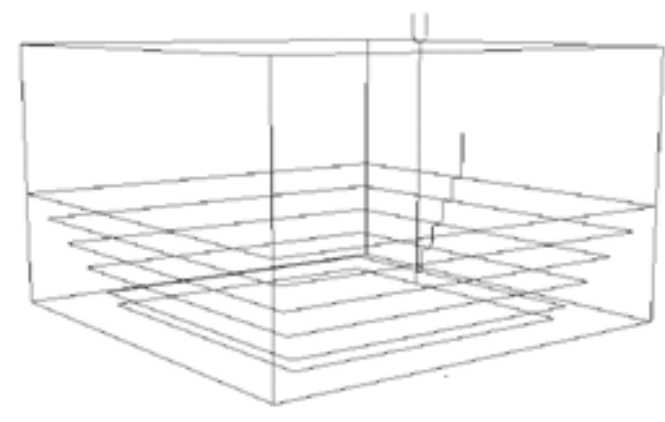

(a)

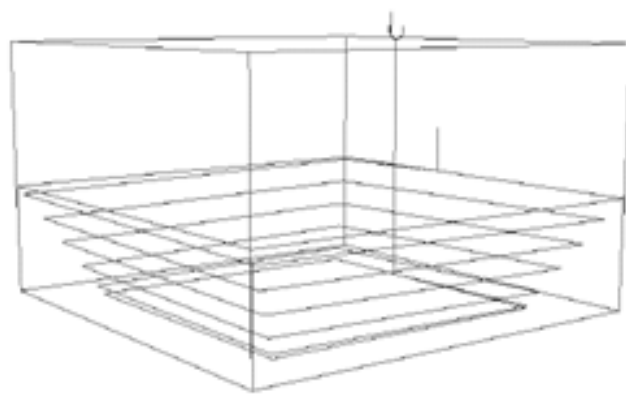

(b)

Figura 8 -. Trajetória da ferramenta. (a) Incremento em Z no início do ciclo. (b) Incremento helicoidal. Adaptado de Skjoedt et al., 2007.

Um efeito associado ao avanço em $Z$ é o aparecimento de irregularidades na superfície da peça, resultado do movimento da ferramenta. Estratégias usando avanço helicoidal podem ser aplicadas com a finalidade de reduzir o efeito de picos e vales e também reduzir o tempo de execução do processo. A Figura 9 ilustra como o avanço em $Z$ pode ser variado e como influencia na superfície, variando o tamanho das cristas formadas. Deve-se ter cautela, pois com o aumento do incremento em Z aumenta a força da ferramenta sobre a chapa (DUFLOU et al., 2007a).

A velocidade de rotação da ferramenta é um parâmetro que gera polêmica entre os pesquisadores da área. Ambrogio et al. (2005) e Ham e Jeswiet. (2006) afirmam que a velocidade de rotação gera aquecimento localizado tanto na chapa quanto na ferramenta, contribuindo para a deformação do material e, no entanto, gera desgaste na ferramenta. Já Silva et al. (2008b) realizaram ensaios com a ferramenta livre e concluíram que este parâmetro não tem influência no processo. 


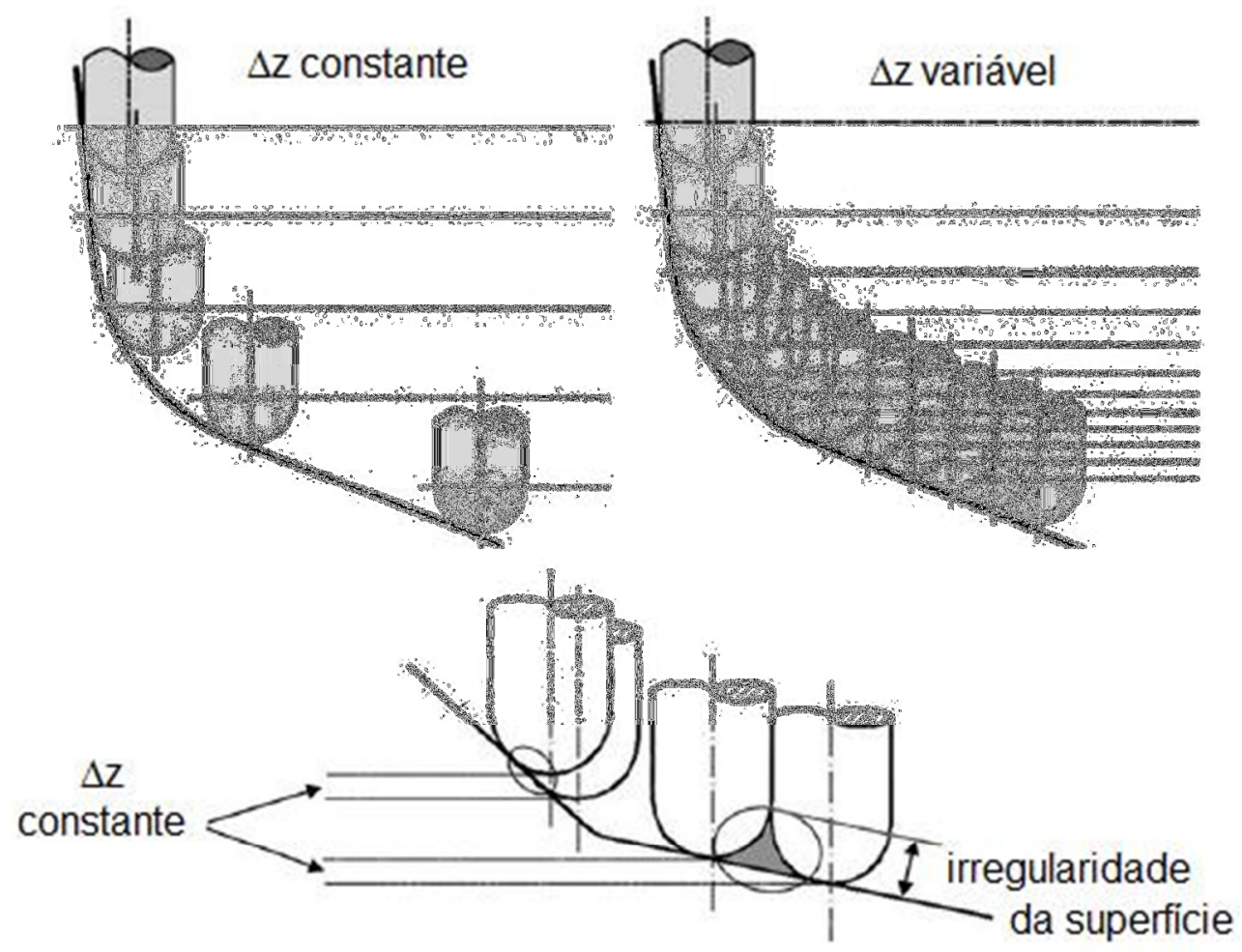

Figura 9 - Comparação entre uma superfície conformada com incremento vertical constante e variável. Adaptada de Attanasio et al. (2008)

A operação em condição de rotação zero no eixo-árvore, dependendo da máquina, pode ocasionar esforços no cabeçote, já que a sua natureza é voltada à usinagem. Para tanto, quando se deseja operar com rotação livre, pode-se adaptar um suporte com rolamentos para a ferramenta ao eixo-árvore.

Mesmo sem a imposição de velocidade de rotação à ferramenta, há o aquecimento da chapa e da ferramenta, gerado pelo atrito entre eles (JESWIET et al., 2005b). Para preservar as características tribológicas do material, durante e após a deformação, é usado um fluido lubrificante. A escolha do lubrificante depende do material em trabalho e do projeto da peça (KOPAC; KAMPUS, 2005).

A Figura 10 mostra um exemplo de peças obtidas pela estampagem incremental com e sem a utilização de lubrificantes. 


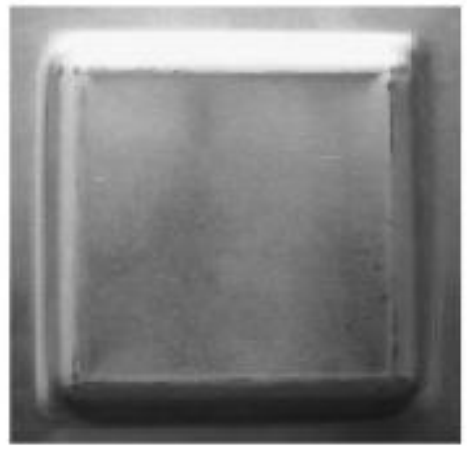

(a)

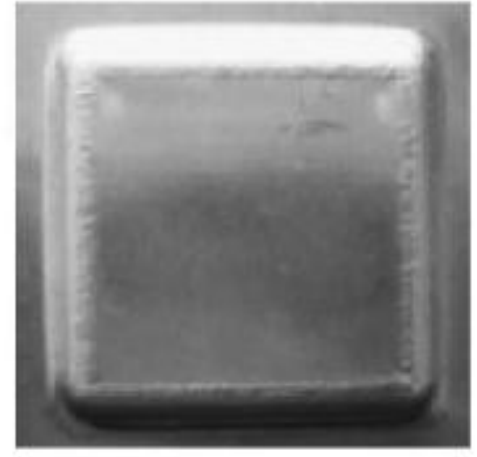

(b)

Figura 10 - Peças obtidas do processo de AISF. (a) com uso de lubrificante; (b) sem uso de lubrificante. Adaptado de Kopac e Kampus (2005)

Observando a Figura 10 verifica-se que com o uso do lubrificante adequado a rugosidade diminui, bem como o aparecimento de imperfeições na superfície da peça (KOPAC; KAMPUS, 2005).

\subsubsection{Parâmetros do material}

Os parâmetros do material que mais influenciam a estampagem incremental são o ângulo máximo de estampagem, $\psi_{\max }$, a curva limite à estriç̧ão, CLE, e a curva limite à fratura, CLF, os quais permitem quantificar o nível de deformação na estampagem. As curvas limite de estampagem à estricção e à fratura definem, no plano das deformações principais, a deformação plástica limite admissível a partir da qual ocorre a estricção e a fratura da chapa, respectivamente.

O ângulo máximo de estampagem, $\psi_{\max }$, é o maior ângulo obtido sem que ocorra o fenômeno de fratura na peça. O valor do ângulo máximo de estampagem depende do material da chapa. O $\psi_{\max }$ é determinado através de geometrias cônicas truncadas. Normalmente, o ângulo inicial de estampagem é $\psi=30^{\circ}$ e aumenta progressivamente em função da profundidade $\psi(h)$, até atingir o ângulo máximo de estampagem, onde ocorre o início da fratura (Figura 11). 


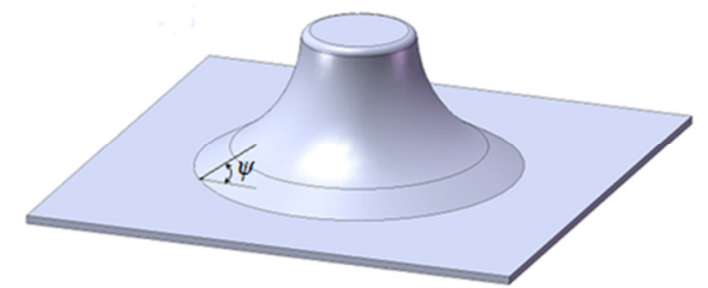

Figura 11 - Determinação do ângulo máximo de estampagem por trajetória variável (CENTENO et al., 2012).

A determinação das curvas CLE e CLF do material ocorre através de vários ensaios experimentais como, por exemplo, tração, Bulge circular e elíptico e Nakazima, ou através de modelos teóricos de previsão.

Quando se trata dos processos convencionais de estampagem a atenção é voltada para a CLE por motivos estéticos e de resistência mecânica, já na estampagem incremental atenta-se para a CLF.

Dependendo do material, os níveis de deformação obtidos pela estampagem incremental são maiores que nos processos convencionais de estampagem devido à influência de vários fatores, sendo a deformação localizada o mais pertinente. No entanto, devido ao estado anisotrópico do material, a conformabilidade difere de acordo com a direção do movimento da ferramenta (PARK; KIM, 2003). A deformação plástica é localizada e limitada pelo contato entre a extremidade esférica da ferramenta e a superfície de trabalho da chapa.

O modo de deformação na estampagem incremental se encontra próximo ao da deformação plana do material $\left(\varepsilon_{2}=0\right.$ ), quase alongamento puro (FILICE et al., 2002; JESWIET et al., 2005b), como pode ser observado na Figura 12. A deformação continuada do material cria deslocações na sua estrutura interna, podendo dar origem à fratura (EMMENS; BOOGAARD, 2009). Silva et al. (2008) observam a ocorrência de fratura em peças produzidas por estampagem incremental sem sinal de existência de estricção. Este fato é facilmente observado pelo estudo das trajetórias de deformação. A Figura 12 ilustra a trajetória de deformação dos processos de estampagem convencional e incremental. 


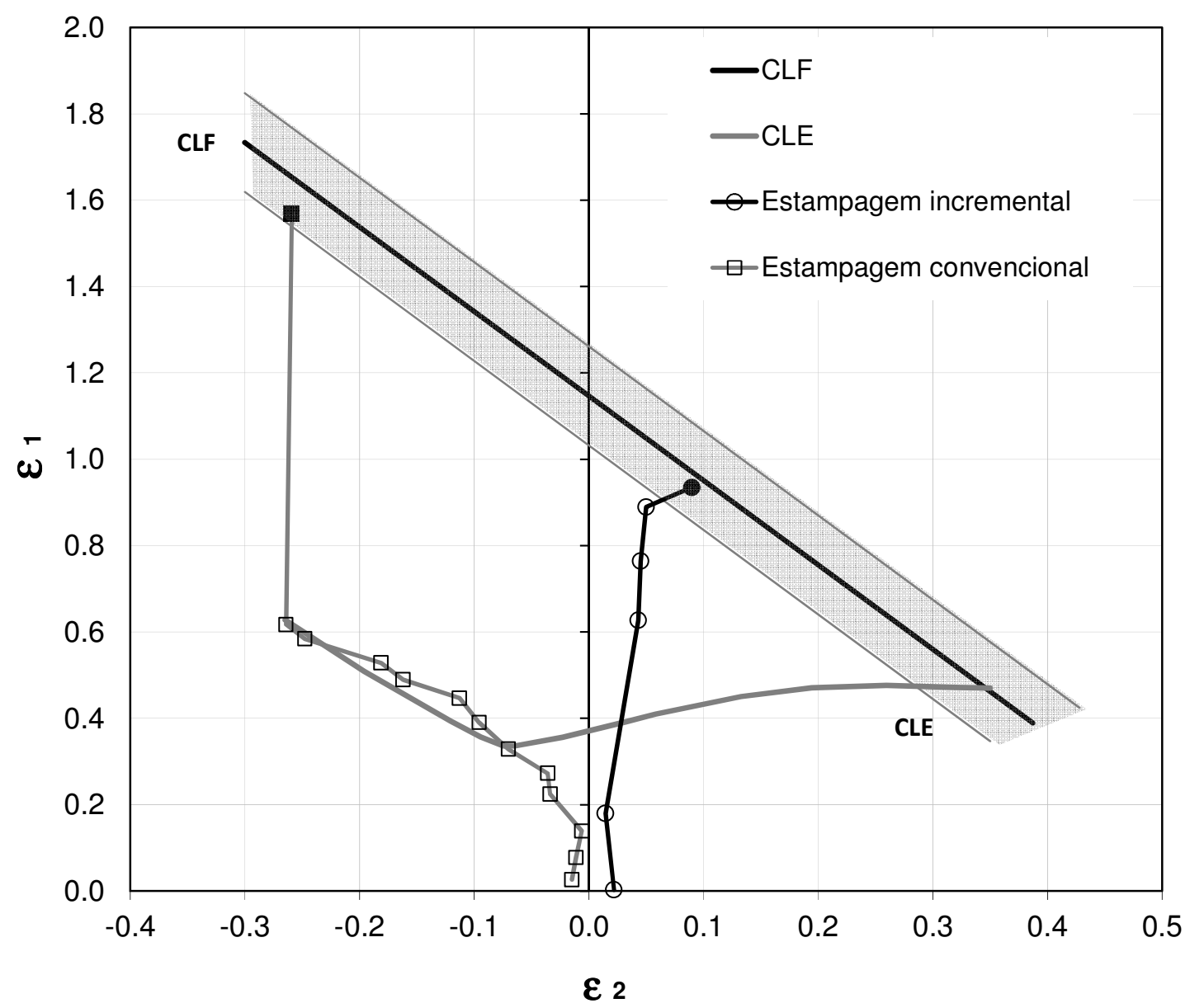

Figura 12 - Trajetória de deformação dos processos de estampagem convencional e incremental. Adaptado de Montanari et al., 2013.

Observa-se na Figura 12 que a tendência de direção da trajetória de deformação na estampagem convencional se altera depois que atinge a CLE, já na estampagem incremental, não há alteração da tendência de direção da trajetória de deformação, ou seja, no caso da estampagem incremental as trajetórias de deformação crescem linearmente e monotonicamente, desde a origem até os valores máximos. Esta análise permite a afirmação de que na estampagem incremental para a fabricação de flanges circulares ocorre a falha por fratura sem a ocorrência anterior da estricção (SILVA et al., 2013).

Há outros mecanismos que auxiliam na explicação para o aumento da deformação até a ruptura: forças normais (tensão de contato), a combinação do alongamento com a tensão de cisalhamento, a trajetória cíclica de deformação e o efeito da razão de triaxilidade de tensões (EMMENS; BOOGAARD, 2009; MALHOTRA et al., 2011). 
A tensão de contato se refere à tensão de compressão, normal à superfície da chapa, gerada pelo contato da ferramenta e atua como um mecanismo de deformação contínuo. Quanto menor o diâmetro da esfera da ferramenta, maiores são as tensões de contato. No entanto, essas tensões atuam de modo diferente para os processos de estampagem incremental com e sem matriz, justamente pelo tipo de contato existente. Na estampagem incremental sem matriz, a tensão de contato ocorre somente do lado onde há o contato entre a ferramenta e a peça. Apenas na estampagem incremental com matriz total a espessura suporta melhor as tensões de contato (EMMENS; BOOGAARD, 2009). A distribuição de esforços na chapa durante a estampagem incremental é consequência de vários fatores. No início do processo o aumento da força de deformação pode ser atribuído a mecanismos de flexão (AMBROGIO et al., 2006). Em outras etapas do processo, o aumento da força de deformação ocorre devido ao estiramento do material, reduzindo a espessura da chapa (PETEK et al., 2009). O alongamento dos grãos, provocados pelas altas tensões aplicadas pela ferramenta, também influenciam no processo de deformação, pois aumenta a tenacidade da chapa (JESWIET et al. 2005b) e, com isso, exige maior força para deformar plasticamente a chapa, mas, por outro lado, aumenta o limite de ruptura (ARAGHI et al., 2009).

A tensão de cisalhamento é causada pelo deslocamento tangencial resultante do movimento da ferramenta. Na ausência da tensão de cisalhamento, a tensão de escoamento no plano aumenta e os mecanismos de deformação estabilizam até a tensão ser suficiente para deformar a chapa. O nível de tensão de cisalhamento depende do diâmetro da ferramenta, dos valores dos avanços em $Z$, da velocidade de rotação da ferramenta, da velocidade de avanço e do atrito na interface ferramenta/peça (MALHOTRA et al., 2011).

$\mathrm{Na}$ estampagem incremental a ferramenta passa várias vezes pelo mesmo ponto da chapa, causando um efeito cíclico. A sua passagem provoca carga e descarga da chapa favorecendo a deformação reversível do material, proporcionando o efeito Bauschinger (EMMENS; BOOGAARD, 2009).

O efeito do momento fletor difere do efeito da tensão de contato e tensão de cisalhamento sobre o material. Uma diferença que pode ser observada é o fato das 
tensões de contato e cisalhante serem consideradas apenas em situações estáticas, enquanto os efeitos do momento fletor se baseiam no fato da zona deformada se movimentar, ou seja, a zona de contato é carregada e descarregada continuamente (EMMENS; BOOGAARD, 2009). Esse mecanismo ocorre quando o material se movimenta sob a superfície de contato da ferramenta esférica e a sua ocorrência alonga o material em algumas direções da zona de contato e o seu crescimento dependente da espessura da chapa e do diâmetro da ferramenta (EMMENS; BOOGAARD, 2009).

Outro fator que contribui para aumentar o limite de conformabilidade na estampagem incremental é o efeito da razão de triaxilidade de tensões (JESWIET et al., 2005b). A razão de triaxialidade de tensões é definida pela razão entre a tensão hidrostática $\left(\sigma_{m}\right)$ e a tensão equivalente $\left(\sigma_{e}\right), \mathrm{R}=\frac{\sigma_{\mathrm{m}}}{\sigma_{\mathrm{e}}}$. O nível da razão de triaxilidade é maior no caso da estampagem convencional se comparado à estampagem incremental (SILVA et al., 2008a). Este fato esclarece o motivo pelo qual a ruptura ocorre, preferencialmente, nos cantos quando se trata de peças não circulares, cujas deformações ocorrem em duas direções, enquanto nas superfícies planas laterais a razão de triaxilidade é mais baixa, já que as deformações ocorrem numa única direção (SILVA et al., 2008a).

Foi desenvolvido um modelo analítico para determinar as tensões e deformações que se desenvolvem durante a estampagem incremental de chapa metálica, as quais são obtidas por meio do equilíbrio de forças para um elemento infinitesimal representativo da região em deformação plástica, cujas três zonas de deformação típicas são A, B e C, durante o contato instantâneo da ferramenta com a chapa, mostradas na Figura 13. 


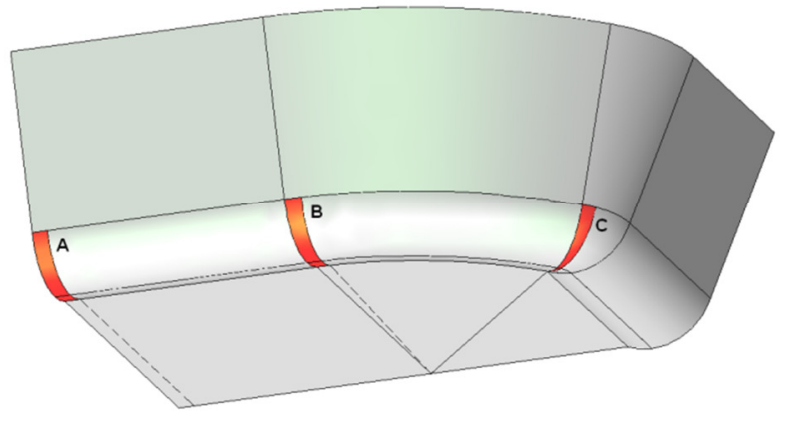

Figura 13 - Representação esquemática das três regiões em deformação plástica (A, B e C) durante a estampagem incremental de chapa metálica (SILVA et al., 2008b).

Desprezam-se os momentos fletores, considera-se que as direções circunferencial $(\theta)$, meridional $(\Phi)$ e da espessura da chapa $(t)$ são direções principais. Admite-se que o material é rígido perfeitamente plástico e isotrópico e que a tensão de atrito na interface de contato com a ferramenta possui duas componentes: uma meridional resultante do movimento descendente da ferramenta $-\mu_{\phi} \sigma_{t}$ e uma componente circunferencial, originada pelo avanço da ferramenta $-\mu_{\theta} \sigma_{\mathrm{t}}$. Esta última hipótese simplificativa, a qual é um modo não tradicional de tratar o coeficiente de atrito, implica que este seja definido por $\mu=\sqrt{\mu_{\phi}^{2}+\mu_{\theta}^{2}}$.

A distribuição de tensões na região em deformação plástica resulta do equilíbrio de forças nas direções meridional $(\Phi)$ (eq.(1)), circunferencial $(\theta)$ (eq.(2)) e segundo a espessura da chapa (t) (eq.(3)). Figura 14.

$$
\begin{gathered}
\left(\sigma_{\phi}+d \sigma_{\phi}\right)(r+d r) d \theta(t+d t)-\sigma_{\phi} r d \theta t+\mu_{\phi} \sigma_{t} r d \theta r_{1} d \alpha \\
-\sigma_{\theta} \frac{d \theta}{2} r_{1} d \alpha t \sin \alpha-\left(\sigma_{\theta}+d \sigma_{\theta}\right) \frac{d \theta}{2} r_{1} d \alpha t \sin \alpha=0 \\
\sigma_{\theta} \mathrm{r}_{1} \mathrm{~d} \alpha\left(\mathrm{t}+\frac{\mathrm{dt}}{2}\right)-\mu_{\theta} \sigma_{\mathrm{t}} \mathrm{r}_{1} \mathrm{~d} \alpha\left(\mathrm{r}+\frac{\mathrm{dr}}{2}\right) \mathrm{d} \theta-\left(\sigma_{\theta}+\mathrm{d} \sigma_{\theta}\right) \mathrm{r}_{1} \mathrm{~d} \alpha\left(\mathrm{t}+\frac{\mathrm{dt}}{2}\right)=0 \\
\sigma_{t} r d \theta r_{1} d \alpha+\sigma_{\phi} r d \theta t \sin \frac{d \alpha}{2}+\left(\sigma_{\phi}+d \sigma_{\phi}\right)(r+d r) d \theta(t+d t) \sin \frac{d \alpha}{2}+ \\
\sigma_{\theta} r_{1} d \alpha t \sin \frac{d \theta}{2} \cos \alpha+\left(\sigma_{\theta}+d \sigma_{\theta}\right) r_{1} d \alpha t \sin \frac{d \theta}{2} \cos \alpha=0
\end{gathered}
$$



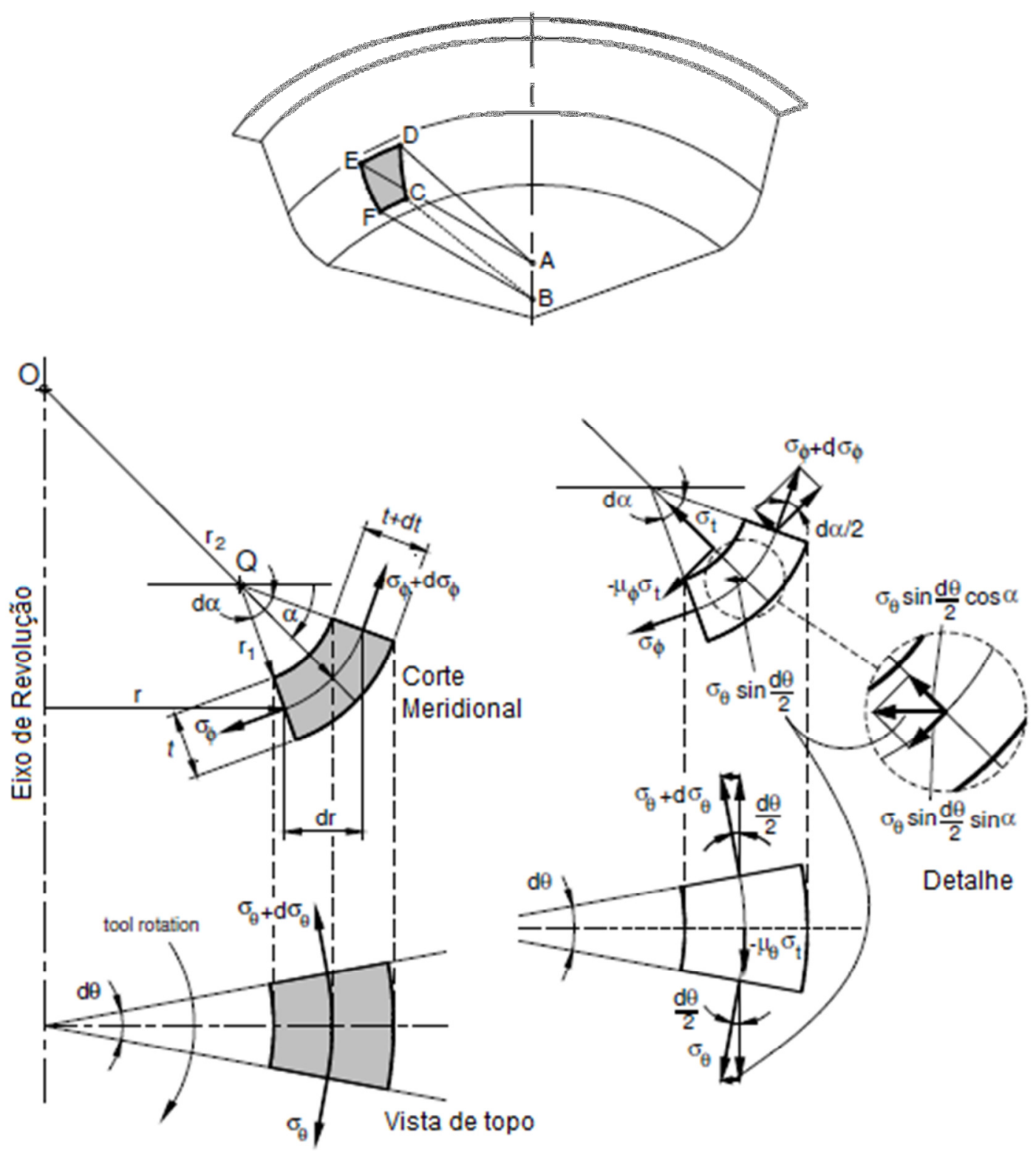

Figura 14 - Modelo teórico para estampagem incremental de ponto único. Adaptado de (SILVA et al., 2008a)

Simplificando e eliminando os termos de ordem superior, obtém-se a distribuição de tensões nas zonas em deformação plástica ( $A, B$ e $C$ da Figura 13), que são as três zonas de deformação, típicas da estampagem incremental. 


$$
\begin{gathered}
\frac{d \sigma_{\phi}}{d r}+\frac{\sigma_{\phi}-\sigma_{\theta}}{r}+\frac{\mu_{\phi} \sigma_{t}}{t \sin \alpha}+\frac{\sigma_{\phi}}{t} \frac{d t}{d r}=0 \\
d \sigma_{\theta}=-\mu_{\theta} \sigma_{t} \frac{r d \theta}{t} \cong-\mu_{\theta} \sigma_{t} \\
\frac{\sigma_{t}}{t}+\frac{\sigma_{\phi}}{r_{1}}+\frac{\sigma_{\theta}}{r_{2}}=0
\end{gathered}
$$

Partindo da equação de equilíbrio na direção da espessura (eq. (6)) com simplificações geométricas, considerando o critério de plasticidade de Tresca e assumindo que a operação de estampagem incremental de superfícies planas e simétricas de rotação é realizada em condições de deformação plana (zonas A e B) $\left(\mathrm{d} \varepsilon_{\theta}=0\right)$, enquanto que nos cantos (zona $C$ ) se realiza em condições de deformação biaxial simétrica $\left(\mathrm{d} \varepsilon_{\theta}=\mathrm{d} \varepsilon_{\phi}\right)$, obtém-se a distribuição de tensões $\mathrm{e}$ deformações características da estampagem incremental de metais, apresentadas na Tabela 1.

Tabela 1 - Modos de deformação e tensões características dos processos de estampagem incremental de metais (SILVA, 2008b).

\begin{tabular}{cccc}
$\begin{array}{c}\text { Modos de } \\
\text { deformação }\end{array}$ & Deformações & Tensões & $\begin{array}{c}\text { Tensão } \\
\text { Hidrostática }\end{array}$ \\
\hline $\begin{array}{c}\text { Deformação } \\
\text { Plana }\end{array}$ & $d \varepsilon_{\phi}=-d \varepsilon_{t}>0$ & $\sigma_{\phi}=\sigma_{1}=\frac{\sigma_{e}}{\left(1+\frac{t}{r_{f}}\right)}>0$ & $\sigma_{m}=\frac{\sigma_{e}}{2}\left[\frac{r_{f}-t}{r_{f}+t}\right]$ \\
(Zona A e B) & $d \varepsilon_{\theta}=0$ & $\sigma_{\theta}=\sigma_{2}=\frac{1}{2}\left(\frac{\left.\sigma_{1}+\sigma_{3}\right)}{r_{t}}\right)$ & \\
\hline $\begin{array}{c}\text { Deformação } \\
\text { Biaxial Simétrica }\end{array}$ & $d \varepsilon_{\phi}=d \varepsilon_{\theta}>0$ & $\sigma_{\phi}=\sigma_{\theta}=\sigma_{1}=\frac{\sigma_{e}}{\left(1+\frac{2 t}{r_{f}}\right)}>0$ & \\
(Zona C) & $d \varepsilon_{t}<0$ & $\sigma_{t}=\sigma_{3}=-2 \sigma_{e} \frac{t}{\left(2 t+r_{f}\right)}<0$ & $\sigma_{m}=\frac{2 \sigma_{e}}{3}\left[\frac{r_{f}-t}{r_{f}+2 t}\right]$
\end{tabular}




\subsubsection{Parâmetros de projeto}

Os parâmetros de projeto mais importantes na estampagem incremental são a geometria da peça, a espessura do material e a estratégia para deformação.

É possível obter peças com diversas geometrias, desde formas simples como cones e pirâmides, até geometrias mais complexas, como próteses médicas (Figura 15). A geometria final das peças é de fundamental importância, já que diferentes geometrias correspondem a diferentes tipos de deformação.

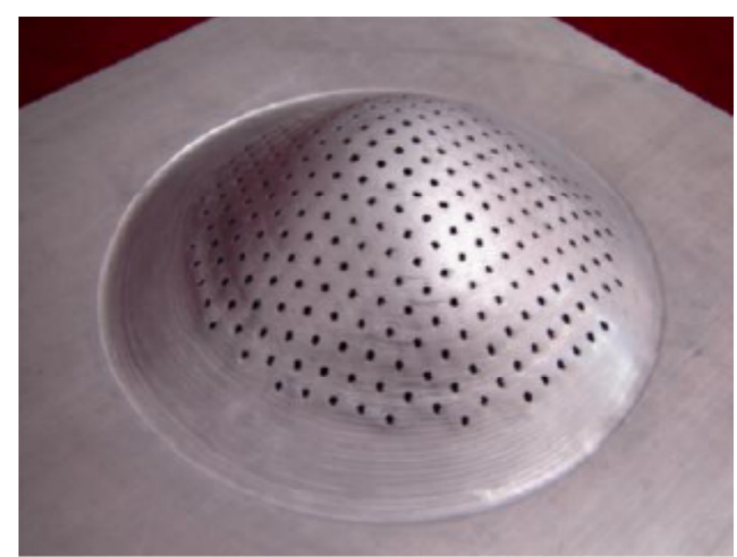

(a)
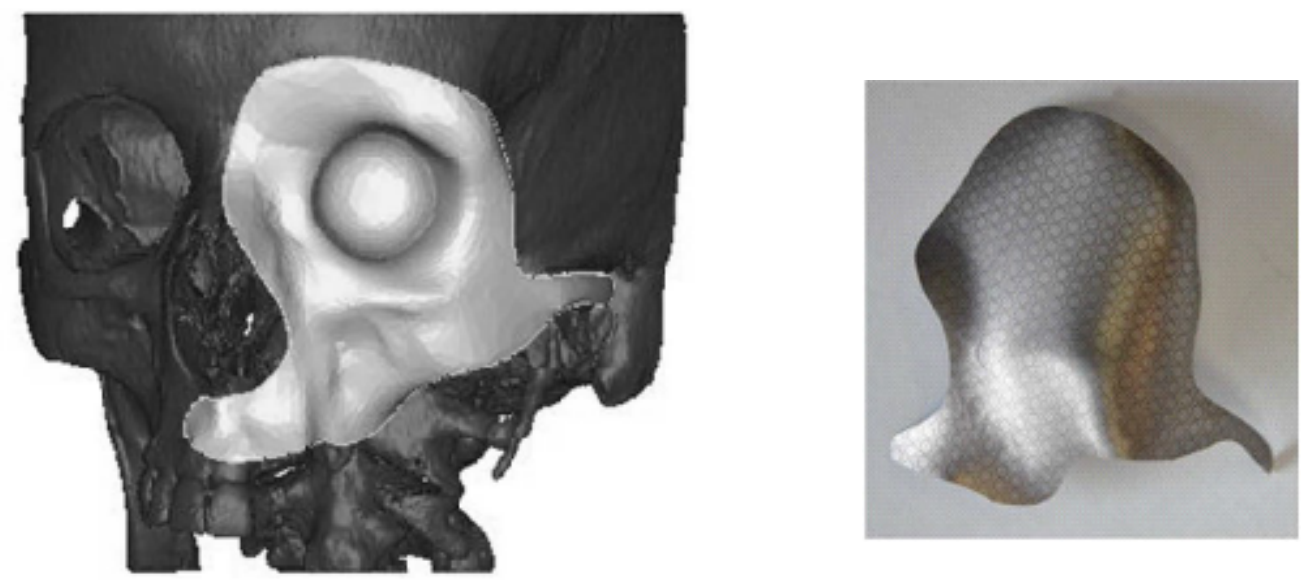

(b)

Figura 15 - Peças fabricadas pela estampagem incremental. (a) Prótese craniana (HAN et al., 2010). (b) Implante facial fabricado em titânio comercialmente puro de grau 2 (ARAÚJO et al., 2014).

A espessura da chapa a ser empregada na estampagem incremental é limitada pela capacidade da máquina. À medida que a espessura aumenta a força de contato 
entre ferramenta e peça sobe e o consequente esforço sobre os mancais da máquina-ferramenta também aumenta.

Quanto maior for a espessura inicial da chapa maior será o ângulo máximo de estampagem e, consequentemente, maior será a conformabilidade, uma vez que existe maior quantidade de material para deformar (PARK e KIM, 2003; HIRT, 2004; JESWIET, 2005a; HAM e JESWIET, 2006).

Uma importante correlação no projeto de peças a serem fabricadas pela estampagem incremental é a lei dos senos, que se baseia na conservação do volume de uma porção da chapa durante a deformação. Tal relação torna possível prever a espessura da chapa quando o ângulo de parede e a espessura inicial são conhecidos. A relação usada na estampagem incremental provém do processo de repuxamento (Figura 16).

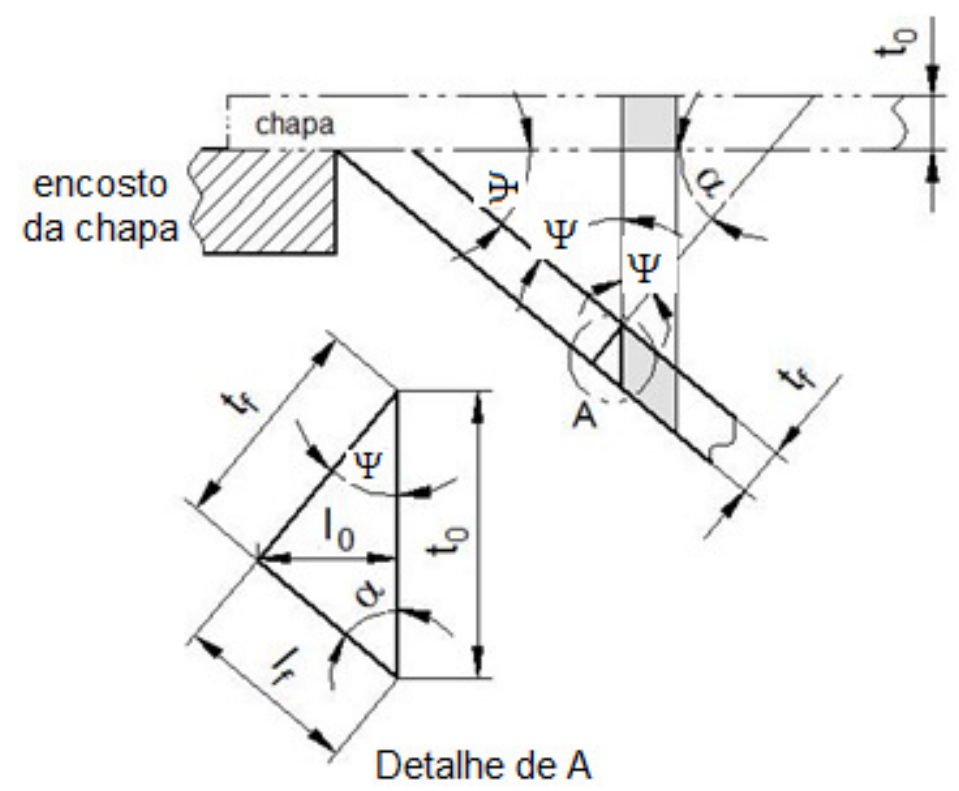

Figura 16 - Relações geométricas aplicadas a estampagem incremental, derivadas do processo de repuxamento. Adaptado de Jeswiet et al. (2005a)

Pela análise da Figura 16 e aplicação dos conceitos de trigonometria obtém-se a eq. (7). 


$$
t_{f}=t_{0} \operatorname{sen} \alpha=t_{0} \cos \psi
$$

Onde:

$t_{\mathrm{f}}=$ espessura final

$\mathrm{t}_{0}=$ espessura inicial

$\propto=$ ângulo da parede

$\psi=$ ângulo de estampagem

$\mathrm{l}_{\mathrm{f}}=$ comprimento final da chapa depois de deformar

$\mathrm{l}_{0}=$ comprimento inicial da chapa antes de deformar

Pela aplicação da lei dos senos é impossível obter geometrias com ângulo de 90 graus. Uma estratégia para solucionar esse problema é a aplicação da técnica de estampagem incremental multi-passagem, que consiste basicamente em obter a geometria final através de diversas fases com ângulos de estampagem distintos. Por exemplo, para obtenção de flanges com paredes a 90 graus, Montanari et al. (2013) iniciou o processo com o ângulo de estampagem em $\psi_{1}=65^{\circ}$ (inferior ao ângulo limite de estampagem para o material em estudo) e foi aumentando num intervalo de 5 graus até atingir o ângulo final, $\psi_{N}$, como mostra a Figura 17.

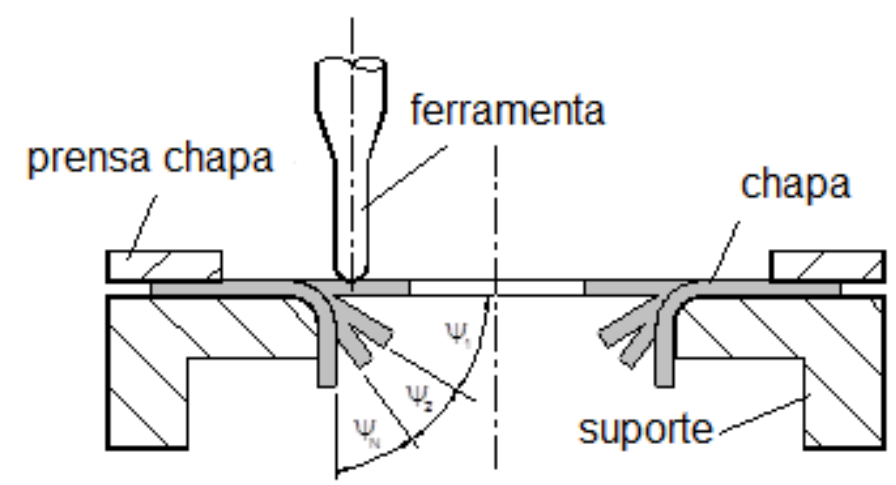

Figura 17 - Variação do ângulo de estampagem na estampagem incremental múltipla para a fabricação de flanges. Adaptado de Montanari et al. (2013). 


\subsection{Máquinas}

As máquinas comumente usadas nos processos de estampagem incremental são os braços robóticos ou máquinas com comando numérico computadorizado (CNC), como centros de usinagem.

Os braços robóticos oferecem a possibilidade de trabalhar, simultaneamente, os dois lados da peça, aumentando a flexibilidade do processo. O robô impulsiona a ferramenta sobre um lado da peça contra a ferramenta de apoio, caso seja a estampagem incremental com matriz. A chapa é deformada num processo gradual, ao longo de trajetórias programados no plano $X Y$, sem ajustes da ferramenta de apoio na direção Z. No entanto, apresenta como desvantagens o alto custo do equipamento, a limitação do uso somente para esta finalidade e a falta de rigidez do sistema (JESWIET et al., 2005a). Isso pode ser compensado usando robôs com capacidade de carga elevada em comparação com as forças que ocorrem na estampagem incremental ou, ainda, usar estruturas robóticas paralelas. Desse modo, além de melhorar a rigidez do sistema, oferece melhor relação entre volume de trabalho/custo.

Já o uso de uma máquina CNC é atraente porque os custos iniciais de operação são baixos e a rigidez da máquina é alta (KOPAC e KAMPUS, 2005), porém há algumas desvantagens (ALLWOOD et al., 2005b):

- Geralmente, o projeto das máquinas não é concebido para cargas elevadas no eixo-árvore, o que limita o processo ao limite da máquina.

- Máquinas CNC normalmente não fornecem instrumentação para a medição de força nos três eixos.

- O acesso do lado oposto da superfície de trabalho da peça é limitado pela mesa de trabalho da máquina CNC.

As chapas a serem deformadas são fixadas à máquina por meio de um dispositivo fabricado para esse fim normalmente são diferentes quando se trata da estampagem incremental com suas variantes sem matriz e com matriz. A ferramenta é guiada por 
um programa NC (numericamente controlado) que define a sua trajetória. A trajetória, por sua vez, é definida por um modelo CAD (Computer Aided Design).

\subsection{Outras abordagens da estampagem incremental}

Há diversos estudos que buscam ultrapassar as limitações da estampagem incremental, sejam elas, o longo tempo para fabricação de cada peça, a uniformidade de redução de espessura da chapa, o nível de deformação, a precisão geométrica e o planejamento do processo. Com o intuito de aprimorar e aumentar a capacidade da estampagem incremental há vários estudos que propõem mudanças estratégicas no modo de realizar a deformação incremental como, por exemplo, combinar dois processos (estampagem e estiramento) e trabalhar a quente.

Araghi et al. (2009) apresentam uma solução híbrida para aumentar a rapidez do processo e uniformizar a redução de espessura. A solução consiste em combinar a estampagem incremental com matriz com o processo de estiramento. Inicialmente a chapa é estirada contra uma matriz semelhante à usada na estampagem com matriz e, em seguida, a chapa sofre a ação da ferramenta de estampagem incremental, conforme mostra a Figura 18. 

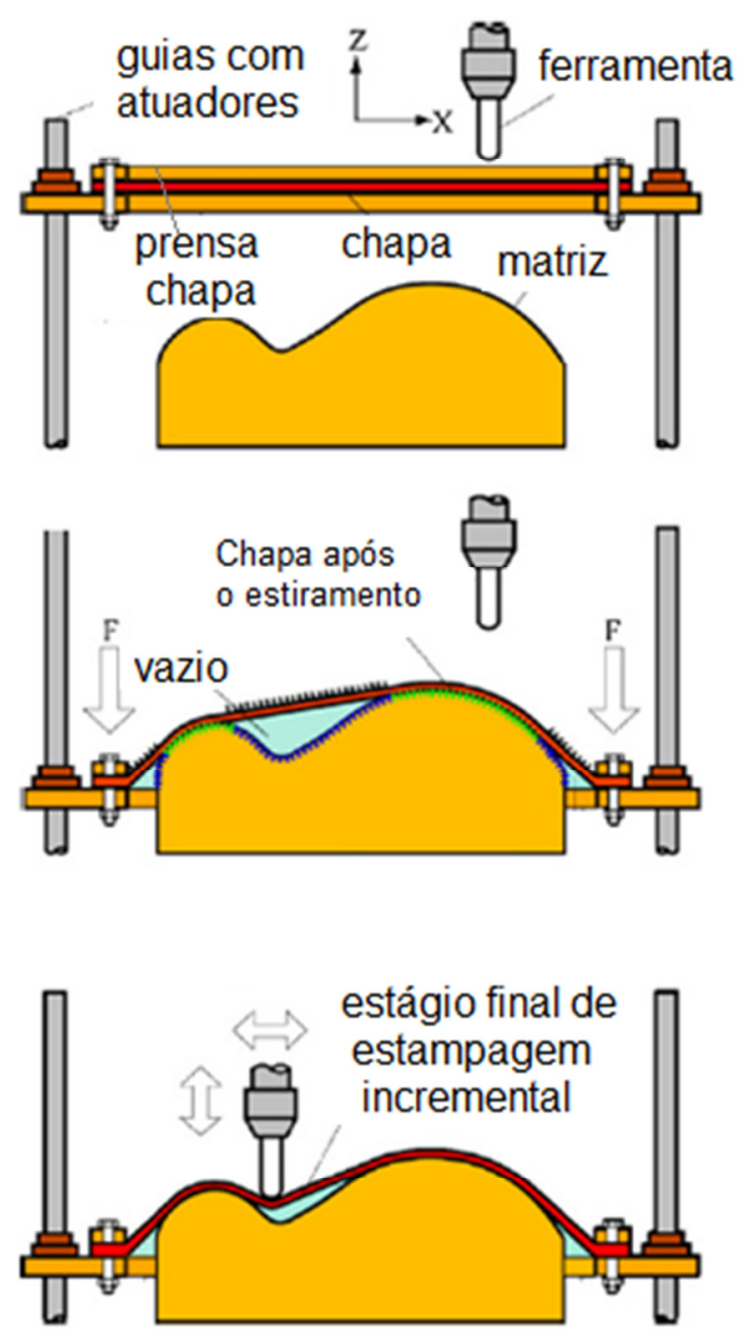

Figura 18 - Processo híbrido - estiramento e estampagem incremental. Adaptado de Araghi et al. (2009).

O suporte é especial, onde as guias de movimento vertical são atuadas de maneira a forçar a chapa contra a matriz utilizada na estampagem incremental com matriz.

Em 2011, Araghi et al. integram à solução híbrida o uso de Laser. O sistema do feixe Laser é montado de forma a aquecer a peça durante a estampagem incremental. Com essa solução, além dos outros benefícios já alcançados pela solução híbrida, também houve melhora na precisão dimensional da peça. 
A aplicação de Laser para o aquecimento pontual da chapa, à frente da trajetória da ferramenta, na estampagem incremental foi inicialmente estudado por Duflou et al. (2007b). Durante o processo de aquecimento local da zona de deformação, as forças, os efeitos de retorno elástico e as deformações plásticas inesperadas das vizinhanças são reduzidos, o que torna o processo mais controlável.

O aquecimento da região de contato entre a ferramenta e peça diminui a força de trabalho, reduz os efeitos do retorno elástico e melhora as características da peça obtida. Tais melhorias podem ser explicadas pela redução temporária do módulo de elasticidade apenas na região de contato entre a ferramenta e a peça. (DUFLOU et al., 2007)

Ambrogio, Filice e Gagliardi (2012) utilizam corrente elétrica para aquecer o ponto de contato entre a ferramenta e a peça. Como a resistência de contato entre a ferramenta e a peça é a maior do circuito, é nela onde ocorre a maior geração de calor. O esquema que ilustra o processo é mostrado na Figura 19. Com relação ao nível de deformação do material pode-se afirmar que há benefícios, entretanto prejudica a qualidade superficial da peça devido à oxidação e aumento das cristas deixadas pela ponta da ferramenta.

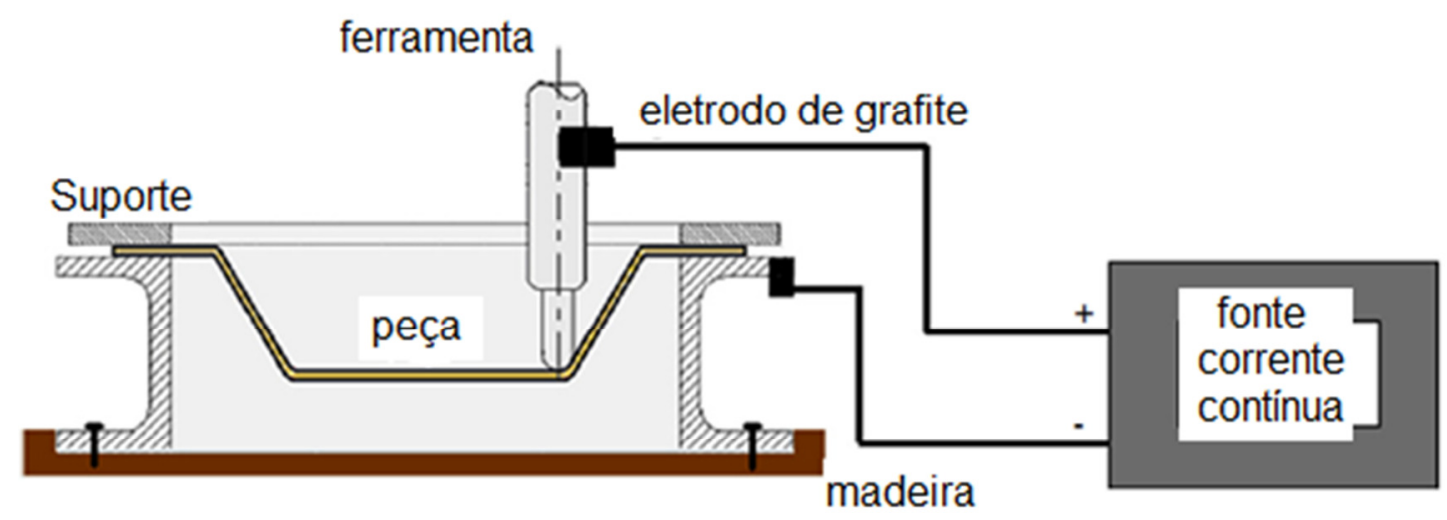

Figura 19 - Estampagem incremental com aquecimento por corrente elétrica Adaptado de Ambrogio et al. 2012. 


\subsection{Fabricação de flanges}

Flangeamento é o dobramento de uma pequena parte ou dimensão da extremidade da chapa ou de um furo. Flanges são elementos funcionais usados para, por exemplo, fazer a ligação entre tubos, fortalecer as bordas de peças fabricadas em chapa, como para-lamas dianteiros e painéis de automóveis (TEIS, 1999). Com a operação de flangeamento evitam-se arestas cortantes e as paredes do flange tornam-se lisas e com boa aparência. Além disso, as operações de flangeamento contribuem para o aumento da rigidez da peça. A indústria aeronáutica também requer componentes com diversas formas diferentes e faz uso das operações de flangeamento (POWELL; ANDREW, 1992).

O processo convencional de flangeamento com furo consiste em expandir um furo pré-fabricado em uma chapa, por meio de um punção, através de uma matriz (Figura 20(a)). Neste processo (de estampagem convencional) as maiores deformações estão localizadas na periferia do furo inicial expandido (KACEM et al., 2013). A Figura 20(b) mostra um exemplo de peça com flange.

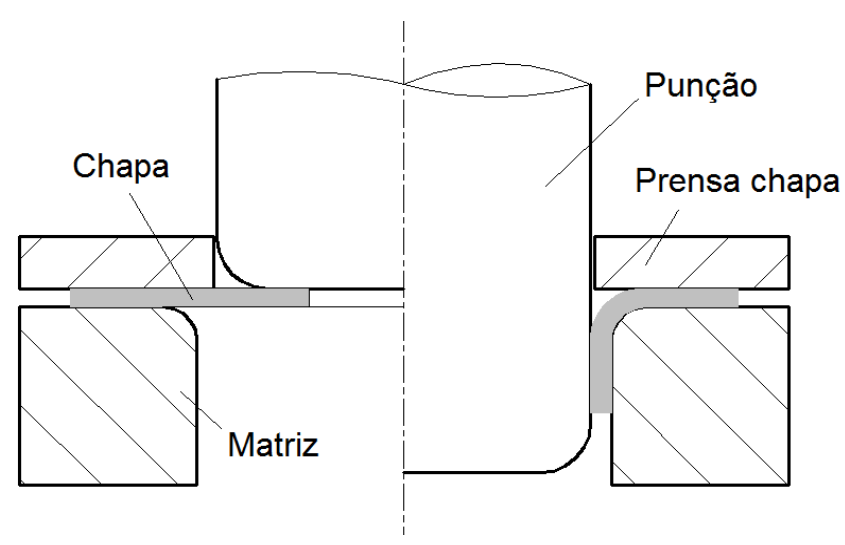

(a)

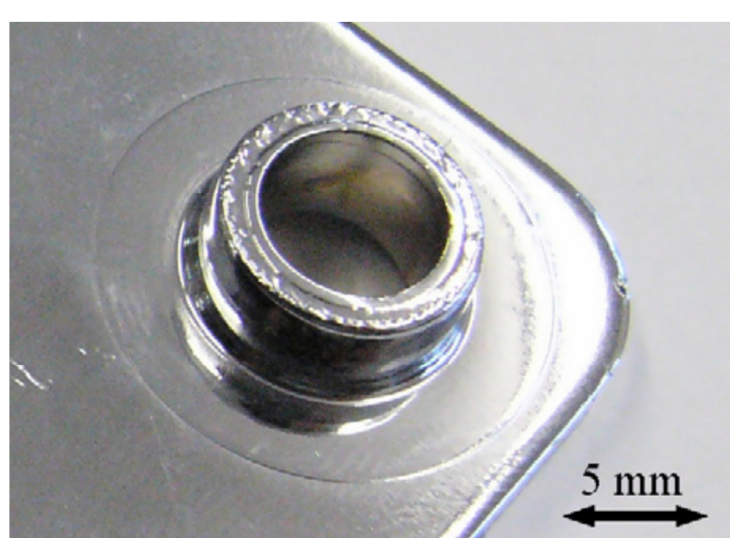

(b)

Figura 20 - (a) Representação da estampagem convencional para a fabricação de flanges em chapas previamente furadas. Adaptado de Montanari et al. (2013). (b) Exemplo de peça automotiva com flange (THIPPRAKMAS et al., 2007). 
O ferramental usado para o processo de flangeamento de furos por estampagem convencional é complexo e está sujeito a certas limitações do processo. Flanges obtidos pela estampagem com chapas previamente furadas podem ser usadas nas aberturas para os tubos de trocadores de calor, união entre tubos, como saliências ou reentrâncias em diversas aplicações como, por exemplo, em furos escareados.

O coeficiente limite de deformação para a fabricação de flanges previamente furadas, CLD, é definido como o quociente entre o diâmetro máximo interior do flange produzida, $D_{\text {máx }}$, e o diâmetro inicial do furo, $D_{0}$ (eq. (8)), representado na Figura 21.

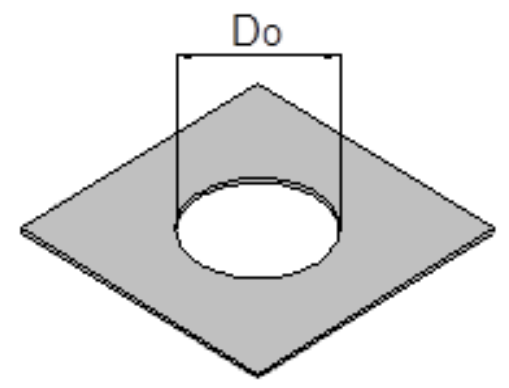

Chapa previamente furada

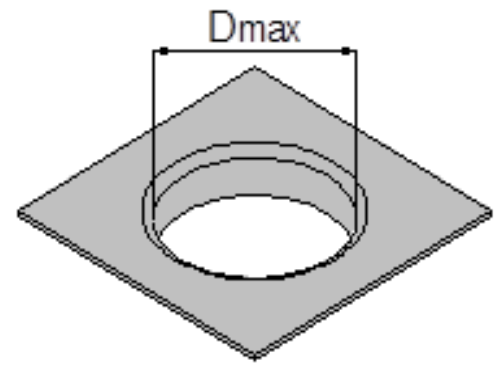

Chapa deformada

Figura 21 - (a) Flanges em chapas previamente furadas. Adaptado de Montanari et al. (2013).

$$
\operatorname{CLD}=\frac{\mathrm{D}_{\text {máx }}}{\mathrm{D}_{0}}
$$

Quanto se trata da operação de flangeamento pela estampagem convencional são encontradas pesquisas desde a década de 1960 (Yamada; Koide, 1968 e Kacem et 
al., 2013); já a fabricação de flanges por estampagem incremental é um processo emergente e com grande potencial, implementada como alternativa em pequenos lotes. O processo consiste em fixar uma chapa plana previamente furada ao suporte adaptado ao centro de usinagem e deformá-la utilizando estratégia multi-passagem. A ferramenta movimenta-se de maneira a expandir o furo (PETEK et al., 2011).

O primeiro trabalho de pesquisa sobre fabricação de flanges circulares por estampagem incremental foi realizado por Cui e Gao (2011), que estudaram a influência da trajetória da ferramenta e a sua implicação nos limites de conformação da liga de alumínio AA1060. Os autores concluíram que ao selecionar uma estratégia de deformação, no qual se aumenta o diâmetro do furo com passagens progressivas, evita uma redução excessiva da espessura da chapa e assegura uma distribuição mais uniforme da espessura ao longo de toda a parede do flange.

O trabalho realizado por Petek et al. (2011) focou na viabilidade de empregar trajetórias multi-passagens para produzir flanges simétricas em chapas de aço DC05 com trajetórias ascendentes da ferramenta (Figura 22(a)). O emprego de trajetórias ascendentes se justifica quando é difícil de obter flanges na estampagem incremental com a trajetória descendente da ferramenta, por exemplo, em flanges fabricados no exterior de peças (Figura 22(b)) ou quando o acesso à máquinaferramenta é prejudicado. Petek et al. (2012) concluíram que os parâmetros que mais influenciam a distribuição de espessura e a altura da parede do flange na estampagem incremental em que a trajetória da ferramenta é ascendente são as dimensões da ferramenta e os seus movimentos verticais e horizontais. 


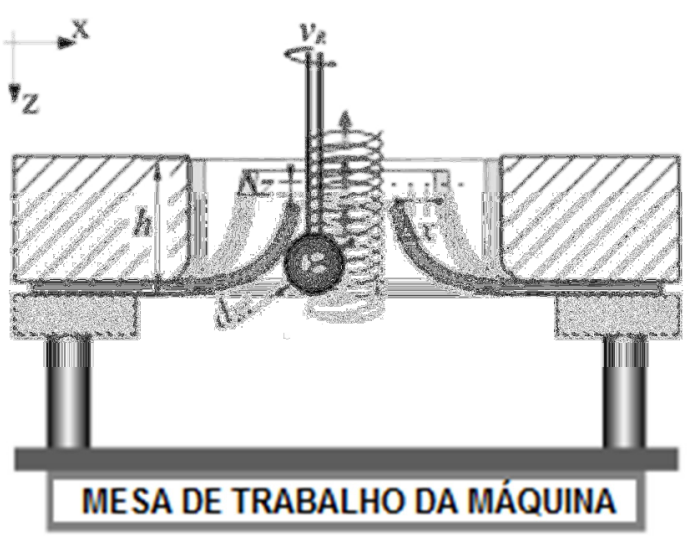

(a)

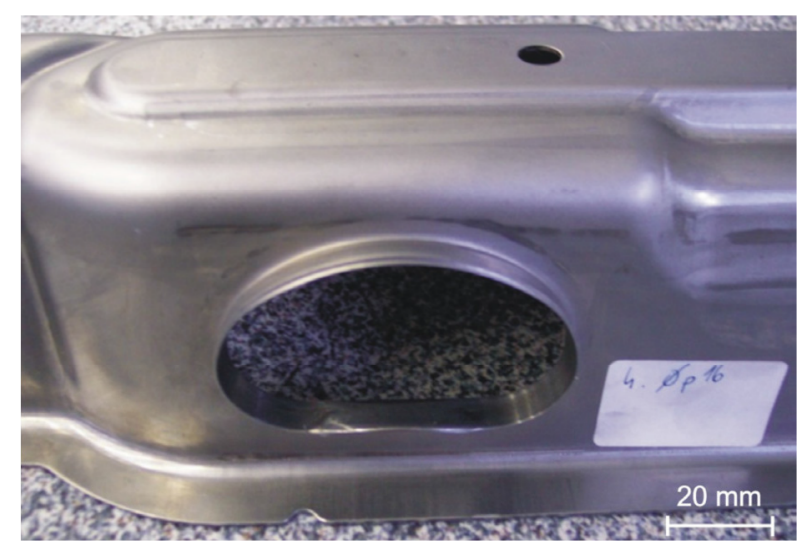

(b)

Figura 22 - (a) Fabricação de flanges com trajetória ascendente da ferramenta. Adaptado de Petek et al. (2011). (b) Exemplo de peça cuja trajetória da ferramenta deve ser ascendente (PETEK; KUZMAN, 2012).

Centeno et al. (2012) e Silva et al. (2013) estudaram os mecanismos de deformação e como ocorre a falha na estampagem incremental de chapa para a liga de alumínio AA1050 H111 e o titânio comercialmente puro de grau 2, respectivamente. Centeno et al. (2012) afirmam que nos casos cujo diâmetro do pré-furo é pequeno, o seu efeito pode ser negligenciado e a conformabilidade pode ser avaliada pelos ensaios realizados com geometrias padrões de cones, sem o furo inicial. No entanto, nos casos em que o diâmetro do pré-furo é grande, a deformação existente na periferia do furo influencia na maneira como a deformação evolui no processo.

Silva et al. (2013) concluíram que o processo de fabricação de flanges por estampagem incremental apenas apresenta coeficiente limite à deformação mais favorável que o processo de fabricação de flanges por estampagem convencional quando a CLF se encontra muito acima da CLE no espaço das deformações principais. Esta é a razão pela qual o processo de fabricação de flanges por estampagem incremental da liga de alumínio AA 1050-H111 apresenta coeficiente limite de deformação maior que o processo de fabricação de flanges por estampagem convencional do mesmo material, observando-se o inverso para 0 titânio comercialmente puro de grau 2 (Figura 23). 
Montanari et al. (2013) estudaram os mecanismos de deformação para a fabricação de flanges em aço inoxidável AISI 304L. Os autores indicaram que o limite da razão de conformação dos flanges circulares pela estampagem convencional é superior ao limite da razão de conformação dos flanges circulares do processo por estampagem incremental para o material em estudo. Na verdade, a estampagem convencional permitiu fabricar flanges circulares com paredes verticais com diâmetros a partir de $D_{0} \geq 95 \mathrm{~mm}$, enquanto na estampagem incremental o sucesso ocorreu para flanges com furos inicias de $D_{0} \geq 115 \mathrm{~mm}$.

Este resultado não condiz com o apresentado na literatura sobre a vantagem da estampagem incremental comparado a estampagem convencional e também diverge dos resultados de investigações em alguns materiais, como a liga de alumínio AA1050 H111 (CENTENO et al., 2012 e CUl et al., 2008). Entretanto, os resultados obtidos com o aço inoxidável AISI304L são consistentes com os resultados observados em flanges circulares de titânio comercialmente puro de grau 2 (SILVA, 2013) (Figura 23). 


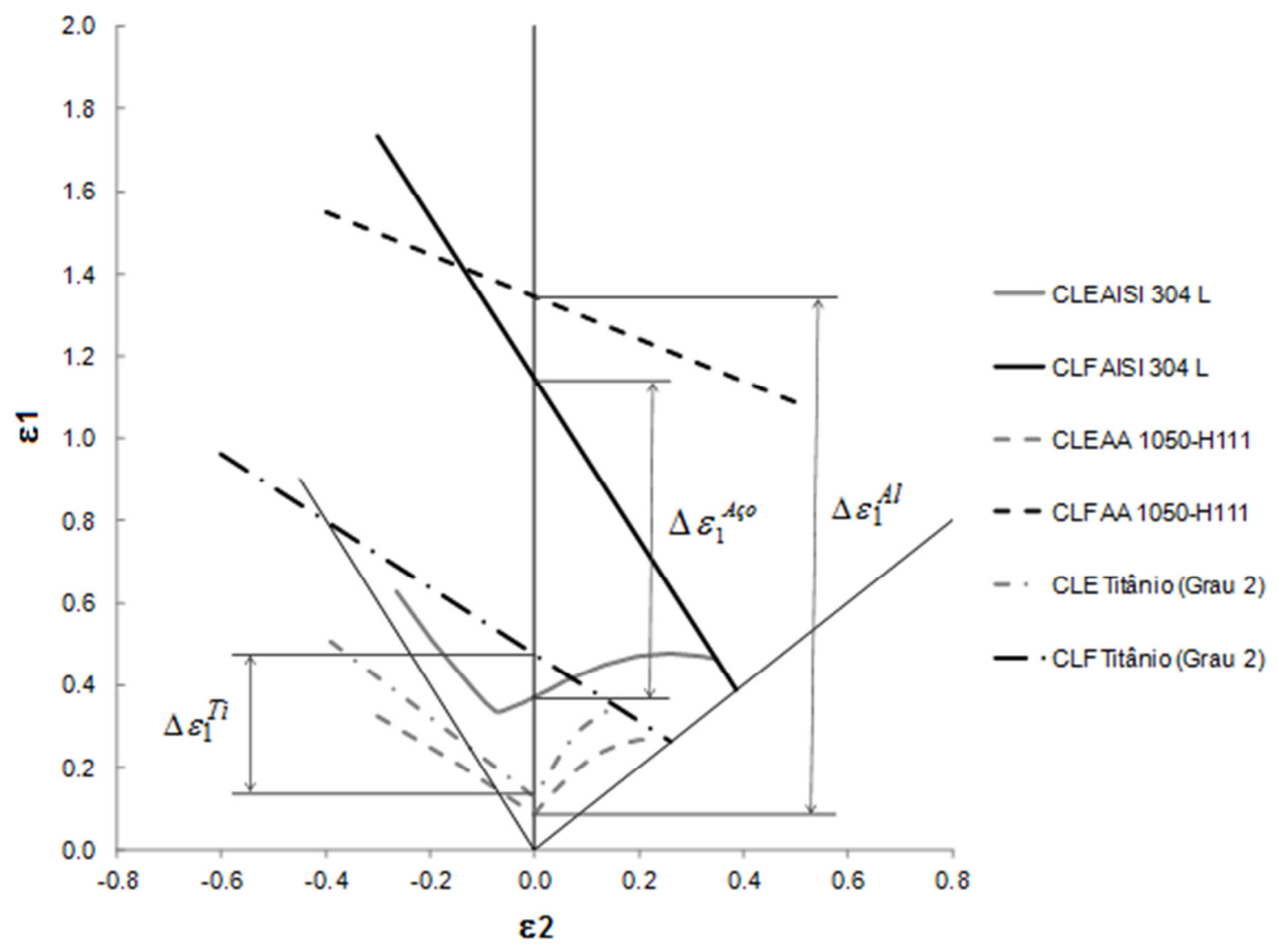

Figura 23 - Representação da CLE e CLF do aço inoxidável AISI304L, da liga de alumínio AA1050 H111 e do titânio comercialmente puro de grau 2. Adaptado de Montanari et al. (2013).

Como visto na Figura 23, a combinação entre a distância da CLE e CLF e a inclinação da CLF do aço inoxidável AISI304L, da liga de alumínio AA1050 H11 e do titânio comercialmente puro de grau 2 conduzem à afirmação de que o nível de deformação pode ser mais elevado na estampagem incremental que na estampagem convencional dependendo do material.

Operações de flangeamento para obtenção de flanges com paredes retas, côncavas e convexas (sem furos iniciais) foram objetos de estudo de Voswinckel et al. (2014). Os autores analisaram a influência da trajetória da ferramenta, do comprimento do flange e do raio do flange na estampagem incremental com matriz. Através dos seus estudos, os autores afirmam que o processo de fabricação de flanges por estampagem incremental apresenta menos limitações que o processo de fabricação 
de flanges por estampagem convencional, no que diz respeito a razão entre o comprimento e o raio do flange.

As estratégias usadas pelos autores estão representadas na Figura 24. Foram usadas quatro estratégias da trajetória da ferramenta. A primeira consistia em produzir flanges com paredes à $90^{\circ}$ numa única passagem. A segunda baseou-se numa estratégia multi-passagem em que o ângulo da parede aumentava a cada passagem, com a sequência $30^{\circ}, 50^{\circ}, 70^{\circ}, 90^{\circ}$. Na terceira estratégia, também multipassagem, era produzida um flange com uma parede a $90^{\circ}$ que aumentava o seu comprimento em $10 \mathrm{~mm}$ a cada passagem. A quarta estratégia consistia numa combinação da segunda com a terceira estratégia, sendo também multi-passagem, com um aumento do ângulo da parede e do comprimento do flange a cada passagem.

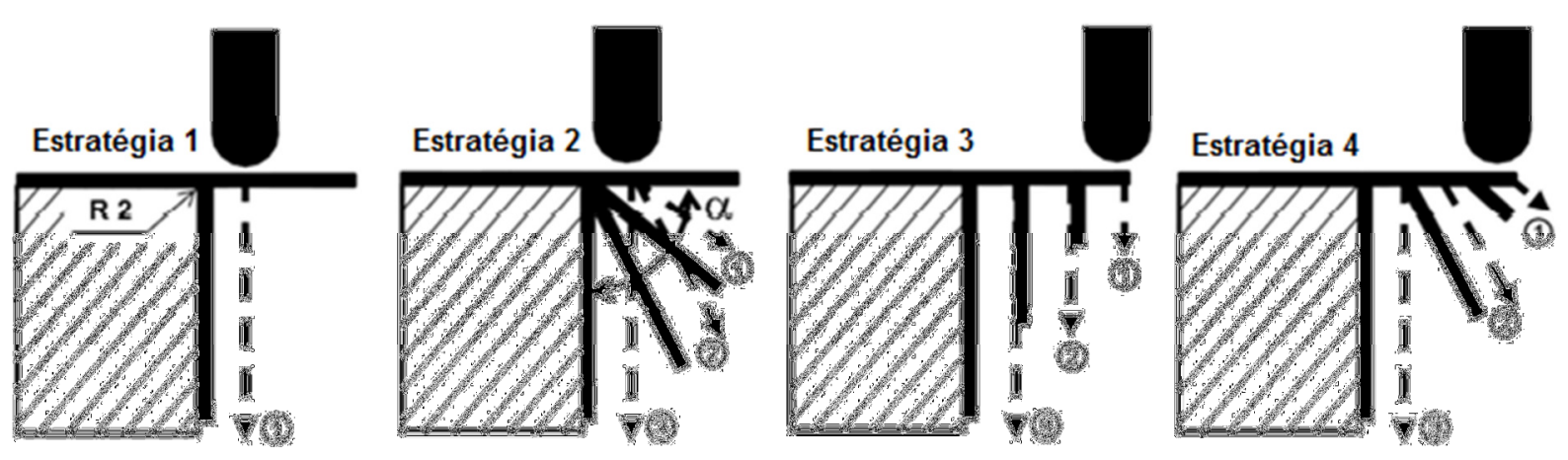

Figura 24 - Representação esquemática das estratégias para a trajetória da ferramenta. Adaptado de Voswinckel et al. (2014).

Os resultados obtidos mostraram que o excesso de material nos flanges côncavos e convexos criou protuberâncias nas peças e deu origem ao fenômeno de orelhamento, fraturas e inclinações, como mostra a Figura 25 e não foram observadas vantagens na utilização das estratégias mais complexas 2, 3 e 4 para a trajetória da ferramenta. 

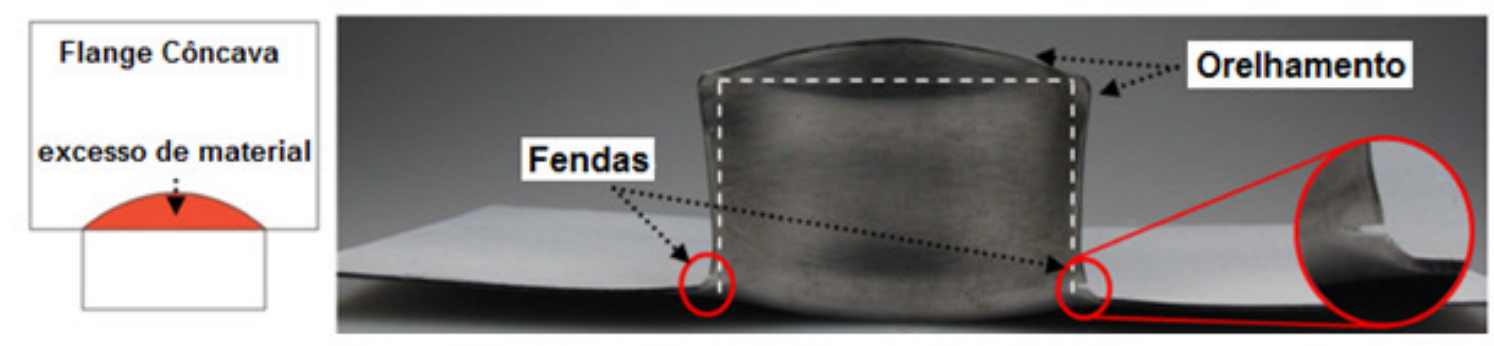

(a)

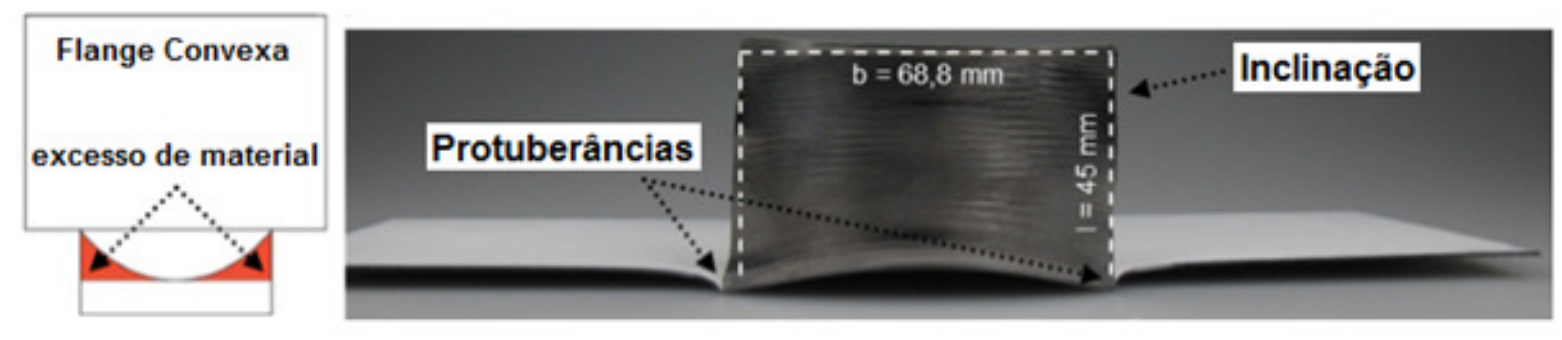

(b)

Figura 25 - Fenômenos observados nos flanges. (a) Côncavas. (b) Convexas. Adaptado de Voswinckel et al. (2014).

Com o intuito de prever a fratura na estampagem incremental, além de analisar o mecanismo de deformação e otimizar o processo, é comum que os pesquisadores tendam pela simulação numérica. Dessa forma, na sequência, encontra-se breve descrição de criação do modelo matemático, implícita e explícita, bem como a descrição de algumas pesquisas sobre simulação numérica que vem sendo desenvolvida, aplicada a estampagem incremental.

\subsection{Simulação numérica - método de elementos finitos}

O método de elementos finitos permite calcular a solução de um problema reduzindo-o para um sistema de equações algébricas. Trata-se de discretizar o meio continuo em nós, cujo comportamento elástico é descrito e estruturado por um conjunto equações de equilíbrio, que podem, dependendo do tipo de problema, ser estáticas ou dinâmicas (eq. (9)) HALLQUIST (1993). 


$$
M x^{\prime \prime}+C x^{\prime}+F_{\text {int }}=F_{\text {sup }}+F_{\text {cont }}+F_{\text {ext }}
$$

Onde:

$$
\begin{aligned}
& \mathrm{Mx}^{\prime \prime}=\text { Forças de inércia } \\
& \mathrm{Cx}^{\prime}=\text { Forças de amortecimento } \\
& \mathrm{F}_{\text {int }}=\text { Forças internas } \\
& \mathrm{F}_{\text {sup }}=\text { Foças dos suportes (graus de liberdade fixos) } \\
& \mathrm{F}_{\text {cont }}=\text { Forças de contato } \\
& \mathrm{F}_{\text {ext }}=\text { Forças externas aplicadas }
\end{aligned}
$$

A eq. (9) é avaliada nos nós do sistema. O lado esquerdo da eq. (9) representa as forças inerciais envolvidas. Podem-se dividir os termos da esquerda em forças inerciais, devidas às acelerações das massas dos nós; forças de amortecimento, decorrentes da velocidade; e em forças internas, mais difíceis de serem calculadas, pois, para que sejam obtidas, envolvem o uso dos deslocamentos nodais o cálculo das deformações equivalentes e uso das relações constitutivas do material.

A integração da eq. (9) no tempo é numericamente calculada e prova a solução em tempos discretos. Podem-se usar duas estratégias de integração: a implícita ou a explícita.

\subsubsection{Estratégia de integração explícita}

A estratégia explícita inicia com o cálculo da equação de equilíbrio no começo do incremento de tempo. Isso requer o cálculo das forças internas usando as deformações e as leis constitutivas como ocorre para a estratégia implícita. 0 desequilíbrio entre as forças internas e as forças externas provê as acelerações nodais iniciais. Com isso as posições nodais no final do incremento de tempo são calculadas usando as posições nodais iniciais e as acelerações nodais calculadas. Esse processo é mostrado na Figura 26. 


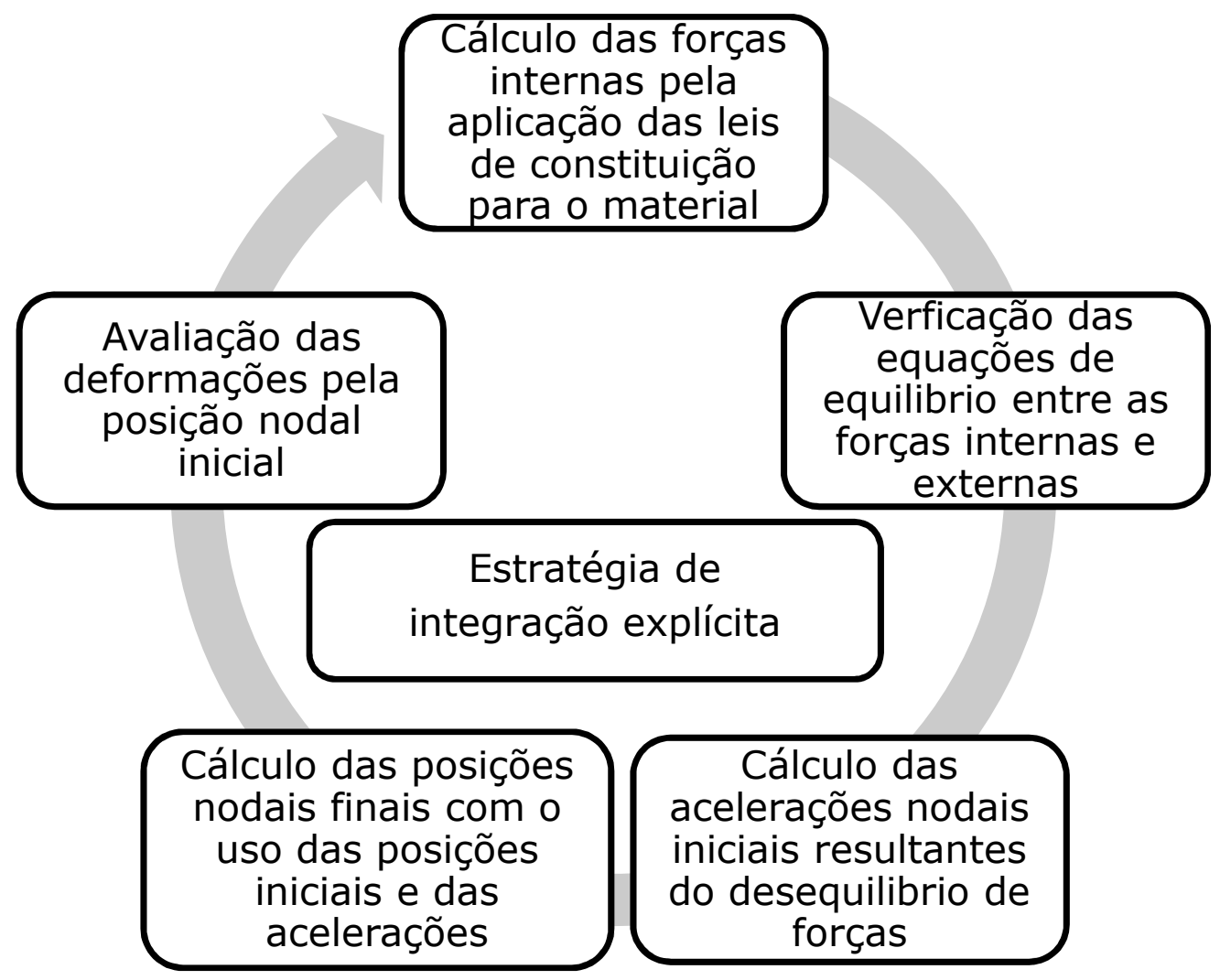

Figura 26- Estratégia de integração explícita

Como no método a equação de equilíbrio nem sempre é tem solução numérica exata, esse método é condicionalmente estável. Deve-se assumir que o desequilíbrio remanescente será insignificante sob a condição de que a amplitude do incremento de tempo seja menor do que um valor crítico. Esse valor crítico depende do menor tamanho do elemento utilizado, do parâmetro Módulo de Young e da densidade do material, conforme a condição de estabilidade de Courant, eq. (10).

$$
\Delta \mathrm{tc} \propto \mathrm{L}_{\min } \cdot \sqrt{\frac{\rho}{\mathrm{E}}}
$$

Onde:

$\Delta \mathrm{tc} \quad=$ Incremento de tempo crítico

$\mathrm{L}$ min = Comprimento mínimo de referência dos elementos (diagonal ou lado)

$\rho \quad=$ Densidade do material

$\mathrm{E} \quad=$ Módulo de Young 
Geralmente a massa pode ser artificialmente aumentada o que eleva o incremento de tempo crítico, sem uma significante perda na precisão. Esse artifício é chamado de escalonamento na massa (mass scaling). Outro artifício, chamado escalonamento do tempo (time scaling), pode ser usado quando aumenta a velocidade da ferramenta, por meio da diminuição do tempo total de processo, diminuindo o tempo total de simulação. HALLQUIST, J. O (1993).

A simulação numérica é empregada no estudo da estampagem incremental de forma a expandir o conhecimento a respeito do processo que se mostra tão promissor. Alguns trabalhos importantes na área de estampagem incremental envolvendo elementos finitos fora estudados e são apresentados de forma simplificada na Tabela 2. Na qual podem ser vistos os parâmetros utilizados no desenvolvimento de simulações numéricas. São mostrados os dados de entrada nas simulações, os parâmetros de condições de contorno, tamanho do elemento, formulação, aspectos da malha dos elementos, tipo e modelo do material, aspectos geométricos e velocidade da ferramenta. Todos os autores citados usaram o software LS-Dyna ${ }^{\mathrm{TM}}$ para desenvolver as suas simulações.

Segundo Henrard (2009), a maioria dos autores que utiliza softwares comerciais para o desenvolvimento de simulações numéricas aplicadas a estampagem incremental afirma que é possível reduzir o tempo de simulação sem uma perda considerável de qualidade de simulação e de maneira eficiente. Na maioria dos trabalhos a estratégia empregada é a explícita usando escala conveniente na massa e no tempo. Henrard (2009) ainda afirma que alguns autores utilizam estratégias implícitas para validar seus resultados com a estratégia explícita e que existe um consenso de que para realizar uma análise de retorno elástico é aconselhável que se use a criação do modelo matemático implícita. 


\begin{tabular}{|c|c|c|c|c|c|c|c|c|c|}
\hline & $\begin{array}{l}\text { Oleksik et al. } \\
\text { (2006) e Cofaru } \\
\text { et al. (2008) }\end{array}$ & $\begin{array}{l}\text { Yamashita et al. } \\
(2007)\end{array}$ & $\begin{array}{l}\text { Dejardin et al. } \\
\text { (2009) }\end{array}$ & $\begin{array}{l}\text { Qin et al. } \\
\text { (2010) }\end{array}$ & $\begin{array}{l}\text { Echrif eHrairi } \\
\text { (2011b) }\end{array}$ & $\begin{array}{l}\text { Thibaud et al. } \\
\text { (2012) }\end{array}$ & $\begin{array}{l}\text { Chera et al. } \\
\quad(2013)\end{array}$ & Cui et al. (2013) & Li et al. (2014) \\
\hline $\begin{array}{l}\text { Condições } \\
\text { contorno }\end{array}$ & Prensa chapas & $\begin{array}{l}\text { Todos graus de } \\
\text { liberdade nas } \\
\text { extremidades }\end{array}$ & - & $\begin{array}{c}\text { Todos graus } \\
\text { de liberdade } \\
\text { nas } \\
\text { extremidades }\end{array}$ & $\begin{array}{l}\text { Prensa } \\
\text { Chapas }\end{array}$ & $\begin{array}{l}\text { Todos graus de } \\
\text { liberdade nas } \\
\text { extremidades }\end{array}$ & Prensa Chapas & $\begin{array}{l}\text { Todos graus de } \\
\text { liberdade nas } \\
\text { extremidades }\end{array}$ & $\begin{array}{c}\text { Todos graus de } \\
\text { liberdade nas } \\
\text { extremidades }\end{array}$ \\
\hline Coeficiente de atrito & - & Zero & 0,3 & - & 0,1 & estático 0.2 & 0,08 & 0,08 & 0,18 \\
\hline Algoritmo de contato & $\begin{array}{l}\text { Automatic } \\
\text { Surface to } \\
\text { Surface }\end{array}$ & - & - & - & - & $\begin{array}{l}\text { Classic Penalty } \\
\text { Method }\end{array}$ & - & - & - \\
\hline Tipo de elemento & Shell 163 & Solid & Shell & Shell 163 & Shell type 16 & Solid & Shell 163 & Shell & Shell \\
\hline $\begin{array}{l}\text { Tamanho médio } \\
\text { elemento }[\mathrm{mm}]\end{array}$ & $3 \times 3$ & $0,25 \times 0,25 \times 0,125$ & $5 \times 5$ & $2,5 \times 2,5$ & - & $0,283 \times 0,283 \times 0,21$ & $4 \times 4$ & $1 \times 1$ & $1,5 \times 1,5$ \\
\hline $\begin{array}{l}\text { Graus de liberdade } \\
\text { do elemento }\end{array}$ & - & - & 6 & & - & - & & 5 & - \\
\hline $\begin{array}{l}\text { Formulação do } \\
\text { elemento }\end{array}$ & Belytschko-Tsai & - & Belytschko-Tsai & - & Hughes-Liu & Hughes-Liu & Belytschko-Tsai & Hughes-Liu & - \\
\hline $\begin{array}{ll}\begin{array}{l}\text { Elementos } \\
\text { espessura }\end{array} & \text { na } \\
\end{array}$ & 5 & 2 & 5 & - & 5 & 3 & 11 & 5 & - \\
\hline Shear Factor & $5 / 6$ & - & - & - & - & - & $5 / 6$ & - & - \\
\hline Hourglass Control & 0,1 & - & - & - & - & - & 0,1 & - & - \\
\hline Material & - & & Alumínio & Alumínio 1050 & $\begin{array}{c}\text { Alumínio } \\
1050\end{array}$ & Cobre & Aço & Aço & Alumínio 7075 \\
\hline $\begin{array}{l}\text { Comportamento do } \\
\text { material }\end{array}$ & $\begin{array}{l}3 \text { Parâmetros } \\
\text { Barlat }\end{array}$ & Isotrópico & Isotrópico & - & Isotrópico & Isotrópico & $\begin{array}{l}\text { Anisotropia } \\
\text { Transversal }\end{array}$ & $\begin{array}{l}\text { Anisotropia } \\
\text { Transversal }\end{array}$ & Isotrópico \\
\hline $\begin{array}{l}\text { Coeficiente } \\
\text { anisotropia }\end{array}$ & $\begin{array}{l}\mathrm{R} 00=1,04 \\
\mathrm{R} 45=0,86 \\
\mathrm{R} 90=0,72\end{array}$ & - & - & - & & - & 0,997 & 1.85 & - \\
\hline $\begin{array}{ll}\text { Diâmetro } & \mathrm{da} \\
\text { ferramenta }[\mathrm{mm}] & \end{array}$ & $12-20$ & 1 & 10 & 17,5 & 6 & - & 10 & 6 & 30 \\
\hline $\begin{array}{l}\text { Tipo de elemento } \\
\text { para ferramenta }\end{array}$ & - & Rígido & Rígido & Rígido & Rígido & Rígido & - & Rígido & Rígido \\
\hline $\begin{array}{l}\text { Espessura da chapa } \\
{[\mathrm{mm}]}\end{array}$ & 1 & 0,25 & 1 & - & 1 & 0,21 & 0,4 & 1 & 1,016 \\
\hline $\begin{array}{l}\text { Dimensões } \\
\text { superfície da chapa } \\
{[\mathrm{mm}]}\end{array}$ & $R=120$ & $14,5 \times 14,5$ & $300 \times 300$ & & $\mathrm{R}=82,5$ & $17 \times 17$ & $200 \times 200$ & $R=190$ & $300 \times 300$ \\
\hline $\begin{array}{ll}\text { Incremento na } \\
\text { profundidade [mm] }\end{array}$ & - & 1 & 0,2 & 2 & 0,5 & 0,104 & 0,1 & 1 & 0,5 \\
\hline $\begin{array}{ll}\text { Velocidade } & \text { da } \\
\text { ferramenta }\end{array}$ & - & $10000-20000 \mathrm{~mm} / \mathrm{s}$ & $500 \mathrm{~mm} / \mathrm{min}$ & - & - & $1300 \mathrm{~mm} / \mathrm{min}$ & - & $5000 \mathrm{~mm} / \mathrm{min}$ & $1000 \mathrm{~mm} / \mathrm{min}$ \\
\hline Escala na massa & - & Sim & - & Sim & - & - & - & - & $\operatorname{Sim}(16,8)$ \\
\hline
\end{tabular}


Os trabalhos de Oleksik et al. (2006) e Cofaru et al.(2008) analisam aspectos do processo como regiões de concentração de tensão e mostram a influência do diâmetro da ferramenta no processo. Os autores assumem que a simulação por elementos finitos é mais adequada na avaliação de aspectos qualitativos e não quantitativos, dada sua complexidade e não-linearidade.

Yamashita et al. (2007) analisam a fabricação de geometrias padrão piramidais e mostram a influência da trajetória da ferramenta nas forças de deformação exercidas pela ferramenta. Yamashita et al. (2007) utilizam dois tipos de artifícios para acelerar a simulação e mostram como tais artifícios influenciam no resultado da simulação e encontram valores para a velocidade da ferramenta e densidade que julgam adequados do ponto de vista computacional.

Dejardin et al. (2009) utilizam a técnica de simulação com elementos finitos para mostrar a possibilidade de simular o retorno elástico sofrido no final do processo. A geometria padrão analisada é o cone. Neste trabalho os autores dividem as peças obtidas na estampagem incremental em setores circunferenciais e compara com os resultados obtidos com a criação do modelo matemático numérica. Os resultados mostram que a criação do modelo matemático desenvolvido vem de encontro ao resultado obtido experimentalmente.

Qin et al. (2010) demonstram que a simulação por meio de elementos finitos fornece uma boa compreensão das deformações no processo, além disso, também mostra que a diminuição do passo na direção $Z$ influencia de forma positiva na geometria final da peça. Já Thibaud et al. (2012) empregam o software LS-DynaTM para modelar uma pequena pirâmide em uma chapa de cobre e mostra como a variação do passo na direção em $Z$ da ferramenta influencia a espessura de parede obtida na peça final.

Echrif e Hrairi (2011b) mostram através de simulações a importância do ângulo de parede e que o uso de estratégias muti-passagens favorece a obtenção de paredes com ângulos acentuados.

Chera et al. (2013) desenvolvem simulações usando o software LS-Dyna ${ }^{\mathrm{TM}}$. A simulação ocorre na estampagem incremental em sua variante com dois pontos de 
contato entre o conjunto de ferramentas e a peça. Para os pontos são desenvolvidas duas trajetórias separadas por um espaço controlado. Desse modo, os autores obtiveram valores para as forças atuantes durante o processo. Com essa simulação foi possível obter ganhos no processo.

Já Cui et al. (2013) fazem uso de elementos finitos com a finalidade de comparar um modelo matemático analítico, desenvolvido pelos autores, à solução pelo método de elementos finitos utilizando a simulação explícita no LS-Dyna ${ }^{\mathrm{TM}}$.

Por sua vez, Li et al. (2014) estudaram o efeito da dimensão da ferramenta, o atrito entre a chapa e a ferramenta através do LS-Dyna ${ }^{\mathrm{TM}}$ e compararam com resultados experimentais. Os autores afirmam que o método de elementos finitos é eficiente para verificar a influência do diâmetro da ferramenta no mecanismo de deformação e na distribuição de espessuras.

Os trabalhos citados na Tabela 2 e brevemente discutidos forneceram importante contribuição ao trabalho de simulação que será desenvolvido nesta dissertação. A seguir, encontra-se o capítulo referente às simulações numéricas aplicadas a estampagem incremental para obtenção de flanges em chapas previamente furadas. 


\section{CAPÍTULO 3}

\section{Simulações numéricas}

Este capítulo tem como finalidade a construção de um modelo explicito em elementos finitos e sua avaliação segundo parâmetros de entrada definidos. As variáveis de entrada são determinísticas, portanto os resultados provenientes do modelo construído também deverão ser bem determinados.

São adotadas as seguintes etapas para condução do estudo de simulação:

- Definição do sistema e construção do modelo (Metodologia)

- Planejamento da simulação

- Execução das simulações

- Análise dos resultados

Essas etapas não estão ordenadas como são apresentadas, mas de maneira iterativa. A adoção desses passos visa assegurar que as simulações sejam executadas e apresentadas de maneira organizada.

\subsection{Metodologia}

Inicialmente define-se o tipo de simulação a ser implementado e cria-se o modelo do material. Então se realiza um teste de contato simples, onde uma esfera é comprimida contra uma seção de chapa. Nessa simulação são analisados aspectos como a rigidez do contato, as condições de contorno utilizadas, sua influência sobre a seção da chapa e o tamanho do elemento utilizado.

Em seguida, realiza-se um teste de deformação da chapa, cuja trajetória da ferramenta é em linha. Avalia-se a velocidade da ferramenta e o uso de fatores de massa e tempo com a finalidade de melhorar e acelerar as simulações. Essa metodologia é baseada na metodologia usada por Henrard (2009), entretanto em seu trabalho ela é utilizada em código específico, o Lagamine, desenvolvido em sua instituição de pesquisa. 
Em seguida realizam-se simulações em flanges e mostra-se a influência do coeficiente de atrito estático do modelo e a sua influência sobre as deformações. Simula-se a fabricação de dois flanges, um com diâmetro $D_{0}=102 \mathrm{~mm}$ e outro com diâmetro $D_{0}=121 \mathrm{~mm}$ para o furo inicial.

Para verificar a ocorrência da fratura analisa-se a redução da espessura da chapa quando deformada. E, por fim, calcula-se, pelo critério de Rice e Tracey (1969), o dano crítico.

\subsubsection{Definição do sistema e construção do modelo e geometria}

O modelo é constituído por uma chapa que, por deslocamentos da ferramenta, é transformada no produto final pela ação de uma esfera com diâmetro definido, representando a ferramenta. As geometrias usadas nas simulações variam em dimensões e forma.

\subsubsection{Sistema de coordenadas}

O sistema de coordenadas global para a simulação foi definido como o da chapa e

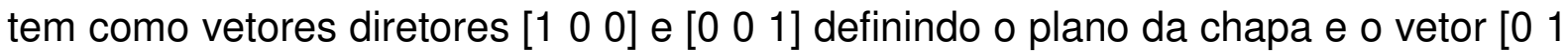
0] definindo a direção normal a chapa. A geometria foi criada de maneira que a origem do sistema de coordenadas permaneça no centro da chapa sob trabalho.

\subsubsection{Conexões entre as peças}

A determinação do contato entre as peças pode ser extremamente difícil. Por essas razões, o software LS-DYNA ${ }^{\mathrm{TM}}$ conta com algoritmos de contato para tornar o contato entre as superfícies o mais eficiente possível (HALLQUIST, 1993).

O algoritmo de contato selecionado no LS-DYNA ${ }^{\text {TM }}$ foi o Surface- to-Surface (STS). Nele o contato é estabelecido quando a superfície de um corpo penetra a superfície do outro corpo. Ele é recomendado em problemas nos quais os corpos apresentam áreas de contato grandes (HALLQUIST, 1993), como no caso chapa. Na simulação 
a esfera foi definida como o elemento que busca o contato, contact, e a chapa como o elemento a ser buscado, target.

Nos testes de contato e no teste em linha foi utilizado um modelo sem atrito, já no teste de flange utilizou-se coeficiente de atrito variando de 0,1 até 0,3. Essa foi a maneira encontrada de determinar o coeficiente de atrito adequado, dada a complexidade em sua medição.

\subsubsection{Tipo de elemento usado na simulação}

O tipo de elemento utilizado nas simulações pode influenciar a qualidade da simulação. Existe um compromisso entre o uso de elementos do tipo casca (shell) e elementos sólidos tridimensionais (brick). Usar poucos elementos na espessura quando se empregam elementos brick pode causar prejuízo na precisão do modelo, pois há uma linearização dos efeitos ao longo da espessura inerente às funções aproximadoras do elemento, desconsiderando efeitos de gradientes intensos.

A razão de não se usar elementos sólidos em simulações de chapas, é que as 3 dimensões do elemento devem ser aproximadas de maneira a não prejudicar o resultado, devido à natureza das funções interpoladoras do elemento, que aproximam os valores internos pelos valores nodais calculados. $\mathrm{O}$ uso de elementos sólidos em chapas finas resulta em um número grande de elementos com a finalidade de manter a homogeneidade entre as dimensões do elemento. $O$ uso de muitos elementos causa aumento do tempo de simulação, pois aumenta o tamanho da matriz a ser resolvida pelo programa de elementos finitos.

Já elementos planos que assumem estado plano de tensões ou de deformações podem representar o comportamento das chapas finas, sem necessariamente terem dimensões reduzidas em sua superfície. Entretanto, podem não fornecer uma análise precisa na espessura, caso o número de elementos na espessura não seja adequado, resultando na linearização dos efeitos na espessura, ou o estado tridimensional de tensões ou deformações influencie o processo. 
Para a criação do modelo matemático da chapa foi utilizado o elemento SHELL 163 do software LS-DYNA ${ }^{\mathrm{TM}}$. Esse elemento conta com 12 graus de liberdade nodais, sendo eles os deslocamentos, as velocidades, as acelerações e as rotações em todos os eixos, apesar das acelerações e das velocidades não serem fisicamente graus de liberdade são assim tratadas pela maneira que são manipuladas na formulação do elemento.

\subsubsection{Anisotropia}

Durante o processo de fabricação, as chapas metálicas passam por processos de laminação, que atribuem aos grãos do material um alinhamento preferencial dos planos cristalográficos na direção de laminação. Assim, os materiais adquirem propriedades mecânicas diferentes como, por exemplo, tensão de escoamento e taxa de encruamento, que variam de acordo com a direção nas quais são medidas.

Os produtos planos laminados apresentam dois tipos de anisotropia: a anisotropia planar e a anisotropia normal. A anisotropia planar é decorrente da variação das propriedades mecânicas no plano da chapa na direção em que são medidas, sendo um indicador do grau de anisotropia existente no plano da chapa. Quando não existir anisotropia planar, o coeficiente de anisotropia no plano da chapa é independente da direção considerada. O fato de não haver anisotropia no plano da chapa não significa que as propriedades segundo a espessura tenham de ser as mesmas. De fato, existem materiais praticamente sem anisotropia planar e com anisotropia normal considerável, que é uma das características que os materiais para estampagem devem possuir (RODRIGUES; MARTINS, 2010).

A anisotropia normal ocorre quando as propriedades na espessura são diferentes das que se obtêm no plano da chapa. Para quantificar a anisotropia segundo a direção da espessura, define-se o coeficiente de anisotropia normal médio (ou apenas coeficiente de anisotropia normal) segundo as direções $0^{\circ}$, 45ำ e $90^{\circ}$ com relação à direção de laminação, dado pela eq. (11).

$$
r=\frac{r_{0}+2 r_{45}+r_{90}}{4}
$$


As propriedades da liga de Alumínio AA1050 utilizada neste estudo foram extraídas de Cristino et al. (2014) e são apresentados na Tabela 3. Essas propriedades foram obtidas experimentalmente.

Tabela 3 - Propriedades da liga de alumínio AA 1050 H111 (CRISTINO et al., 2014).

\begin{tabular}{|c|c|c|c|c|}
\hline $\begin{array}{l}\text { Ângulo com } \\
\text { relação à } \\
\text { direção de } \\
\text { laminação }\end{array}$ & $\begin{array}{l}\text { Módulo de } \\
\text { elasticidade } \\
\text { [GPa], } E\end{array}$ & $\begin{array}{l}\text { Tensão de } \\
\text { escoamento } \\
{[\mathrm{MPa}], \sigma_{\mathrm{y}}}\end{array}$ & $\begin{array}{c}\text { Tensão } \\
\text { limite a } \\
\text { fratura } \\
{[\mathrm{MPa}], \sigma_{\mathrm{R}}}\end{array}$ & $\begin{array}{c}\text { Alongamento } \\
\text { após a fratura } \\
{[\%], A}\end{array}$ \\
\hline $0^{\circ}$ & 72,7 & 115,4 & 119,0 & 7,1 \\
\hline $45^{\circ}$ & 67,9 & 120,4 & 121,2 & 5,2 \\
\hline $90^{\circ}$ & 71,8 & 123,0 & 120,8 & 5,6 \\
\hline Média & 70,0 & 119,6 & 120,3 & 6,8 \\
\hline \multicolumn{5}{|c|}{ Anisotropia } \\
\hline & $\begin{array}{l}\text { Coeficient } \\
\text { anisotror }\end{array}$ & \multicolumn{2}{|c|}{$\begin{array}{c}\text { anisotropia } \\
\text { médio, } r\end{array}$} & $\begin{array}{l}\text { oeficiente de } \\
\text { tropia planar, } \Delta r\end{array}$ \\
\hline $0^{\circ}$ & 0,71 & \multirow{3}{*}{\multicolumn{2}{|c|}{0,84}} & \\
\hline $45^{\circ}$ & 0,88 & & & $-0,09$ \\
\hline $90^{\circ}$ & 0,87 & & & \\
\hline
\end{tabular}

Neste trabalho será usado o valor de anisotropia médio $r=0,84$.

Para a maioria dos materiais, após atingir o limite elástico, a curva tensãodeformação continua a crescer. Desse modo, a tensão de escoamento aumenta de acordo com a deformação, caracterizando o efeito conhecido como encruamento. Pelo fato da deformação na estampagem incremental sem matriz ser localizada a escolha da lei de encruamento se torna muito importante para a determinação das forças envolvidas. Como a ferramenta segue uma trajetória complexa, ela carrega e descarrega cada elemento diversas vezes durante o ciclo. Há vários modelos idealizados para descrever o comportamento elasto-plástico do material. Neste trabalho foi utilizado o modelo elasto-plástico bilinear (Figura 27). 


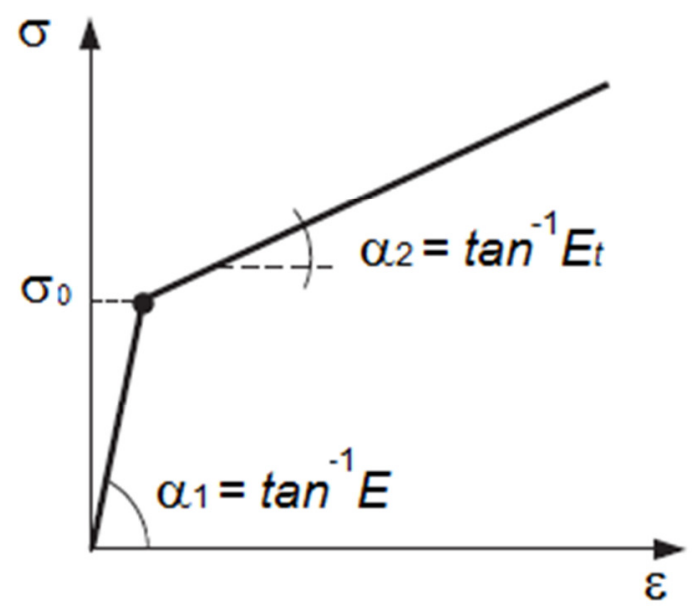

Figura 27- Modelo bilinear idealizando o encruamento.

A reta com inclinação $\alpha_{1}=\tan ^{-1} \mathrm{E}$ corresponde ao trecho elástico da curva tensão $\mathrm{x}$ deformação. Quando o material atinge o escoamento, $\sigma_{0}$, se inicia o comportamento plástico do material que é dado pela reta $\alpha_{2}=\tan ^{-1} \mathrm{E}_{\mathrm{t}}$, onde $\mathrm{E}$ é o módulo de elasticidade e a constante $\mathrm{E}_{\mathrm{t}}$ é conhecida como módulo tangente.

Um modelo elasto-plástico bilinear é apresentado por Lopes et al. (2003) (Figura 29) para curva tensão $x$ deformação da liga de alumínio AA 1050. Em seu trabalho a curva tensão $x$ deformação sofre influência da taxa de deformação aplicada.

Os valores aplicados no modelo matemático para relação tensão $\mathrm{x}$ deformação desenvolvido baseiam-se nos valores encontrados por Lopes et al.(2003), a uma taxa de $0,001 / \mathrm{s}$ e simplificado para modelo um modelo bilinear, conforme mostrado na Figura 28. 


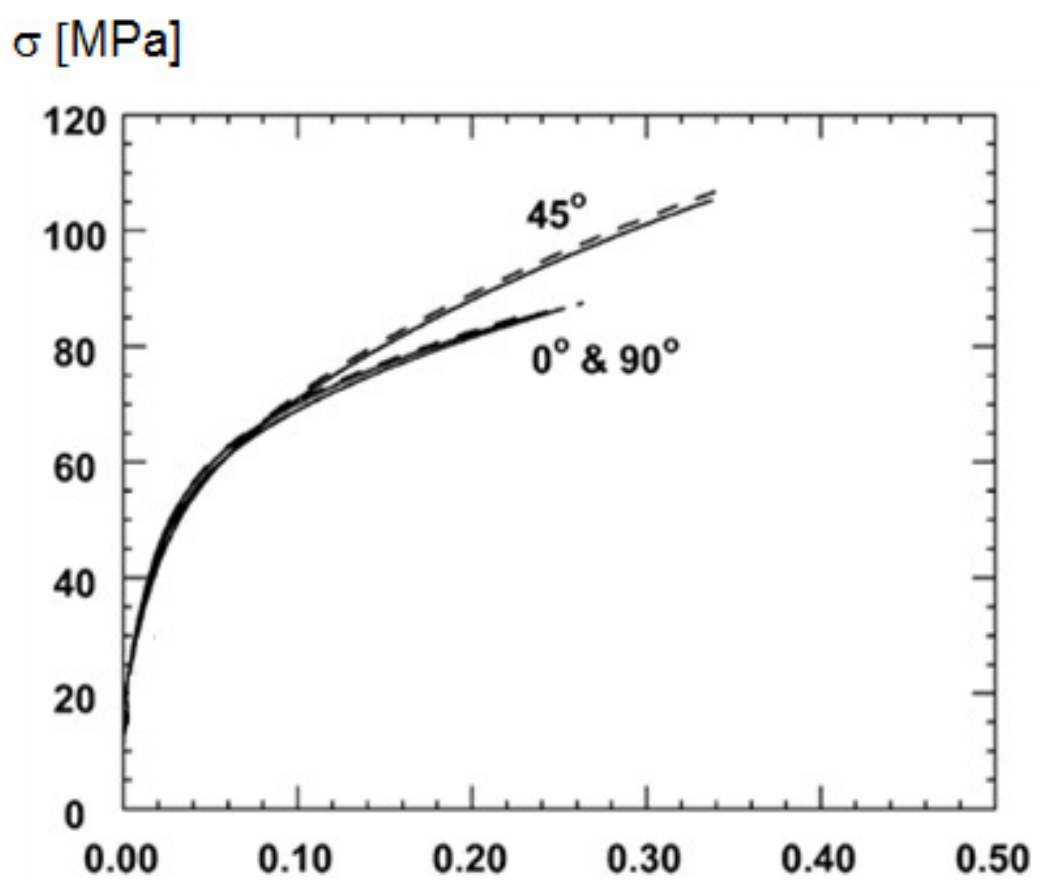

Figura 28- Curva tensão x deformação para a liga de alumínio AA1050 (LOPES et al., 2003).

\subsection{Execução das simulações}

O objetivo principal de efetuar o estudo através de simulações numéricas foi o de reproduzir a estampagem incremental de chapas sem matriz, segundo estratégias de deslocamento da ferramenta. A simulação desenvolvida deve servir como uma ferramenta preditiva do processo, podendo ser utilizado e até mesmo aprimorado em trabalhos futuros.

\subsubsection{Teste de contato}

O teste de contato consiste na deformação da chapa através do contato de uma esfera rígida que representa a ferramenta. É um teste preparatório para posteriormente simular trajetórias mais complexas. O teste é usado para estudar a influência da rigidez de contato, tamanho do elemento e da condição de contorno utilizada. Esse ensaio é realizado em escala reduzida para a chapa e fornece uma ideia da influência dos parâmetros de contato. 
A chapa usada neste ensaio possui espessura de $1 \mathrm{~mm}$ e lados iguais de $8 \mathrm{~mm}$. A chapa é considerada totalmente fixa em seus nós nas extremidades. $O$ diâmetro da ferramenta é de $8 \mathrm{~mm}$ e trata-se de uma semiesfera rígida.

Em todos os ensaios a esfera foi forçada a penetrar na chapa com velocidade constante de $180 \mathrm{~mm} / \mathrm{min}$, até a profundidade de $3 \mathrm{~mm}$ no tempo de $1 \mathrm{~s}$.

A primeira análise considerada foi o tamanho do elemento utilizado. Para isso foram realizadas simulações com 16, 64 e 256 elementos no modelo da chapa e mantiveram-se os elementos da esfera inalterados, como mostra a Figura 29.

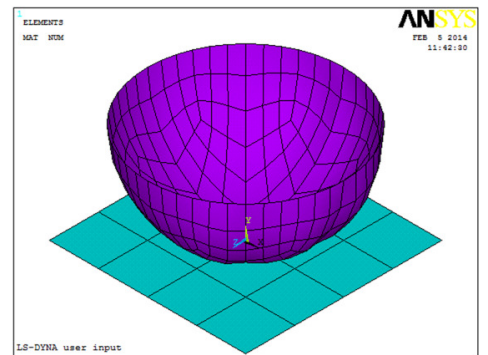

(a)

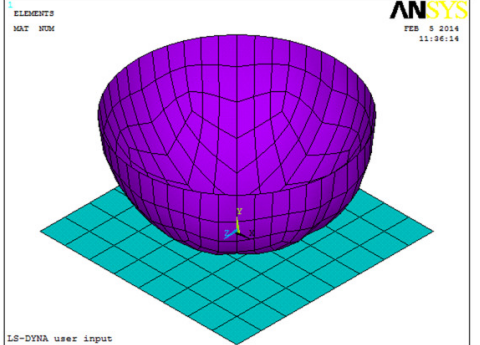

(b)

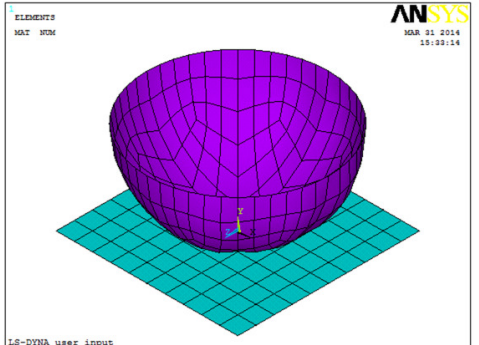

(c)

Figura 29 - Malhas de testes de contato. (a) 16 elementos. (b) 64 elementos. (c) 256 elementos para a chapa.

Os resultados para a tensão principal são apresentados na Figura 30 e os tempos de simulação são mostrados na Tabela 4.

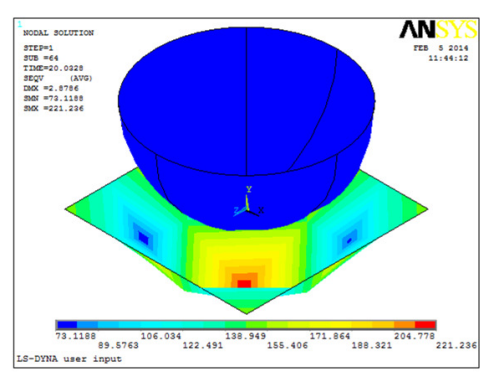

(a)

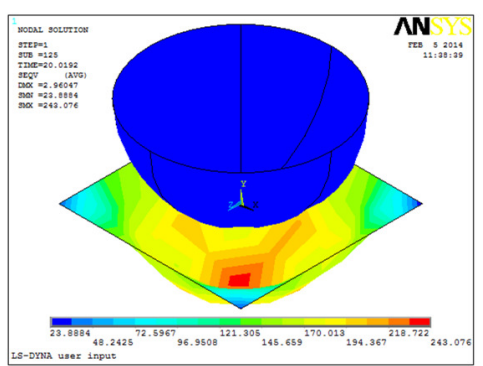

(b)

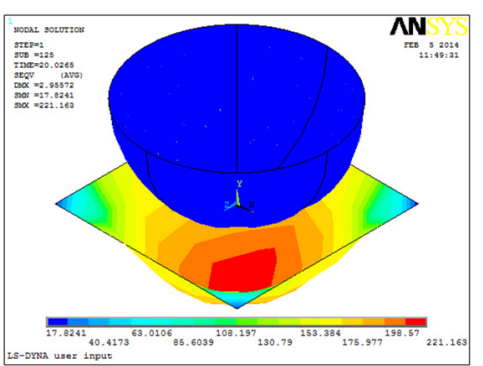

(c)

Figura 30 - Vista isométrica do teste de contato para a tensão de von Mises. (a) 16 elementos. (b) 64 elementos. (c) 256 elementos para a chapa. 
Tabela 4 - Tempos de simulação de contato

Número de elementos

Observando a Tabela 4 verifica que ao aumentar o número de elementos aumenta o tempo de simulação. Além disso, a distribuição de tensão na peça é influenciada pelo número de elementos, como mostra a Figura 30. Nas simulações seguintes esse parâmetro é avaliado com base nessa relação de benefício e no fato de que o elemento Shell não poder ter dimensões diminutas se comparadas à espessura da chapa.

Nas simulações iniciais a rigidez utilizada era de 0,001. Para entender melhor esse parâmetro, presente no algoritmo de solução do LS-DYNA ${ }^{\mathrm{TM}}$, e o modo como ele influencia o contato simulado entre a esfera e a chapa, realizam-se simulações para a rigidez de contato com os valores de 0,$0001 ; 0,001$ e 0,01. Foi usada a malha contendo 64 elementos (na chapa), e os resultados obtidos são mostrados na Figura 31.

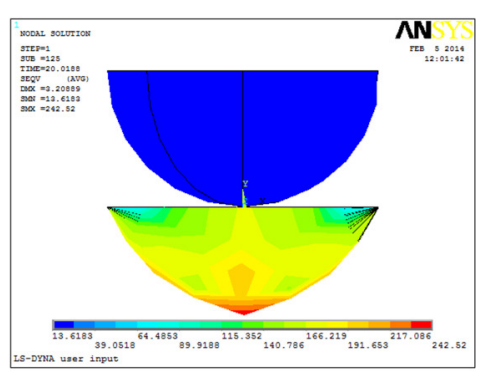

(a)

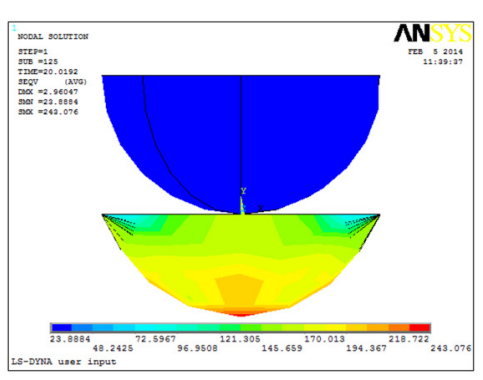

(b)

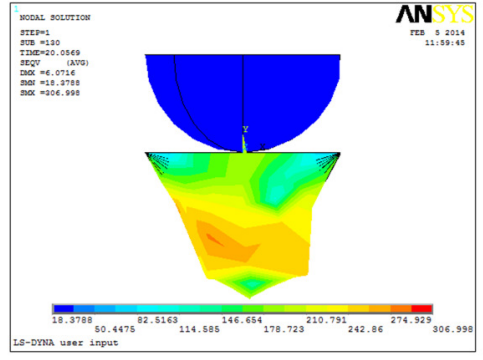

(c)

Figura 31 - Variação da rigidez de contato

Com o teste da variação da rigidez de contato foi possível observar que a distribuição de tensão proveniente da simulação é alterada, sendo mais bem distribuída e apresentando melhor aproximação da geometria da ferramenta para o valor de 0,001. Contudo, o valor de tensão máxima encontrado nas simulações é semelhante. Desse modo, para as próximas simulações, será usado o coeficiente de 0,001 para a rigidez de contato. 
Para a malha contendo 256 elementos foi executado um teste relativo às fixações laterais impostas à chapa com a finalidade de entender o seu comportamento de acordo com a solicitação da ferramenta. Nos testes anteriores as chapas permaneciam com todos os graus de liberdade fixos nas laterais. Neste caso foi liberada a rotação dos elementos laterais, mantendo fixos apenas os deslocamentos. Na Figura 32 são mostradas as tensões resultantes.
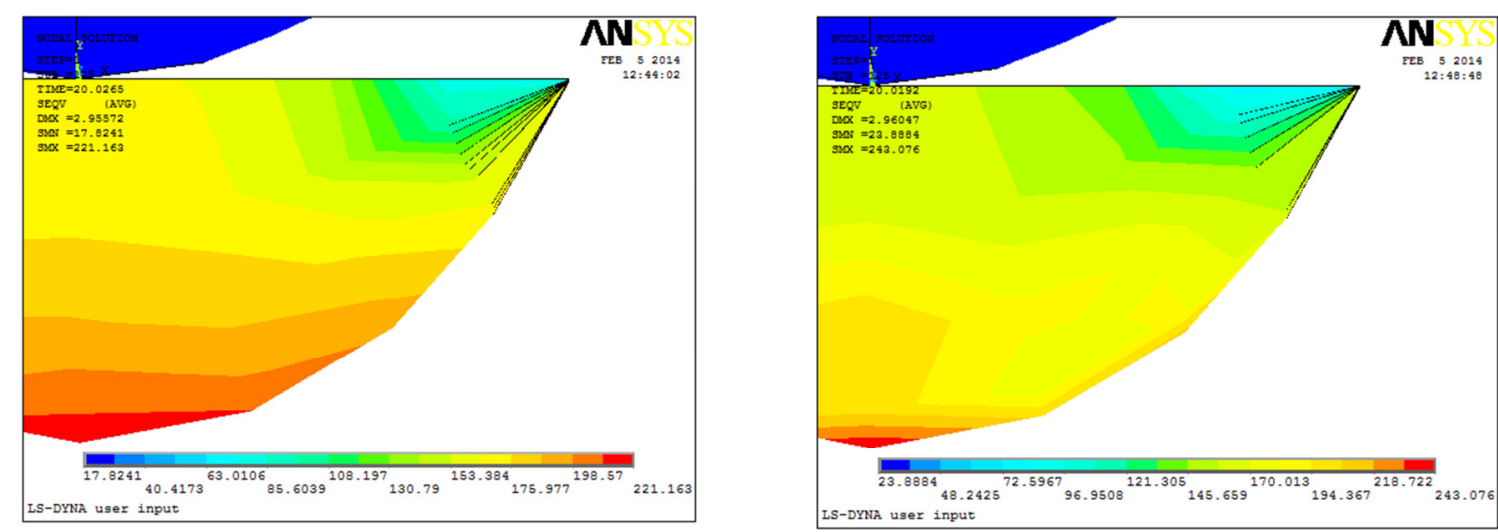

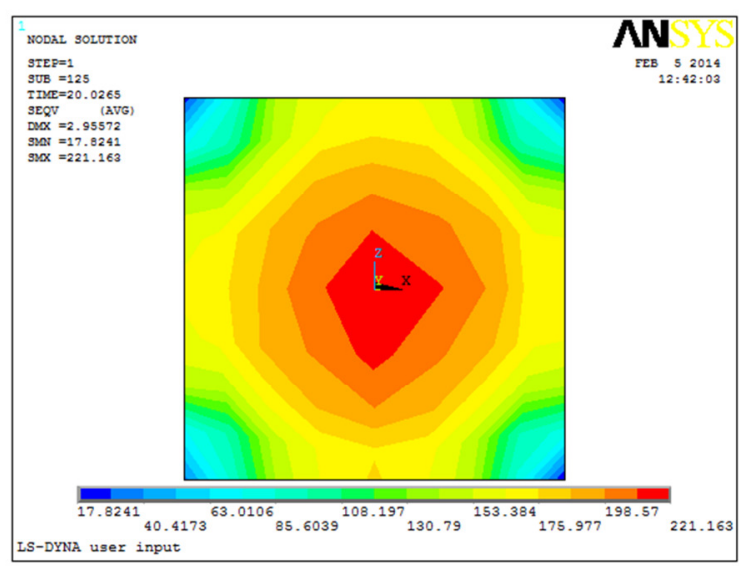

(a)

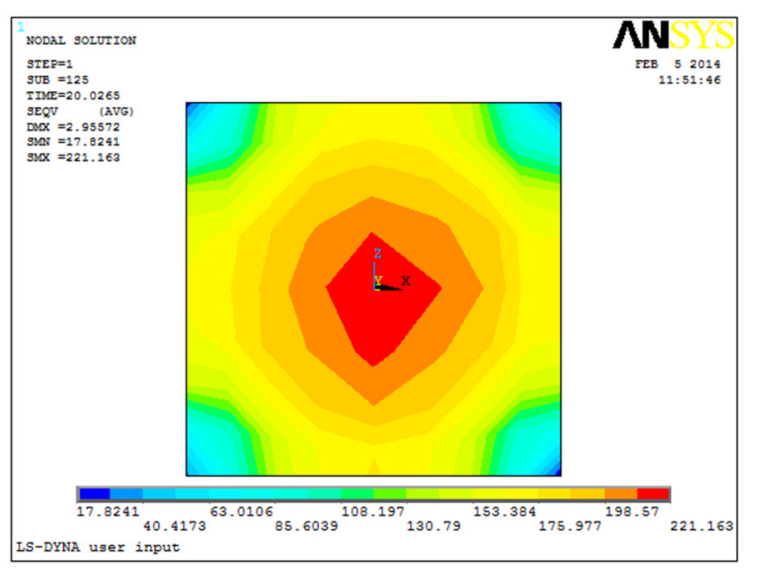

(b)

Figura 32 - (a) Simulação sem limitação de rotação. (b) Simulação com limitação de rotação. As figuras indicam a tensão na vista frontal e na vista superior.

A Figura 32 mostra que com os graus de liberdade laterais de rotação fixos a distribuição das tensões é mais concentrada. De acordo com a semelhança entre os resultados e com o estudo da bibliografia, além da evidência de que não ocorre deformação no contorno da chapa fixa ao prensa chapas, as extremidades da chapa serão engastadas. 


\subsubsection{Teste em linha}

O teste em linha é mais complexo do que o teste de contato por considerar o movimento lateral da ferramenta. Entretanto aproxima-se mais da estampagem incremental sem matriz. A trajetória da ferramenta, Figura 33, consiste em dois deslocamentos lineares de $150 \mathrm{~mm}$ (caminhos B-C e D-E) no centro de uma chapa, com a profundidade de $5 \mathrm{~mm}$ (caminho A-B) e $10 \mathrm{~mm}$ (caminho C-D).

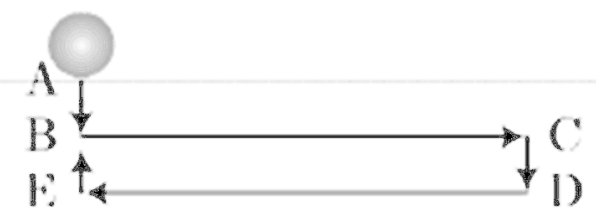

Figura 33 - Trajetória teste em linha. Adaptado de Henrard (2009).

A chapa utilizada possui $1 \mathrm{~mm}$ de espessura com largura e comprimento de $60 \mathrm{~mm} x$ $250 \mathrm{~mm}$, respectivamente. A ferramenta é uma esfera com diâmetro $8 \mathrm{~mm}$. Os elementos da chapa totalizam 1350 , obtendo-se uma razão de $8,33 \mathrm{~mm}^{2}$ de área para cada elemento. Os nós nas extremidades são fixos, já que o teste de contato apresenta resultados interessantes, dado o tempo de simulação. A malha gerada é apresentada na Figura 34.

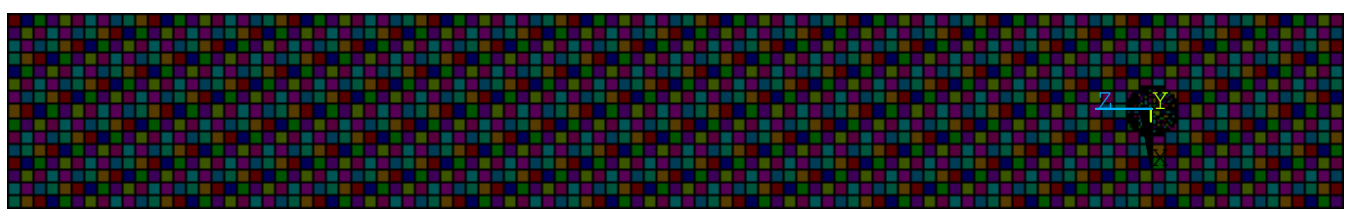

Figura 34 - Malha teste em linha

Inicialmente foram realizadas simulações com o intuito de acelerar o processo. Para isso foi aplicado o recurso do escalonamento de massa com o objetivo de aumentar o incremento de tempo, reduzindo o número de iterações e, por consequência, o tempo total de simulação, seguindo a condição de estabilidade de Courant. Foram simulados o caso em que a densidade do material foi mantida em $2705 \mathrm{~kg} / \mathrm{m}^{3}$, e 
casos acelerados com densidades de 100 e 10 vezes maiores. O resultado para a tensão de von Mises é apresentado na Figura 35.

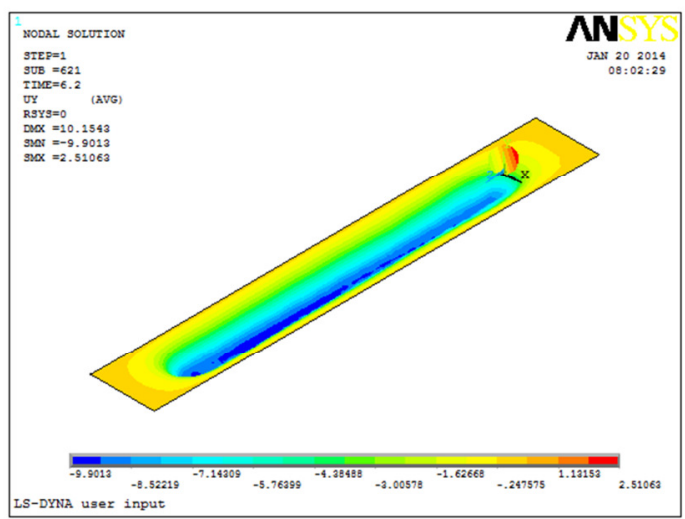

(a)

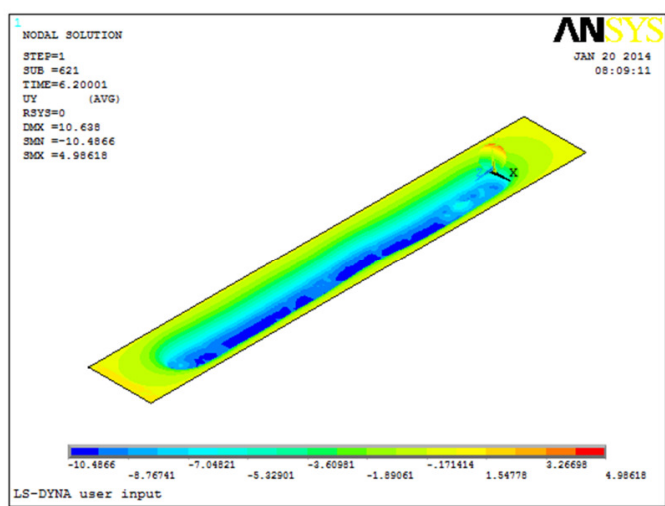

(b)

Figura 35 - Deslocamento em milímetros na direção perpendicular a chapa.

(a) Não acelerado. (b) Acelerado.

O teste em linha mostra que, ao acelerar o processo, ocorre uma variação nas deformações da chapa, resultando em problemas de convergência do modelo matemático e comprometendo o resultado encontrado, por isso, tais artifícios não foram utilizados nas simulações das geometrias de flanges.

\subsubsection{Testes em flanges}

Os testes em flanges têm a finalidade de testar o modelo desenvolvido e comparar os resultados obtidos por Montanari et al. (2013), verificando a possibilidade da utilização da criação do modelo matemático por elementos finitos como ferramenta na predição do estado de deformações e, consequentemente, como ferramenta de prevenção de falha.

Montanari et al. (2013) estudaram a trajetória das deformações e a fratura em flanges circulares obtidas pelos processos de estampagem com diferentes diâmetros de furos previamente cortados para a liga de alumínio AA1050 a partir de trabalhos experimentais. 
A estratégia de deformação utilizada para obter os flanges foi a estratégia multipassagem com um ângulo inicial $\psi_{1}=65^{\circ}$ e incrementos de $\Delta \psi=5^{\circ}$ em cada fase, até surgir uma fratura ou até atingir o ângulo $\psi_{6}=90^{\circ}$ (parede reta). $O$ valor do ângulo inicial $\left(\psi_{1}=65^{\circ}\right)$ foi obtido após ensaios com geometria de cone truncado. Nestes ensaios realizados com ângulo variável foi obtido $\circ \psi_{\max }=76,5^{\circ}$ para 0 diâmetro de 102mm. (Silva, 2013).

A ferramenta possuía trajetória helicoidal, com avanço por volta igual a 0,2 $\mathrm{mm}$ (para baixo) e velocidade de avanço igual a $1000 \mathrm{~mm} / \mathrm{min}$. A ferramenta era de $8 \mathrm{~mm}$ de diâmetro e encontrava-se livre para girar. A Figura 36 mostra um flange obtido por Montanari et al. (2013).

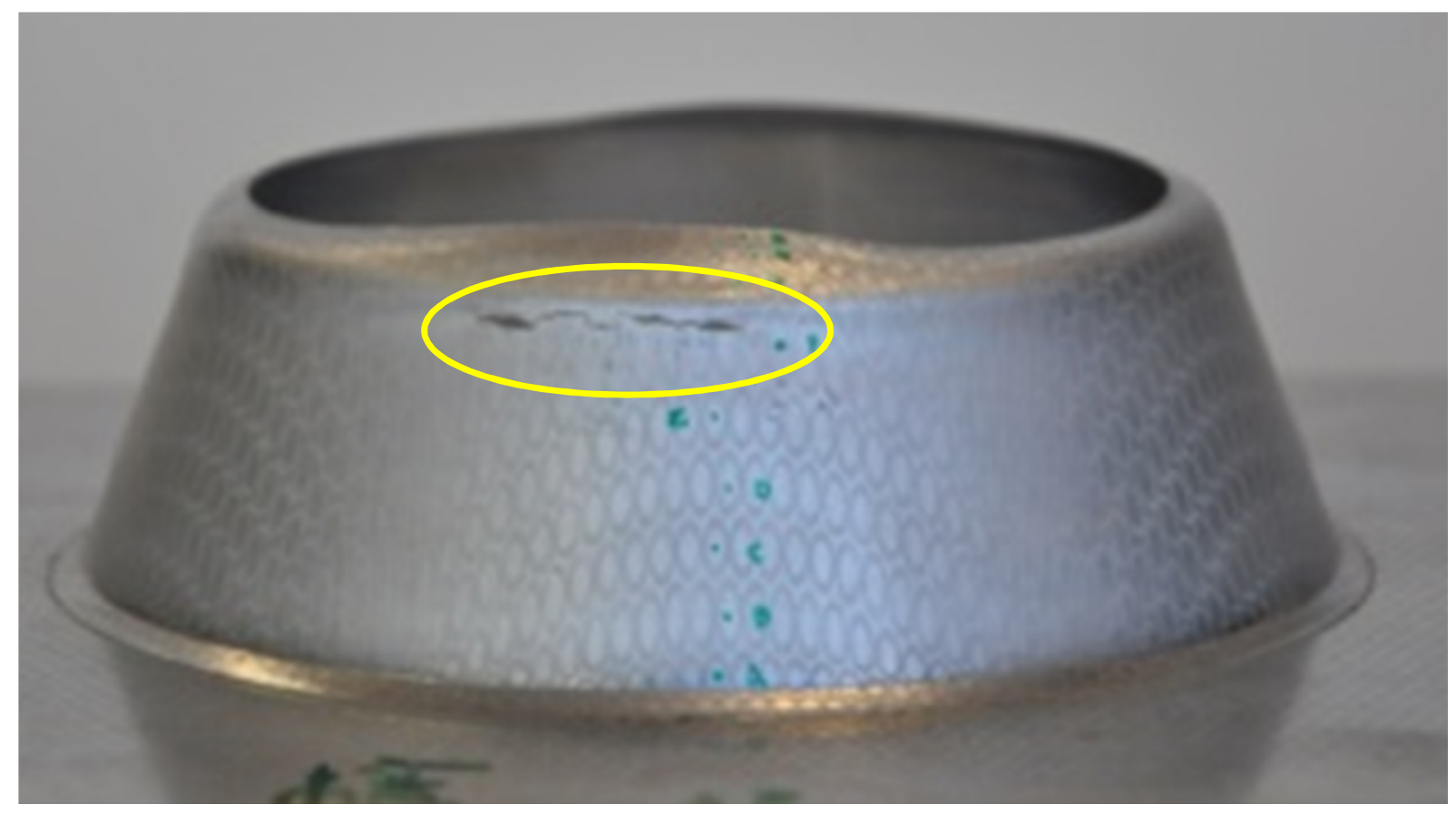

Figura 36 - Flange obtido por Montanari et al. (2013) Em destaque: fratura circunferencial obtida.

Serão analisados dois casos de fabricação de flanges, um com insucesso para a obtenção da parede a $90^{\circ}$ e outro caso de sucesso. A Tabela 5 apresenta os resultados obtidos por Montanari et al. (2013) para essas condições. Como mostra a 
Tabela 5, não foi possível obter flanges com paredes verticais e furos iniciais a partir de $D_{0} \leq 102 \mathrm{~mm}$, devido à ocorrência de fraturas circunferenciais.

\begin{tabular}{cccccccc}
\hline Tabela 5 - Estampagem incremental de chapas. \\
\hline \multicolumn{7}{c}{ Ângulos de estampagem intermediários $\psi_{i}\left({ }^{\circ}\right)$} \\
\hline$D_{0}[\mathrm{~mm}]$ & 65 & 70 & 75 & 80 & 85 & 90 \\
\hline 121 & $\mathrm{x}$ & $\mathrm{x}$ & $\mathrm{x}$ & $\mathrm{x}$ & $\mathrm{x}$ & $\mathrm{x}$ \\
\hline 102 & $\mathrm{x}$ & $\mathrm{x}$ & & & & \\
\hline
\end{tabular}

Nos furos pequenos $D_{0} \leq 102 \mathrm{~mm}$ ocorre uma pequena ou nenhuma expansão, aproximando-se da condição da geometria padrão (cone truncado). É por isso que o $\psi_{\text {máx }}$ para estes casos encontra-se perto do ângulo máximo de estampagem $\psi_{\text {máx }}=76,5^{\circ}$ (Silva, 2013).

Para comparar os resultados deste trabalho com os resultados obtidos por Montanari et al. (2013) serão estabelecidas as mesmas condições, ou seja, será estudado o comportamento das deformações e a redução de espessuras para furos com $D_{0}=102 \mathrm{~mm}$ e $D_{0}=121 \mathrm{~mm}$.

A chapa simulada possui as dimensões de $250 \mathrm{~mm} \times 250 \mathrm{~mm} \times 1 \mathrm{~mm}$ (largura, comprimento e espessura). Para diminuir o tempo de processamento é usado o princípio da simetria, simulando apenas um quarto da peça. O diâmetro da ferramenta é de $8 \mathrm{~mm}$ e a sua representação na simulação é dada pelo emprego de uma esfera. A Figura 37 mostra a malha da chapa com furo inicial $D_{0}=102 \mathrm{~mm}$. 


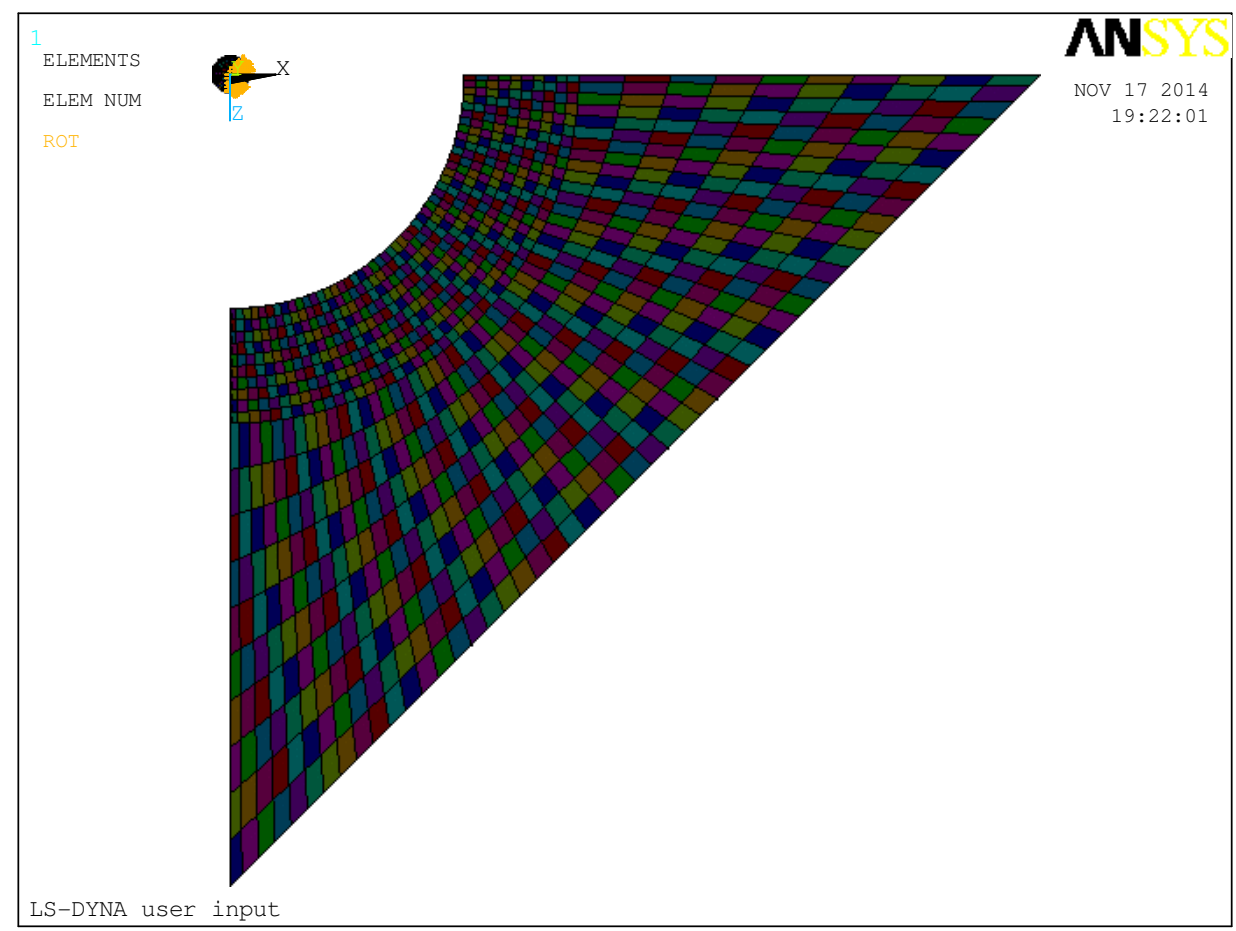

Figura 37 - Malha do teste de flange.

Observa-se na Figura 37 que a malha na região sujeita ao contato com a ferramenta apresenta refinamento da malha, nessa região a razão de área por elemento é de $9,98 \mathrm{~mm}$ /elemento para o diâmetro de $102 \mathrm{~mm}$ e de $9,49 \mathrm{~mm}^{2} /$ elemento para o diâmetro de $121 \mathrm{~mm}$. Esses valores são aproximados aos adotados para o teste em linha e que apresentaram convergência.

No teste, as condições de contorno estabelecidas para o modelo do flange consistem:

- Na restrição de todos os graus de liberdade dos nós na extremidade da chapa.

- Na restrição dos deslocamentos na linha de apoio da chapa no prensa chapas.

- Na restrição de dois deslocamentos em conjunto a uma rotação na região de simetria de maneira que os nós pertencentes àquelas linhas de simetria não saíssem do plano.

Essa disposição é mostrada na Figura 38. 


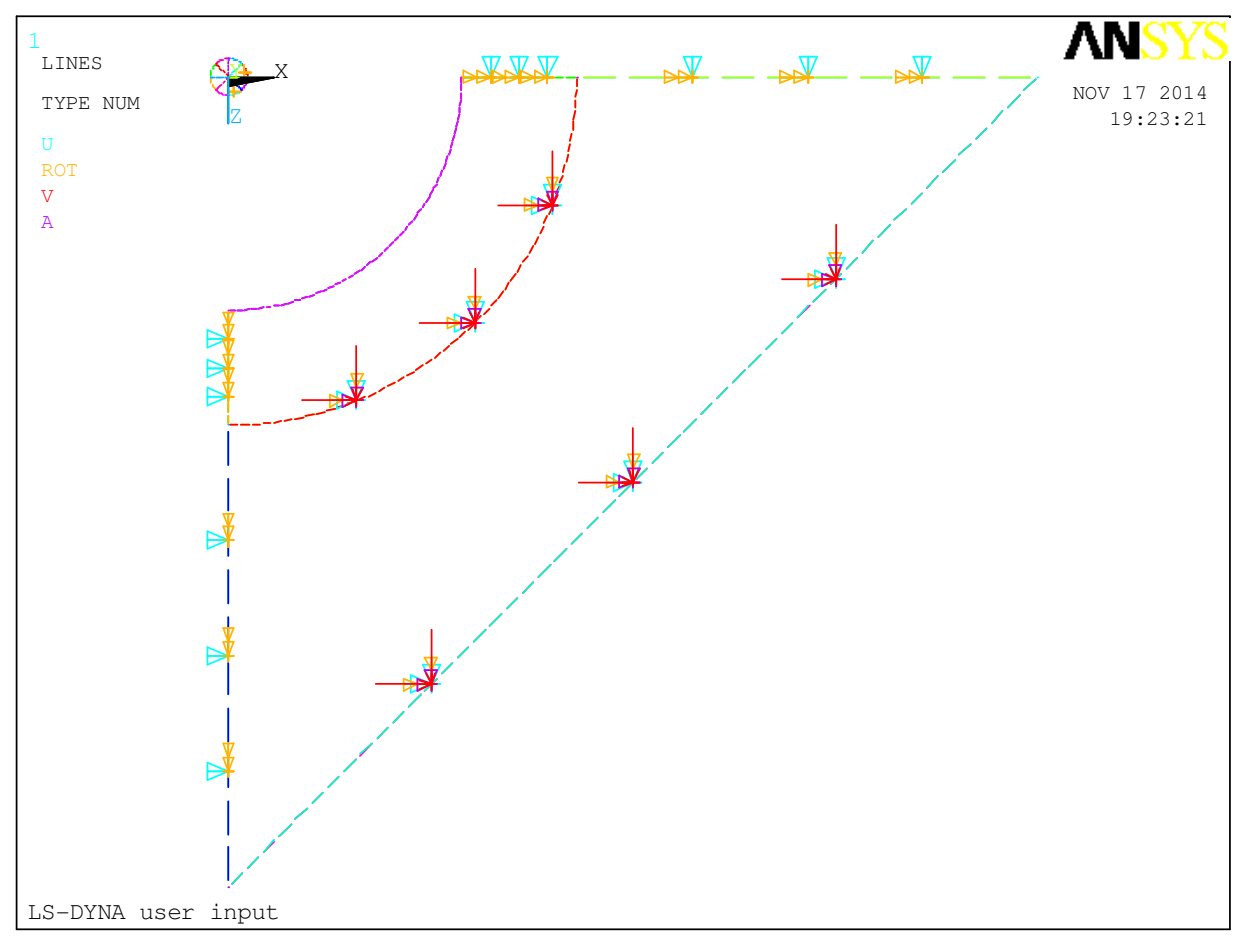

Figura 38- Condições de contorno do teste de flange

\subsubsection{Trajetória da ferramenta}

Para geração das trajetórias de cone a serem inseridas no software ANSYSTM foi elaborada uma rotina em MATLABTM. A rotina permite ao usuário entrar com os parâmetros de geometria do cone desejado. O programa trata o problema em coordenadas polares $(\theta, r, z)$ e gera os vetores, cujas posições são os pontos da trajetória, e então as converte para coordenadas cartesianas $(x, y, z)$. O resultado é a trajetória da ferramenta, com e sem a correção pelo seu diâmetro. Na Figura 390 caminho indicado por linhas vermelhas aponta a trajetória que a ferramenta deve percorrer para fabricação de um cone (caminho pré-definido - linhas pretas). 


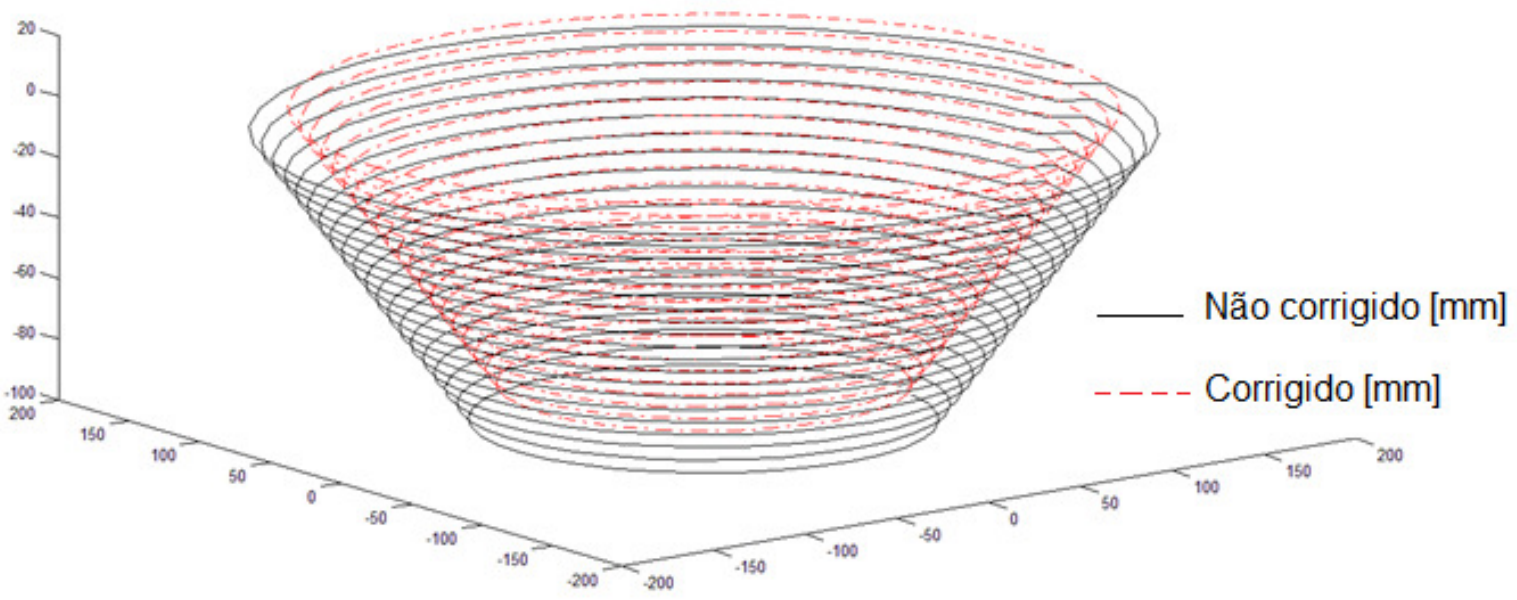

Figura 39 - Trajetória corrigida do centro da ferramenta.

O programa também fornece dados do caminho total percorrido e da velocidade da ferramenta. Os dados de entrada são: profundidade do cone, raio maior do cone, raio menor do cone (Figura 40), incremento em Z (avanço por volta) e diâmetro da ferramenta.

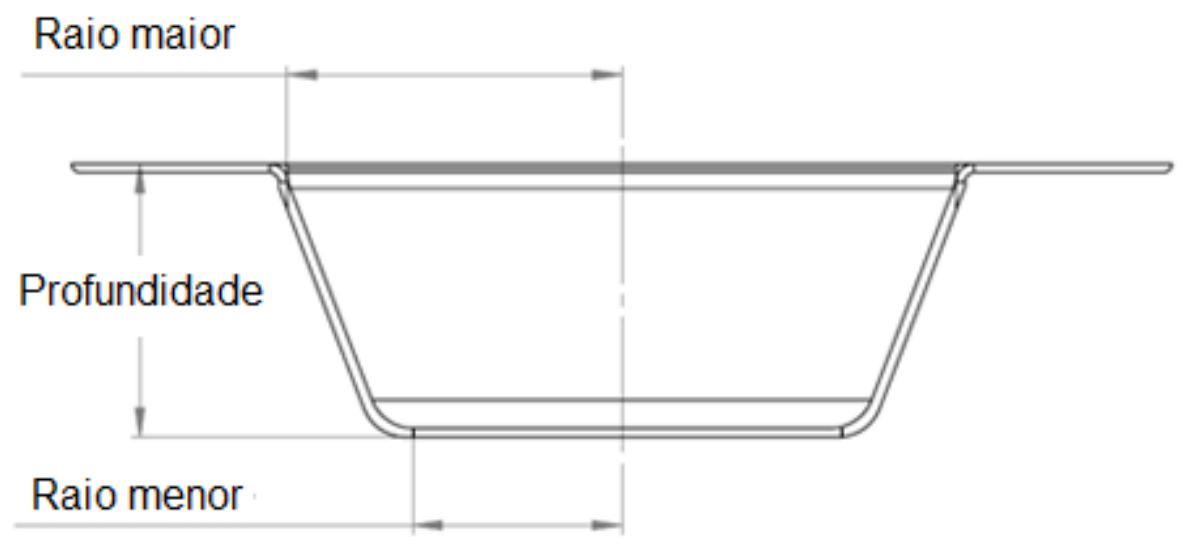

Figura 40 - Parâmetros geométricos de geração de trajetória.

É possível definir o número de pontos por volta gerados através de incrementos angulares em graus, que determinam quantos graus à frente estará o próximo ponto o lugar onde a ferramenta deve seguir. Também é possível estimar a velocidade no decorrer do processo. Para tanto, calcula-se quanto a ferramenta se desloca 
linearmente até o próximo ponto e então divide pelo valor de tempo. Outro modo de se obter o tempo ocorre quando é dada a velocidade desejada da ferramenta.

A correção devido ao diâmetro da ferramenta em coordenadas polares é descrita nas equações (12) e mostrada na Figura 41, sendo que a representação geométrica de cada parâmetro é encontrada na Figura 40. A coordenada angular permanece inalterada.

$$
\begin{gathered}
\tan \alpha=\left(\frac{\Delta z}{\Delta r}\right) \\
\alpha=\tan ^{-1}\left(\frac{\Delta z}{\Delta r}\right) \\
\beta=90-\alpha \\
\Delta \Delta \mathrm{r}=\left(\frac{\emptyset_{\text {ferramenta }}}{2}\right) * \cos (\beta) \\
\Delta \Delta \mathrm{z}=\left(\frac{\emptyset_{\text {ferramenta }}}{2}\right) * \operatorname{sen}(\beta) \\
\mathrm{R}_{\text {novo }}=\mathrm{R}_{\text {antigo }}+\Delta \Delta \mathrm{r} \quad \text { (para cada ponto) } \\
\mathrm{Z}_{\text {novo }}=\mathrm{Z}_{\text {antigo }}+\Delta \Delta \mathrm{z} \quad \text { (para cada ponto) }
\end{gathered}
$$
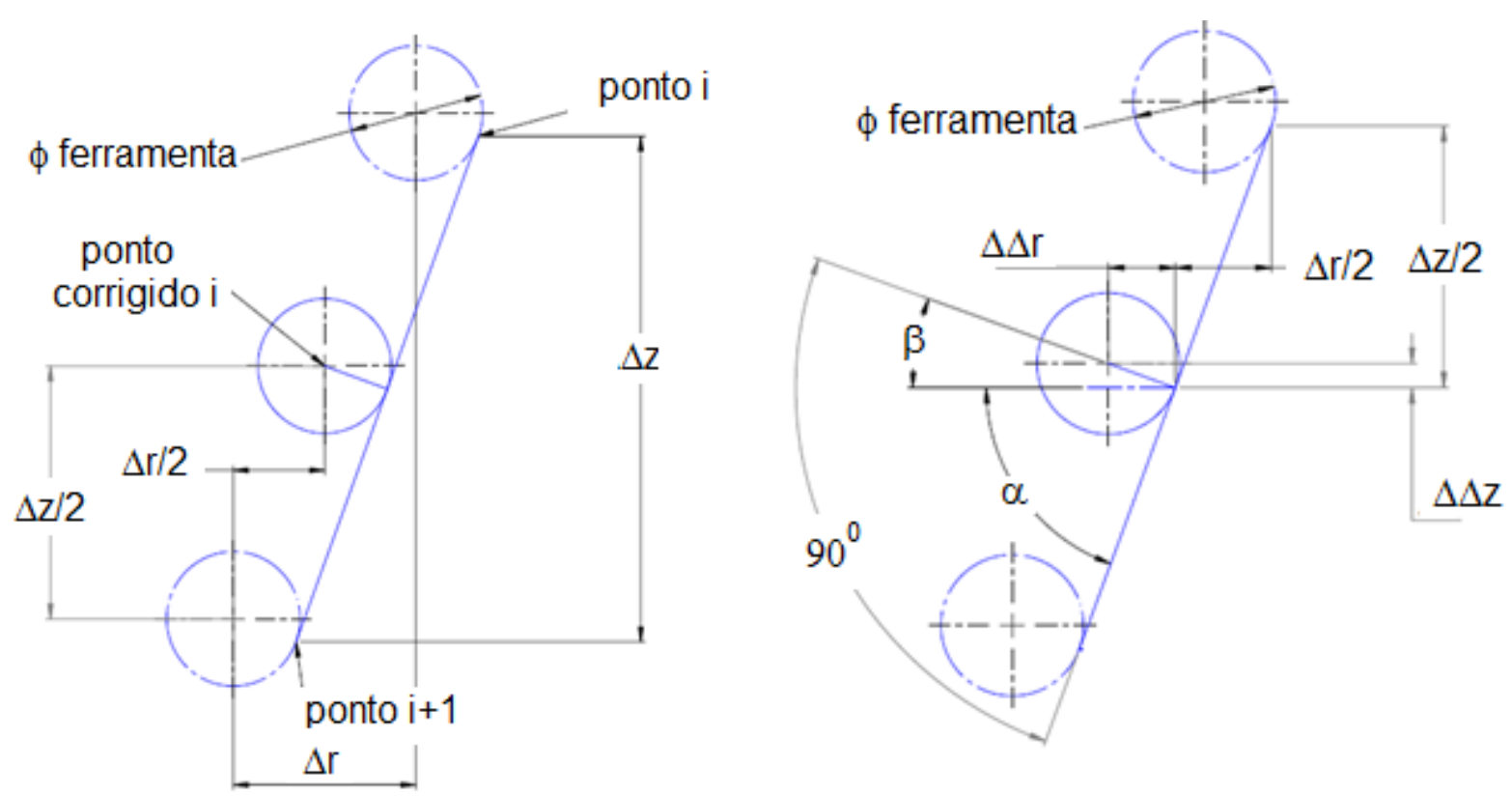

Figura 41 - Correção de trajetória da ferramenta. 
O programa possui duas estratégias de geração de trajetória, uma para incremento em Z variável ao fim de cada volta da ferramenta e outra, cujos incrementos na profundidade são constantes. Apesar disso, neste trabalho, utiliza-se a estratégia de incrementos constantes ao longo da trajetória helicoidal da ferramenta.

As simulações da geometria de flanges foram realizadas com o objetivo de obter um modelo que descreve da melhor maneira possível a distribuição das deformações na superfície da chapa. A Figura 42 mostra a malha deformada após a passagem da ferramenta (para o flange com diâmetro inicial de 102mm). Os deslocamentos das regiões na direção do eixo da ferramenta são apresentados em escala de cores, chegando à profundidade de aproximadamente $30 \mathrm{~mm}$.

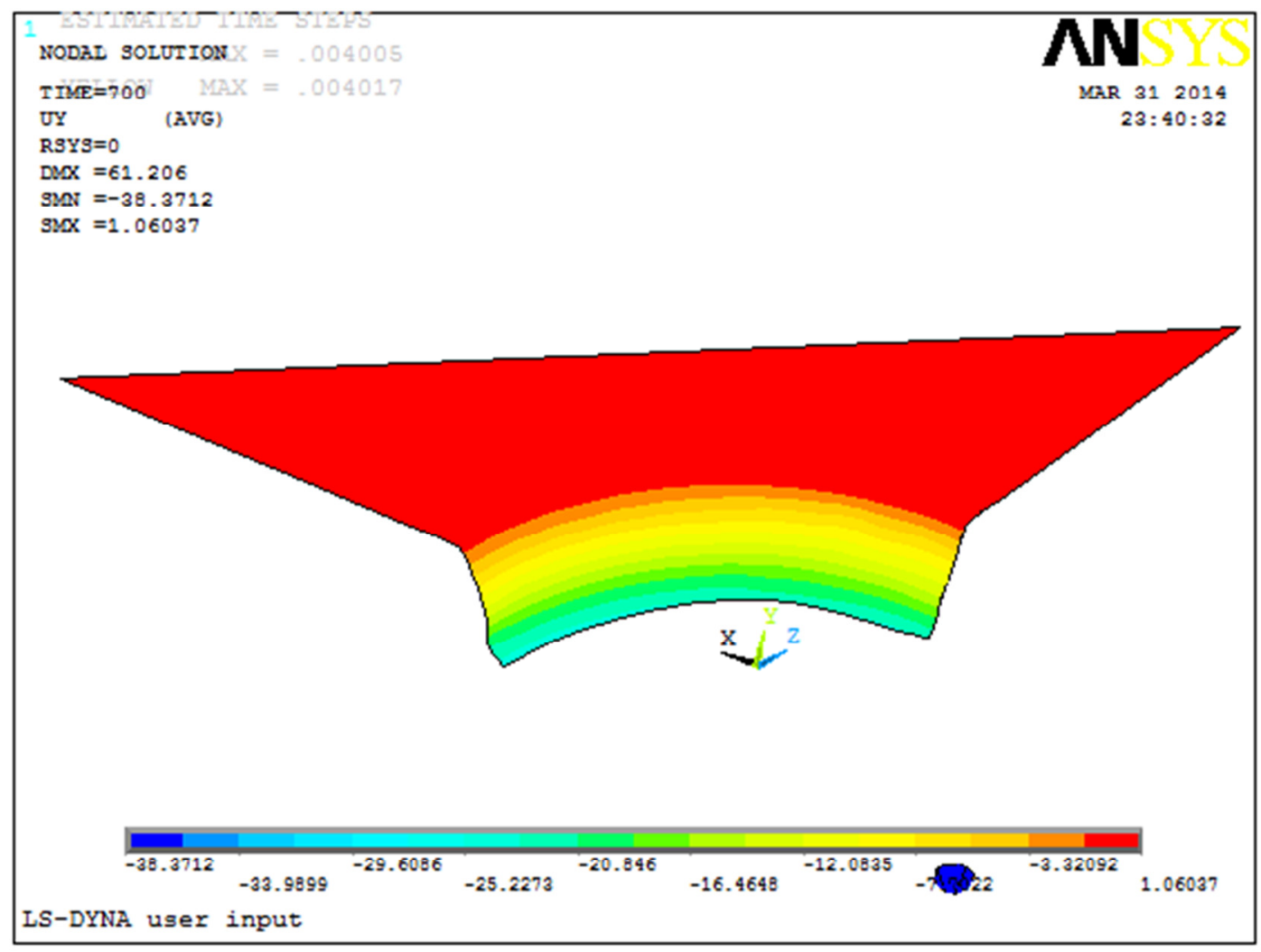

Figura 42- Deslocamentos em milímetros no eixo da ferramenta teste de flange $D_{0}=102 \mathrm{~mm}$.

Para a primeira simulação do flange com $D_{0}=102 \mathrm{~mm}$ estuda-se as deformações em três regiões da chapa $(\mathrm{R} 1, \mathrm{R} 2, \mathrm{R} 3)$. Região $\mathrm{R} 1$ próxima ao apoio do prensa 
chapas, R2 próxima ao meio da chapa e região R3 na borda do pré-furo, conforme indicadas na Figura 43.
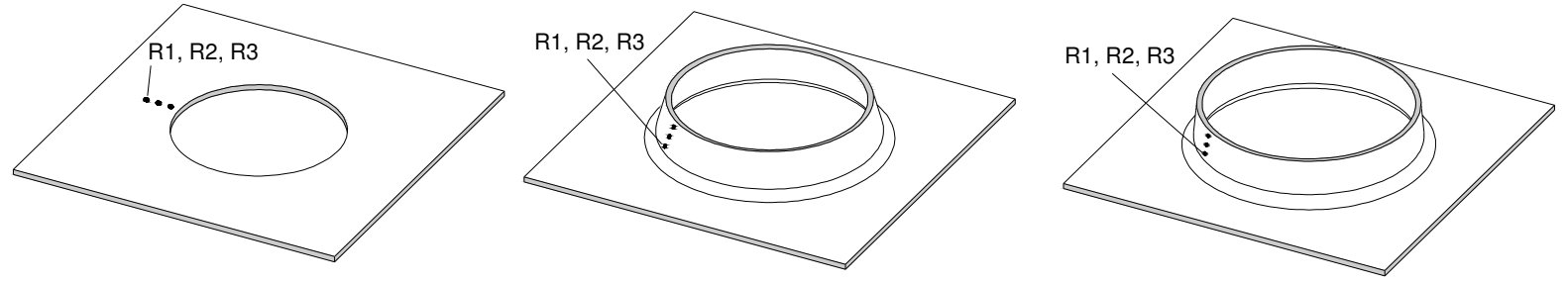

Figura 43 - Regiões de estudo das deformações no teste de flange (MONTANARI et al., 2013).

Para $D_{0}=121 \mathrm{~mm}$, Montanari et al. (2013), analisam 10 pontos (de A a J), ao longo da região deformada com a finalidade de compreender a mecânica de deformação e o aparecimento de fraturas ao longo da direção meridional para os vários ângulos de estampagem $\psi_{\mathrm{i}}$ (Figura 44). No entanto, quando se trata da simulação com elementos finitos, devido às limitações das dimensões do elemento obteve-se poucos nós ao longo da região deformada e assim, foi necessário efetuar uma correlação geométrica entre as regiões apontadas por Montanari et al. e as regiões $\mathrm{R} 1, \mathrm{R} 2, \mathrm{R} 3$ e R4.
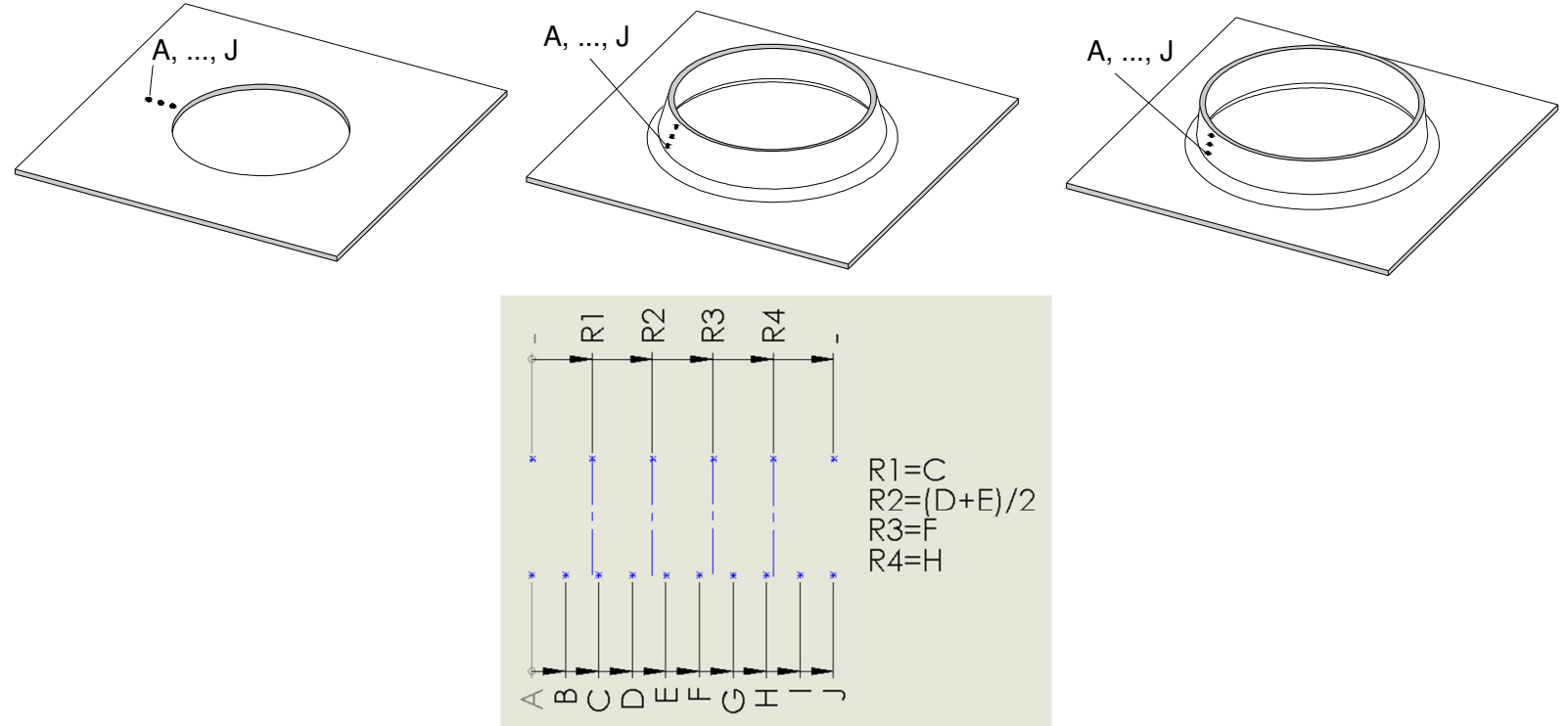

Figura 44 - Correlação das regiões R1, R2, R3, R4 com os pontos apresentados no trabalho de Montanari et al. (2013). 
Tal correlação entre os pontos visa confrontar os resultados obtidos nas simulações com os valores obtidos nos trabalhos experimentais de MONTANARI et al. (2013) para flange com diâmetro inicial de $121 \mathrm{~mm}$, comparando regiões equivalentes. A região $\mathrm{R} 1$ corresponde à região $\mathrm{C}$ do trabalho experimental. $A$ região $\mathrm{R} 2$ corresponde à média simples dos valores das regiões $\mathrm{D}$ e $\mathrm{E}$, a região $\mathrm{R} 3$ teve valores comparados à região $\mathrm{F}$ e, por fim, a região $\mathrm{R} 4$ foi comparada à região $\mathrm{H}$.

Como resumo do proposto e discutido na metodologia e maneira de elucidar alguns pontos apresenta-se na Tabela 6 os parâmetros e condições utilizados durante as simulações dos flanges.

Tabela 6 - Condições utilizadas nos testes de flanges

Condições de contorno

Todos os graus de liberdade restritos na extremidade

Coeficiente de atrito

Sem atrito; 0,1 e 0,3

Algoritmo de contato Automatic surface to surface

Tipo de elemento Shell 163

Número de elementos para a chapa $\mathrm{Do}=102 \mathrm{~mm}$ 375

Graus de liberdade do elemento

$\mathrm{Do}=121 \mathrm{~mm}$ 400

Formulação do elemento 12 graus

Elementos na espessura

S/R Co-rotation

Shear factor

5 elementos

Hourglass control $5 / 6$

Material

0,1

Modelo de encruamento Liga de alumínio AA 1050

Coeficiente de anisotropia médio Isotropia planar

Diâmetro da ferramenta 0,84

Tipo do elemento da ferramenta Espessura da chapa $8 \mathrm{~mm}$ Incrementos na profundidade da ferramenta Rígido Escala de tempo e de massa $1 \mathrm{~mm}$ $0,2 \mathrm{~mm} /$ volta Não utilizado 


\subsection{Resultados e discussão}

\subsubsection{Estudo da trajetória das deformações}

Inicialmente foi estudado o comportamento das deformações para o flange com diâmetro inicial Do $=102 \mathrm{~mm}$. Como apresentado na Tabela 5, para o diâmetro Do $=102 \mathrm{~mm}$, não foi possível obter flanges com paredes retas. O ângulo máximo obtido até a ocorrência da fratura foi de $\psi_{2}=70^{\circ}$. Portanto, neste caso, a simulação será efetuada para os ângulos $\psi_{1}=65^{\circ}$ e $\psi_{2}=70^{\circ}$.

A escolha do tamanho da malha utilizada baseou-se no teste em linha. Foi mantida a mesma relação área por elemento, com sucesso de convergência, como mostra a Tabela 7. Para o flange destaca-se a região que teve contato com a ferramenta.

Tabela 7- Relações de área por elemento na região de contato para as simulações

\begin{tabular}{ccccc}
\hline Teste & Dimensões [mm] & $\begin{array}{c}\text { Área } \\
{\left[\mathrm{mm}^{2}\right]}\end{array}$ & $\begin{array}{c}\text { Número } \\
\text { de } \\
\text { Elementos }\end{array}$ & $\begin{array}{c}\text { Área/Elemento } \\
{\left[\mathrm{mm}^{2}\right]}\end{array}$ \\
\hline Em linha & $60 \times 250$ & 15000,0 & 1350 & 8 \\
\hline Flange $D o=102 \mathrm{~mm}$ & $\begin{array}{c}\text { Região do flange } \\
\text { início do raio= } 51 \\
\text { até 76 }\end{array}$ & 2493,6 & 250 & 9,97 \\
\hline Flange $D o=121 \mathrm{~mm}$ & $\begin{array}{c}\text { Região do flange } \\
\text { início do raio=60,5 } \\
\text { até 76 }\end{array}$ & 1661,7 & 150 & 11,1 \\
\hline
\end{tabular}

Montanari et al. (2013), em seus testes, utilizaram óleo para lubrificar a peça e a ferramenta, considerando o sistema sem atrito. No entanto, para efeito de comparação dos resultados é importante que o nível de deformação tanto dos resultados experimentais quanto numéricos estejam no mesmo patamar. Para tanto, foram escolhidos três coeficientes de atrito diferentes e estudado o comportamento 
das deformações $\left(\varepsilon_{1}\right.$ e $\left.\varepsilon_{2}\right)$ nas regiões mencionadas ( $\left.R 1, R 2, R 3\right)$. Assim, para cada coeficiente de atrito atribuído, é verificado o valor da deformação. O estudo ocorreu para a chapa com $D_{0}=102 \mathrm{~mm}$ e os coeficientes de atrito estático atribuídos foram: $0 ; 0,1$ e 0,3. A malha da chapa continha 375 elementos. Os resultados são apresentados na Figura 45 para as regiões R2 e R3.

Nos gráficos de deformação subsequentes as elipses tracejadas representam níveis de deformação equivalente. Para a sua execução assume-se que os elementos não apresentam rotação, ou seja, a componente de deformação maior $\left(\varepsilon_{1}\right)$ e a componente de deformação menor $\left(\varepsilon_{2}\right)$ estão alinhadas com os eixos $\mathrm{X}$ e $\mathrm{Y}$ locais dos elementos da malha, respectivamente.

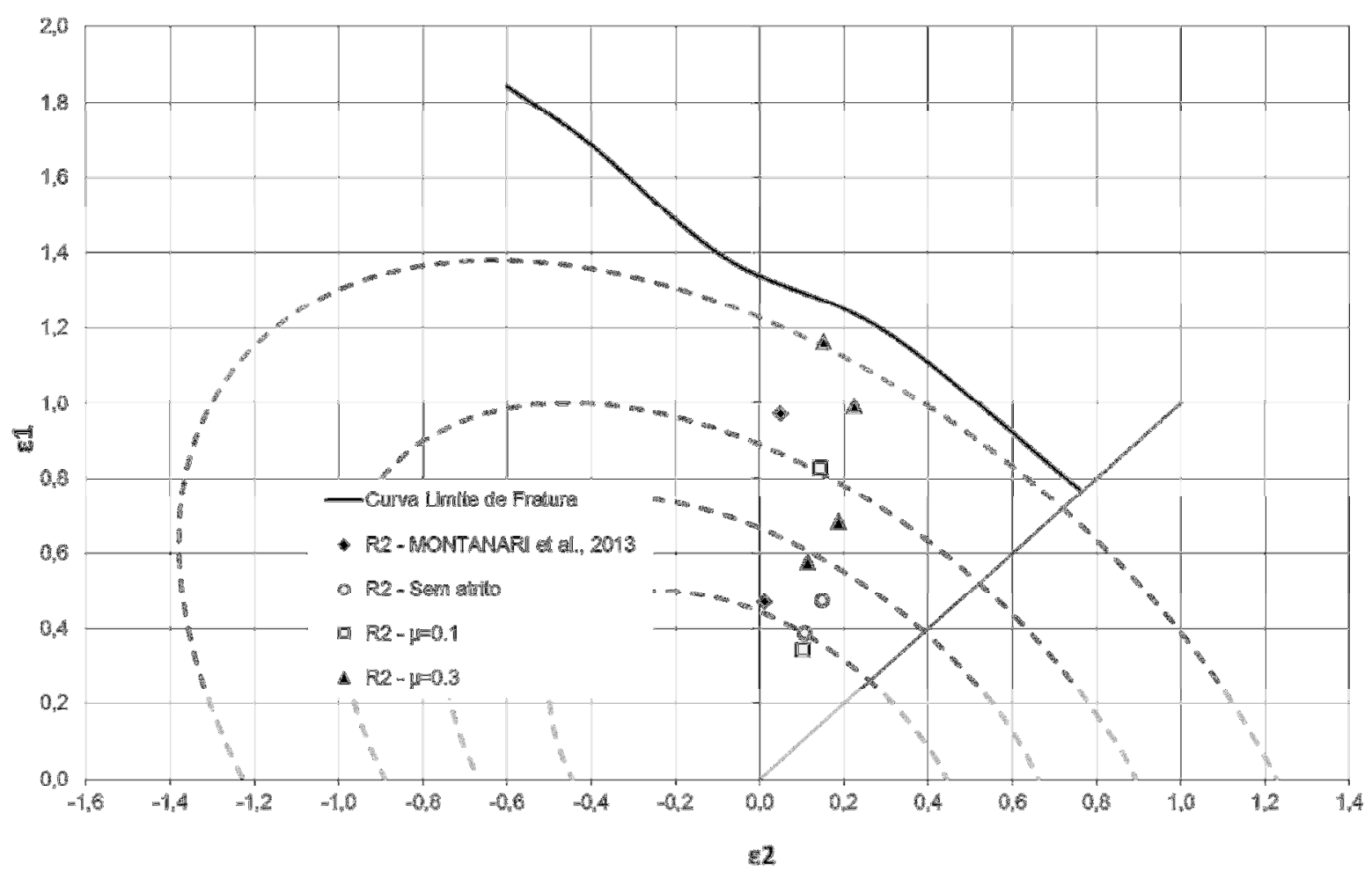

(a) 


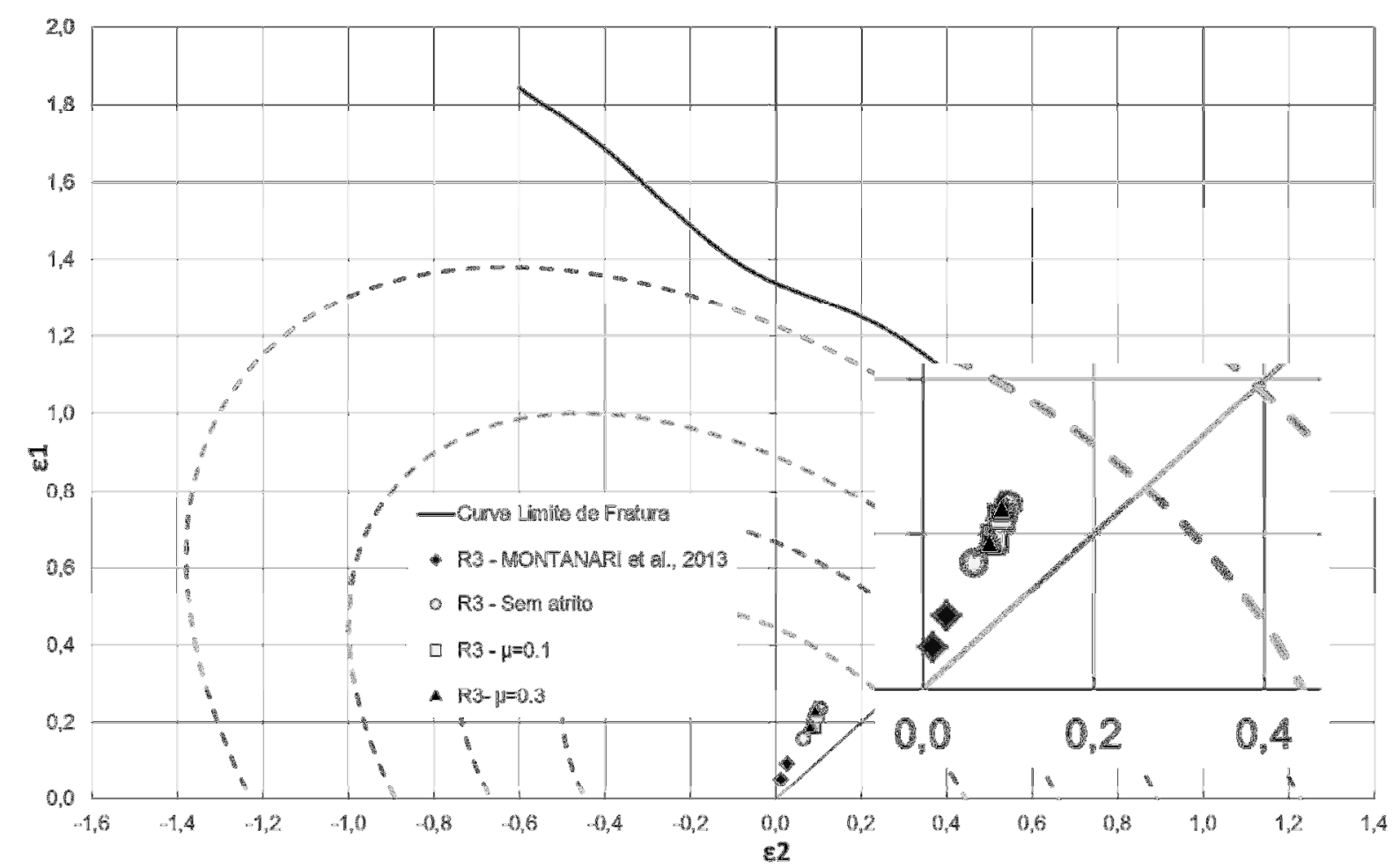

(b)

Figura 45 - Comportamento das deformações com a variação do coeficiente de atrito para as regiões (a) R2. (b) R3 para o flange de diâmetro $D_{0}=102 \mathrm{~mm}$.

Pela análise da Figura 45 nota-se que há ligeiro aumento dos valores de $\varepsilon_{2}$ em relação aos obtidos experimentalmente. Entretanto, para o coeficiente de atrito de 0,1 , o nível de deformação equivalente na simulação se aproxima do valor experimental, $\varepsilon_{e q}=0,9$. Para as condições sem atrito e com coeficiente de atrito de 0,3 não verifica a mesma tendência. Para a condição sem atrito o nível de deformação equivalente é inferior a $\varepsilon_{e q}=0,5$. Para o caso do coeficiente de atrito igual 0,3 , a deformação se encontra em nível superior a $\varepsilon_{\mathrm{eq}}=1,2$.

A análise dos resultados mostra que, apesar da diferença apresentada, com a utilização do coeficiente de atrito de 0,1 a deformação total equivalente se mantém na região R2 dentro da mesma faixa que o processo experimental. Os resultados para a região R3 (Figura 45(b)) mostram que o nível de deformação equivalente está 
próximo de $\varepsilon_{e q}=0,2$, também para o caso do coeficiente de atrito igual a 0,1 . Portanto, será empregado o coeficiente de atrito de 0,1 entre a ferramenta e a peça.

A deformação equivalente $\varepsilon_{e q}$, determinada pelo critério de plasticidade de Hill quadrático (Hill, 1948), é calculada como segue (eq. (13)),

$$
\varepsilon_{e q}=\sqrt{\frac{2}{3} \frac{(2+r)}{(1+2 r)^{2}}\left[r\left(\varepsilon_{1}-\varepsilon_{2}\right)^{2}+\left(\varepsilon_{2}-r \varepsilon_{3}\right)^{2}+\left(\varepsilon_{1}-r \varepsilon_{3}\right)^{2}\right]}
$$

Onde:

$\varepsilon_{e q}=$ deformação equivalente

$r=$ coeficiente de anisotropia normal médio

Observa-se ainda na Figura 45(a) que as deformações da região R2 atingem valores máximos, sendo a região onde ocorre a fratura. Essa região também, provavelmente, é a região onde há a maior redução de espessura.

Para determinar a mecânica da deformação no flange com paredes retas $\psi_{6}=90^{\circ} \mathrm{e}$ furo inicial $D_{0}=121 \mathrm{~mm}$ foram analisadas as regiões $\mathrm{R} 1, \mathrm{R} 2, \mathrm{R} 3$ e R4. A estratégia utilizada foi a multi-passagem, sendo que o ângulo de estampagem aumentou progressivamente com variação de $\Delta \psi=5^{\circ}$, tendo como ângulo inicial $\psi_{1}=65^{\circ}$. 0 coeficiente de atrito utilizado foi de 0,1 . O deslocamento ao longo do eixo da ferramenta para o flange é mostrado na Figura 46. 


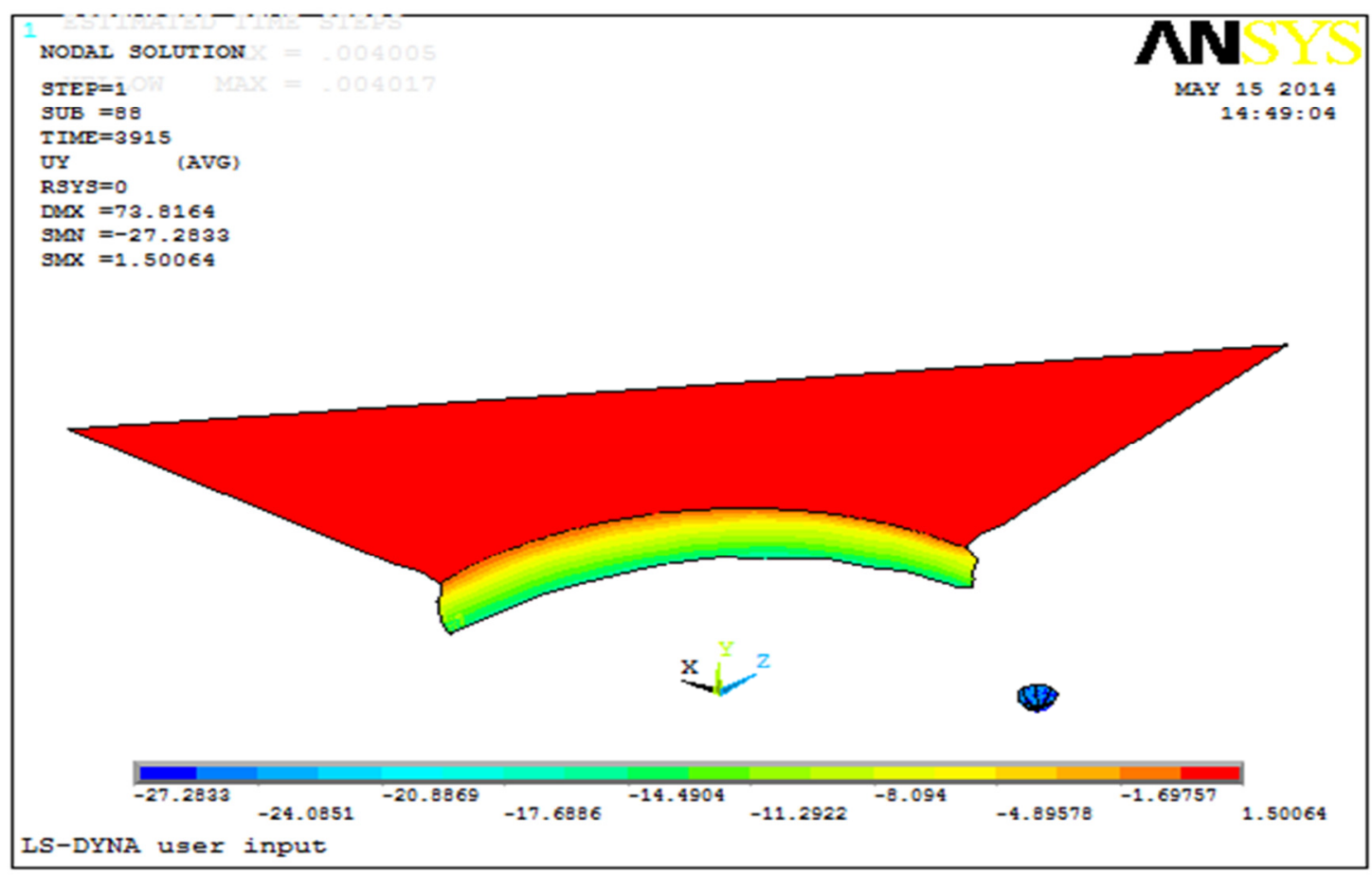

Figura 46 - Deslocamento em milímetros no eixo da ferramenta teste de flange Do $=121 \mathrm{~mm}$.

O modo como ocorre a deformação é mais bem compreendido pelo acompanhamento e medição dos valores de deformação dos pontos das regiões selecionadas ( $R 1, R 2, R 3, R 4)$ ao longo da direção meridional, correspondentes a diferentes regiões da peça em diversas fases intermediárias de deformação (isto é, vários ângulos de estampagem $\psi_{i}$ ). Assim, a Figura 47 mostra o gráfico do comportamento das deformações para a região R1. 


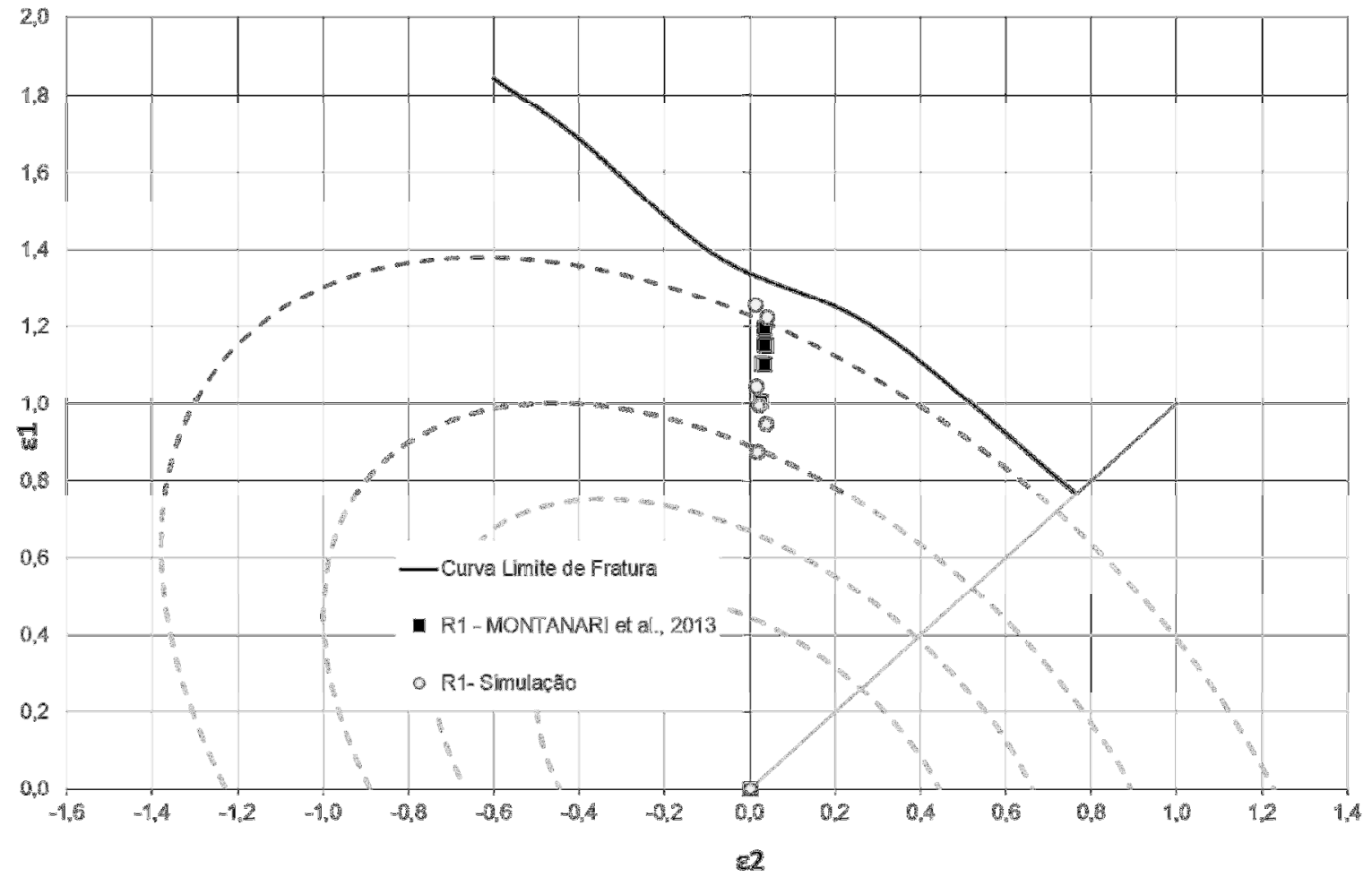

Figura 47 - Comportamento das deformações para a região R1 e diâmetro inicial $D_{0}=121 \mathrm{~mm}$

É possível observar através da Figura 47 que os valores obtidos com a simulação se aproximam dos valores obtidos experimentalmente. Nesta região a deformação tende para a deformação plana $\varepsilon_{2}$ é aproximadamente 0 .

A Figura 48 mostra as deformações obtidas para a região $\mathrm{R} 2$ para o flange com diâmetro inicial $D_{0}=121 \mathrm{~mm}$. 


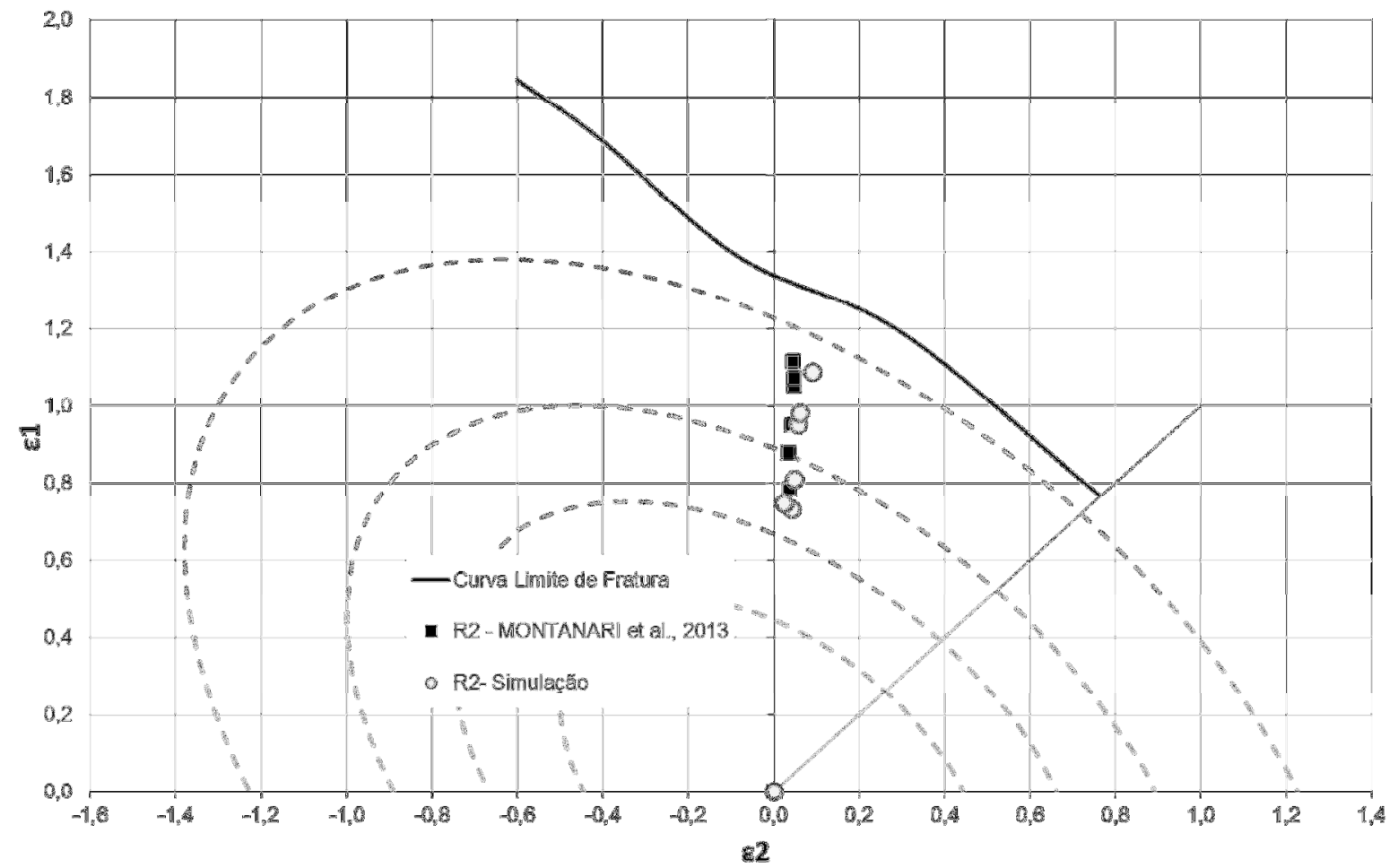

Figura 48- Comportamento das deformações para a região R2 e diâmetro inicial $D_{0}=121 \mathrm{~mm}$.

Para a região $\mathrm{R} 2$ os resultados do modelo em elementos finitos conseguem descrever bem a tendência dos pontos e o nível de deformações. Assim como na região R1, é evidente que as deformações ocorrem sob a condição deformação plana.

Para região R3, os resultados são mostrados na Figura 49 para o flange com diâmetro inicial $D_{0}=121 \mathrm{~mm}$. 


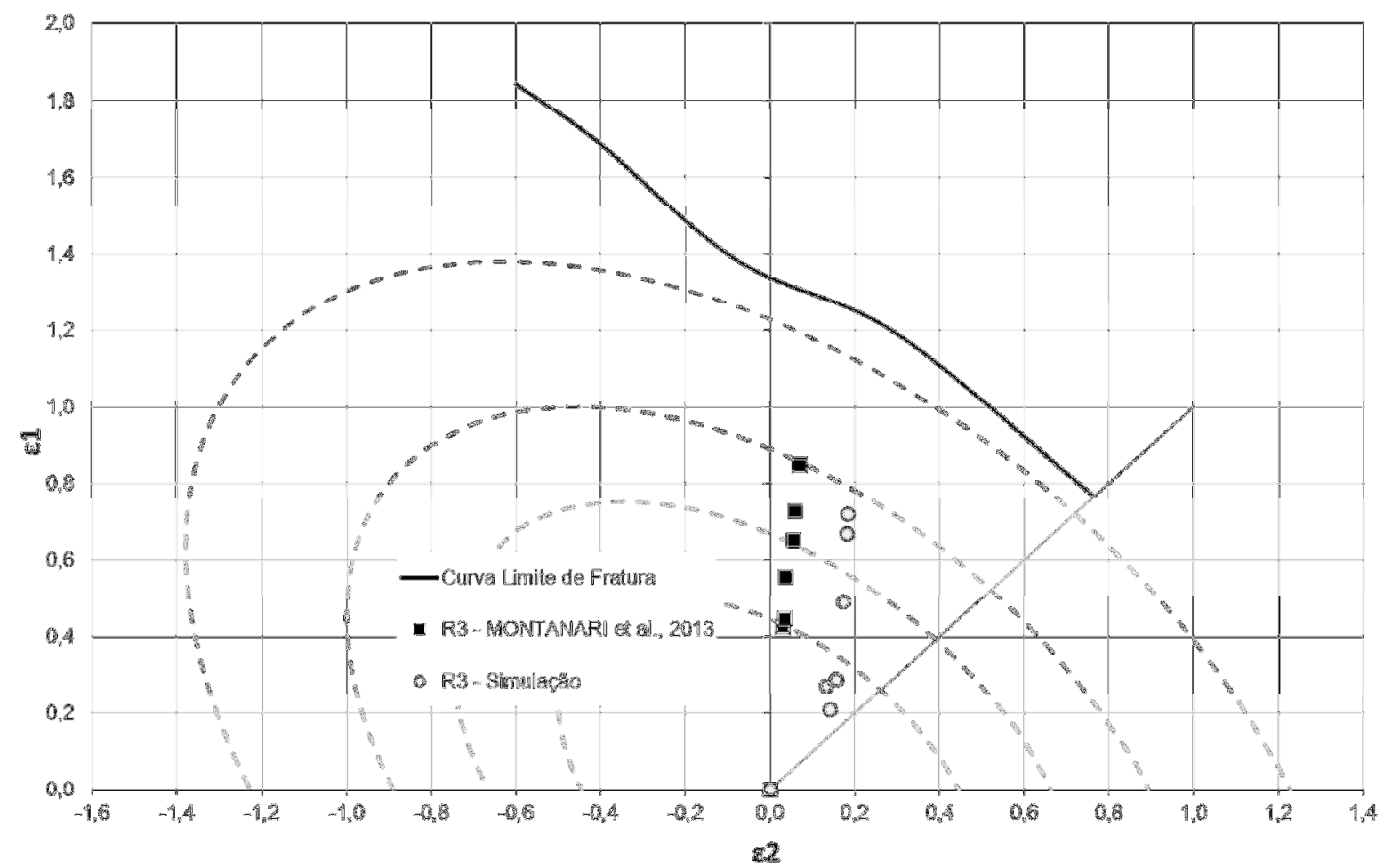

Figura 49 - Comportamento das deformações para a região R3 e diâmetro $D_{0}=121$ $\mathrm{mm}$.

Observando a Figura 49 verifica que para a região R3 há ligeiro aumento dos valores de $\varepsilon_{2}$. Como os valores de $\varepsilon_{2}$ são pequenos e os níveis de deformação se apresentam no mesmo patamar e, tal como os valores experimentais tendem para ao estado plano de deformações, pode-se justificar essa diferença por erros de medição.

Já para a região $\mathrm{R} 4$ os resultados são mostrados na Figura 50 . Nesta região os resultados do modelo em elementos finitos descrevem bem a tendência dos pontos e o nível de deformação atingido. A região $\mathrm{R} 4$ apresenta o comportamento de deformação biaxial. 


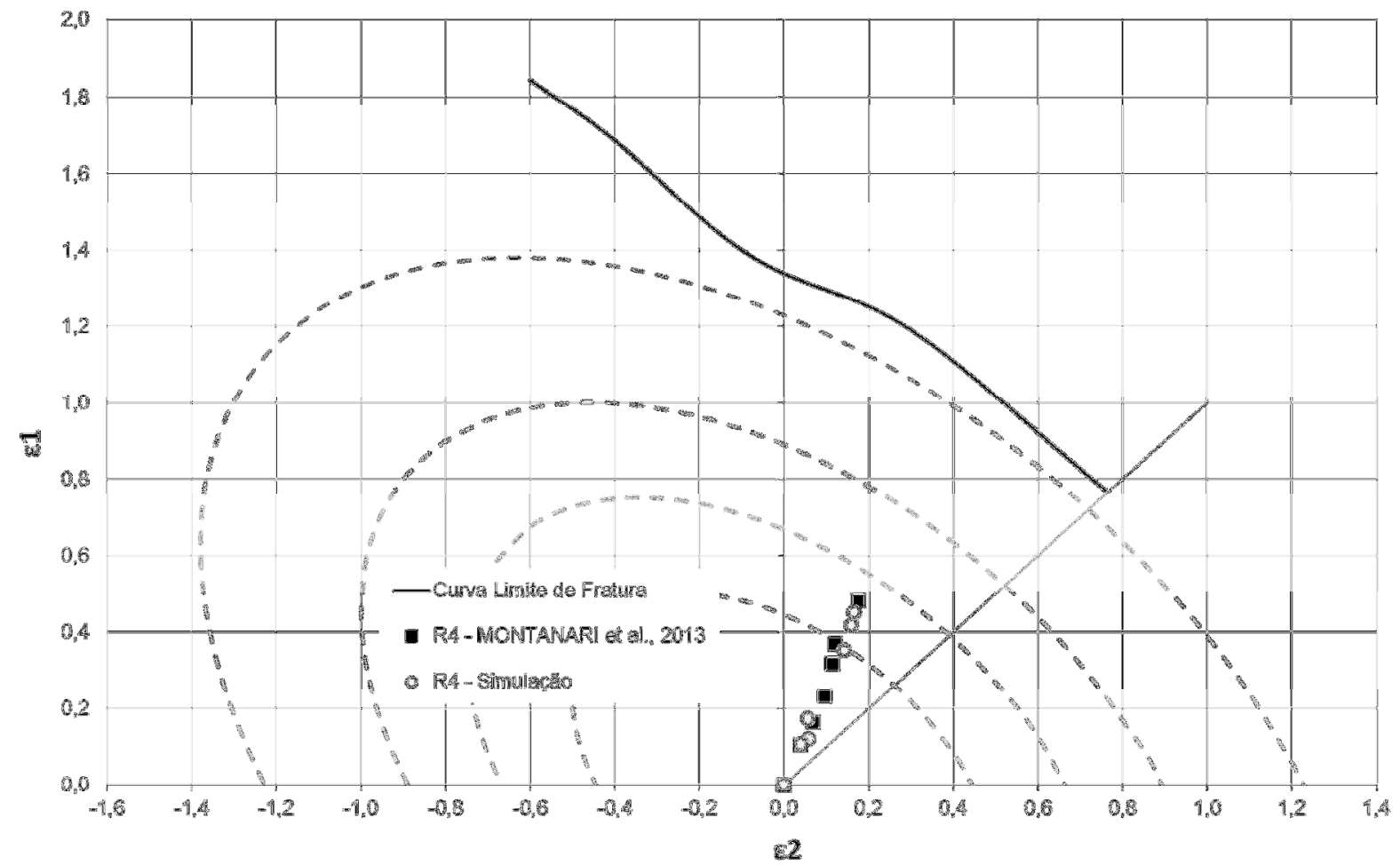

Figura 50 - Comportamento das deformações para região R4 e diâmetro de $D_{0}=121 \mathrm{~mm}$.

Assim como nos resultados experimentais, através das simulações com elementos finitos, é possível verificar que para todas as regiões as deformações se iniciam da origem e crescem monotonicamente até os valores máximos, sem mudança de trajetória, o que condiz com os resultados de Silva et al. (2013), que afirmam que na estampagem incremental a fratura não se dá em decorrência da estricção.

\subsubsection{Redução da espessura da chapa}

$\mathrm{Na}$ estampagem incremental para a fabricação de flanges, à medida que ocorre a expansão do furo, há a redução de espessura na chapa ao longo da periferia do furo expandido, sendo esta a principal razão para o aparecimento de fraturas.

Desse modo é interessante verificar a região onde ocorre a maior redução de espessura com o intuito de prever onde se dará a fratura. Para a obtenção dos valores de redução de espessura foi utilizada a lei de conservação de volume (eq. (14)). 


$$
L_{1 f} \cdot L_{2 f} \cdot L_{3 f}=L_{1 i} \cdot L_{2 i} \cdot L_{3 i} \text { (volume constante) }
$$

Sendo $L_{1 f}, L_{2 f}, L_{3 f}$ são os comprimentos finais de uma chapa em estudo e $L_{1 i}$, $L_{2 i}, L_{3 i}$ são os comprimentos iniciais.

Sabendo que $L_{f}$ é dado pela eq. (15).

$$
L_{f}=(1+\varepsilon) L_{i}
$$

Desse modo é possível obter a eq. (16).

$$
\begin{gathered}
L_{1 f} \cdot L_{2 f} \cdot L_{3 f}=\left(1+\varepsilon_{1}\right)\left(1+\varepsilon_{2}\right)\left(1+\varepsilon_{3}\right) L_{1 i} \cdot L_{2 i} \cdot L_{3 i} \\
\left(1+\varepsilon_{1}\right)\left(1+\varepsilon_{2}\right)\left(1+\varepsilon_{3}\right)=1 \\
\varepsilon_{3}=\left[\frac{1}{\left(1+\varepsilon_{1}\right)\left(1+\varepsilon_{2}\right)}\right]-1
\end{gathered}
$$

Os valores para a redução de espessura obtidos no modelo, para as regiões $R 1, R 2$ e R3, em estudo são mostrados na Figura 52. A análise é realizada para o modelo do flange com diâmetro inicial do furo $D_{0}=102 \mathrm{~mm}$, em decorrência de ter sido o flange escolhido onde ocorreu a fratura. 


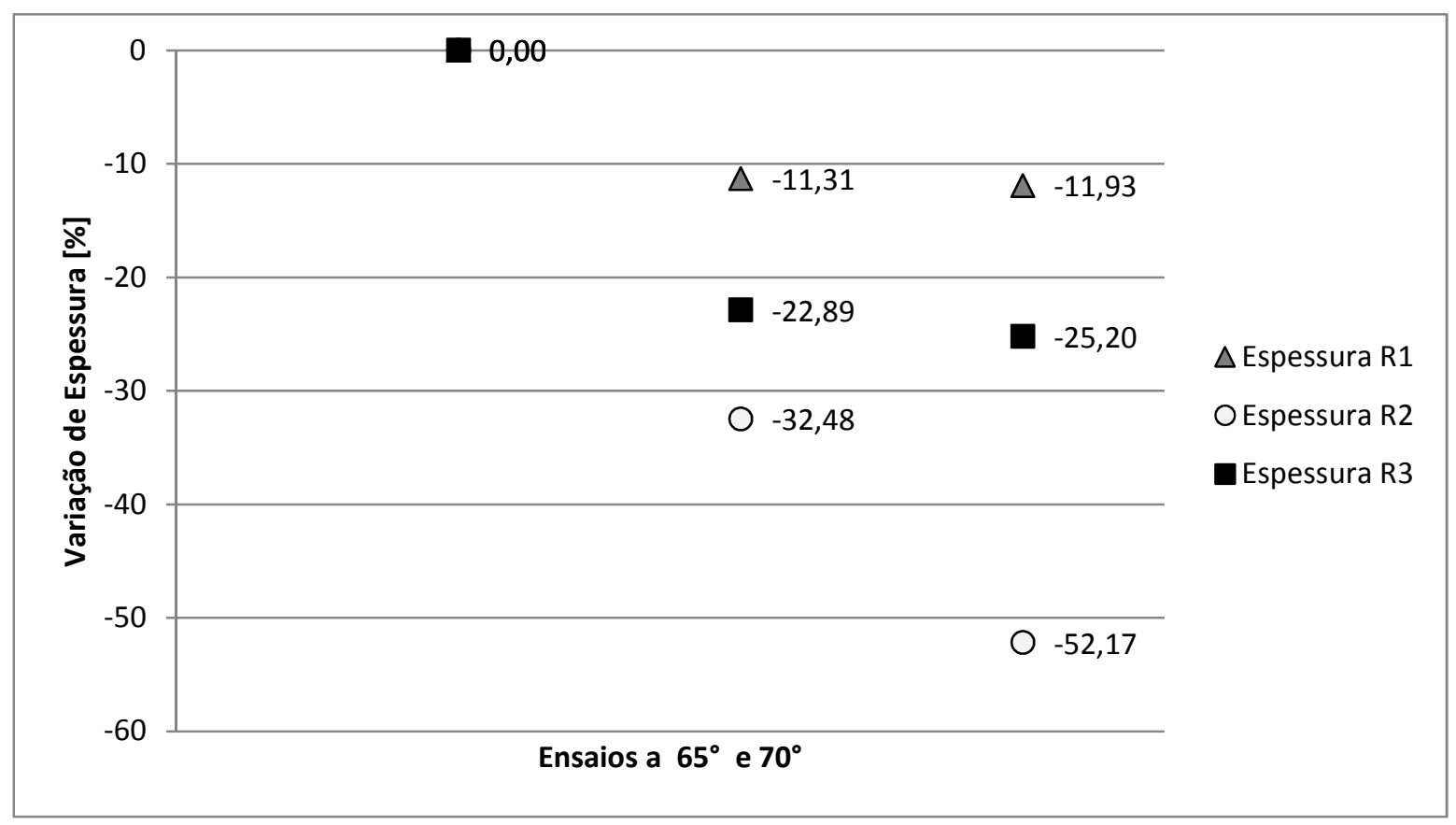

Figura 52 - Variação de espessura par o flange de $102 \mathrm{~mm}$.

Percebe-se que para o diâmetro de $D_{0}=102 \mathrm{~mm}$ a região R2 apresenta uma acentuada redução de espessura, sendo essa região a mais susceptível à falha por fratura. Recorrendo à Figura 45(a), verifica que os valores da deformação na região atinge a área de fratura do material. Este resultado condiz com os resultados experimentais obtidos em Montanari et al. (2013).

\subsubsection{Critério de dano}

Uma forma de investigar o dano ocorrido (fratura) na estampagem incremental para a fabricação de flanges circulares incorporando, simultaneamente, as tensões e as deformações consiste em usar critérios de fratura dúctil (Rodrigues e Martins, 2010).

Há vários modelos envolvendo critérios de dano na deformação plástica. A maioria desses modelos é baseada na ideia do aparecimento, crescimento e coalescência de vazios. Neste trabalho será adotado o critério de Rice e Tracey (1969), representado pela eq. (17), onde D representa o dano acumulado. 


$$
D=\int \frac{1}{1.65} \cdot e^{\left(\frac{3 \sigma_{H}}{2 \sigma_{e q}}\right)} d \varepsilon_{e q}
$$

Onde $\varepsilon_{\text {eq }}$ é a deformação equivalente e $\sigma_{\text {eq }}$ é a tensão equivalente.

Já a tensão hidrostática $\sigma_{H}$ é calculada pela eq. (18):

$$
\sigma_{H}=\left(\sigma_{1}+\sigma_{2}+\sigma_{3}\right) / 3
$$

Onde $\sigma_{\mathrm{i}}$ com $\mathrm{i}=1,2$ e 3 são as tensões principais atuantes.

Para determinar a deformação equivalente $\varepsilon_{\text {eq }}$ e a tensão equivalente $\sigma_{\text {eq }}$ recorre-se às leis de Levy-Mises que regem o escoamento plástico e do critério proposto por Hill (1948) para o escoamento anisotrópico transversal e admite o estado plano de tensões, $\sigma_{3}=0$, eqs. (19), (20) e (21).

$$
\begin{gathered}
d \varepsilon_{1}=\frac{d \varepsilon_{e q}}{\sigma_{e q}} \cdot\left[\frac{1}{(1+r)}\right] \cdot\left(\sigma_{1}+r\left(\sigma_{1}-\sigma_{2}\right)\right) \\
d \varepsilon_{2}=\frac{d \varepsilon_{e q}}{\sigma_{e q}} \cdot\left[\frac{1}{(1+r)}\right] \cdot\left(\sigma_{2}+r\left(\sigma_{2}-\sigma_{1}\right)\right) \\
\sigma_{e q}=\sqrt{\sigma_{1}^{2}+\sigma_{2}^{2}-\frac{2 r}{(1+r)} \sigma_{1} \sigma_{2}}
\end{gathered}
$$

Portanto, a deformação equivalente $\varepsilon_{\text {eq }}$ pode ser obtida através da eq. (22).

$$
d \varepsilon_{e q}=\frac{1+r}{\sqrt{(1+2 r)}} \sqrt{d \varepsilon_{1}^{2}+d \varepsilon_{2}^{2}+\frac{2 r}{(1+r)} d \varepsilon_{1} d \varepsilon_{2}}
$$

Sabendo que os coeficientes $\alpha$ e $\beta$ correspondentes, respectivamente, à trajetória de carregamento (tensão) e à trajetória de deformação através das eqs.(23) e (24). 


$$
\begin{gathered}
\alpha=\frac{\sigma_{2}}{\sigma_{1}} \text { então } \alpha=\frac{\sigma_{2}}{\sigma_{1}}=\frac{(1+r) \beta+r}{(1+r)+r \beta} \\
\beta=\frac{\varepsilon_{2}}{\varepsilon_{1}}
\end{gathered}
$$

As deformações $\varepsilon_{1}$ e $\varepsilon_{2}$ são as deformações verdadeiras no plano da chapa. A deformação $\varepsilon_{3}$, na direção da espessura, é calculada pela lei de conservação do volume de material, conforme eq. (15).

Desse modo, obtêm-se os valores para $\sigma_{1}$ e $\sigma_{2}$ (eq. (25) e (26)).

$$
\begin{aligned}
\sigma_{1} & =\frac{\sigma_{e q}}{\sqrt{\left(1-\frac{2 r}{(1+r)} \alpha+\alpha^{2}\right)}} \\
\sigma_{2}= & \frac{\alpha \sigma_{e q}}{\sqrt{\left(1-\frac{2 r}{(1+r)} \alpha+\alpha^{2}\right)}}
\end{aligned}
$$

A tensão equivalente $\sigma_{\text {eq }}$ é encontrada substituindo a deformação equivalente $\varepsilon_{\text {eq }}$ na eq. (27) resultante da aproximação por mínimos quadrados da curva de Lopes et al. (2003), obtendo uma equação exponencial, Figura 53. A aproximação por uma curva exponencial permite o calculo rápido da tensão equivalente a partir da deformação equivalente.

$$
\sigma_{e q}=108,35 \varepsilon_{e q}^{0,1912}[\mathrm{MPa}]
$$




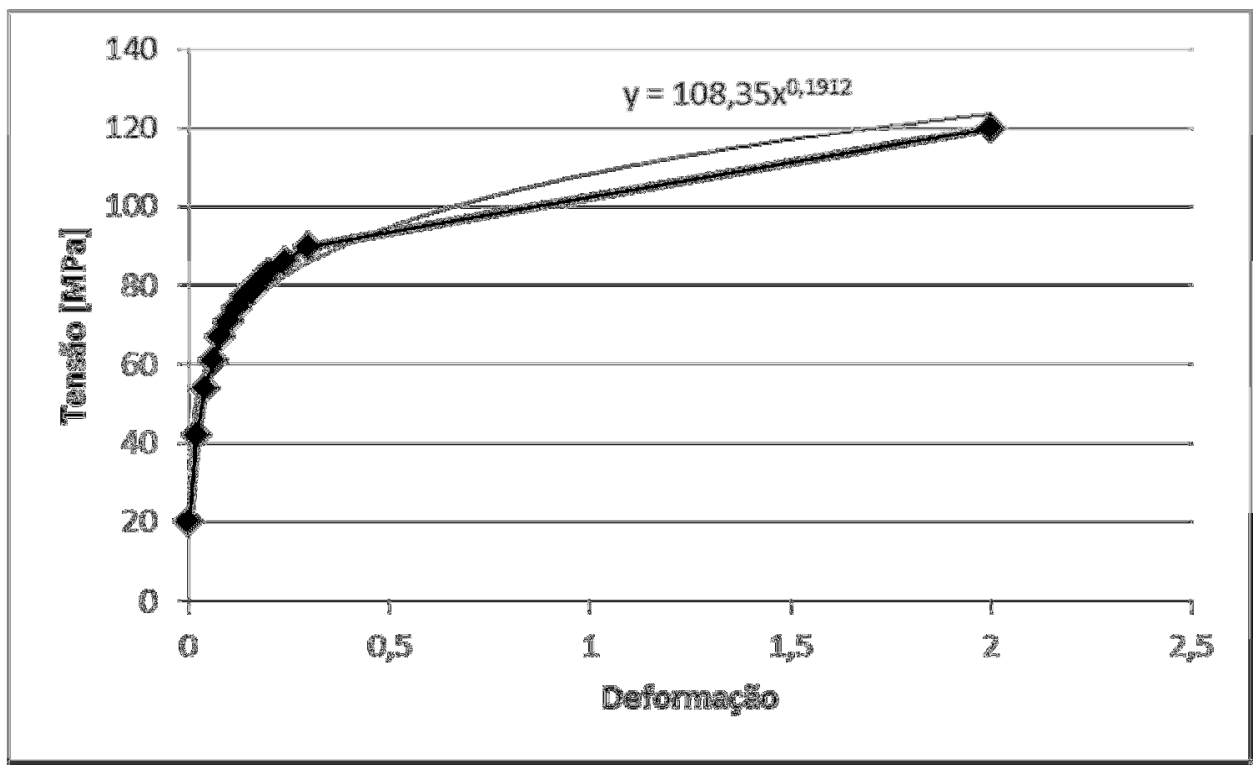

Figura 53 - Relação tensão deformação derivada de Lopes et al (2003).

\subsubsection{Determinação das tensões atuantes}

Para determinar o dano ocorrido nos flanges é necessário encontrar os valores da tensão equivalente $\sigma_{\mathrm{eq}}$ e da tensão hidrostática $\sigma_{\mathrm{H}}$.

Para determinar os valores da tensão equivalente $\sigma_{e q}$, inicialmente, foram obtidas as tensões atuantes em cada ângulo de estampagem $\psi_{i}$. Foram estudados os flanges com $\mathrm{D}_{0}=102 \mathrm{~mm}$ e $\mathrm{D}_{0}=121 \mathrm{~mm}$.

A Figura 54 mostra as tensões resultantes para as deformações encontradas nas simulações para as regiões $R 1, R 2$ e R3 para o flange com diâmetro inicial $D_{0}=$ $102 \mathrm{~mm}$. 


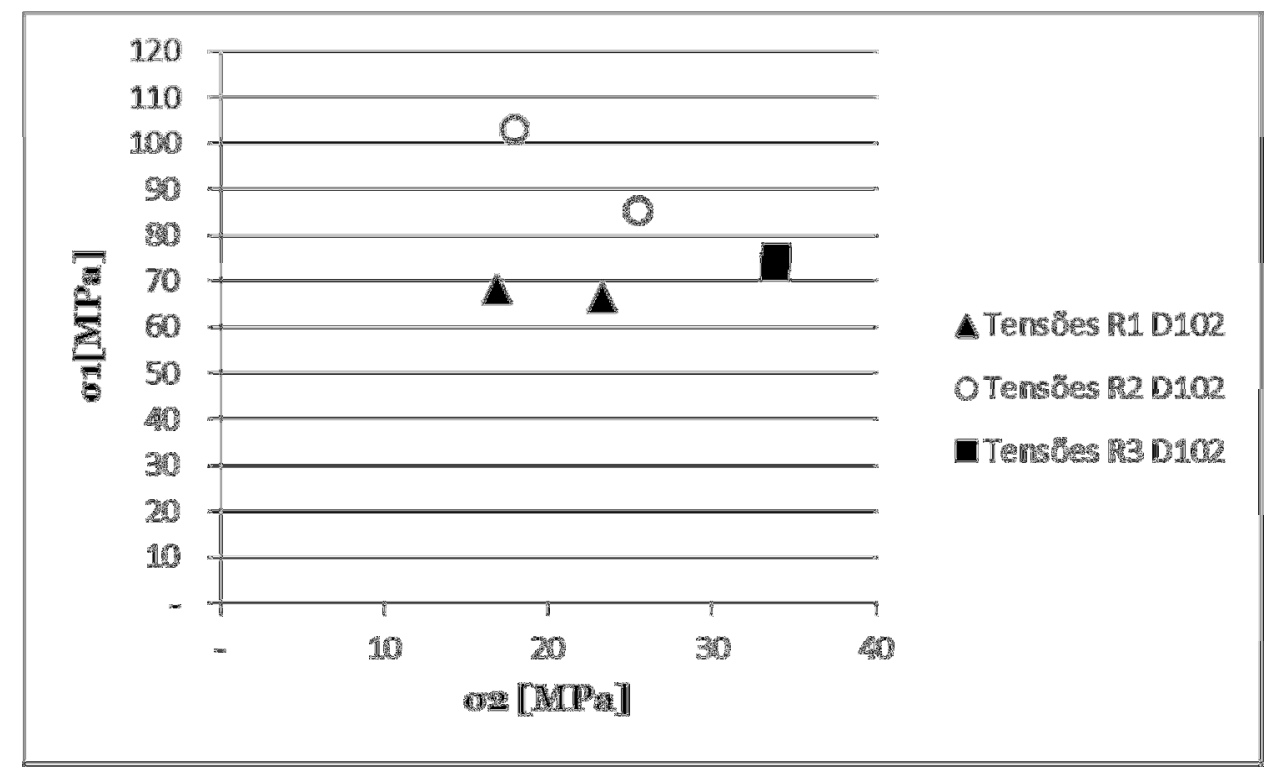

Figura 54 - Tensões atuantes para as deformações encontradas por simulação para o flange com diâmetro inicial $D_{0}=102 \mathrm{~mm}$.

Como mostra o gráfico da Figura 54, as tensões na região R2 são superiores as tensões nas outras regiões. Se observado no trabalho experimental de Cristino et al. (2014) é possível observar que a fratura ocorre na região R2. Além disso, as maiores tensões estão concentradas na região onde há as maiores deformações. Há somente dois valores para a tensão porque cada ponto indica um ângulo de estampagem. Como no flange com $\mathrm{D}_{0}=102 \mathrm{~mm}$ ocorreu a fratura com o ângulo de estampagem $\psi_{2}=70^{\circ}$ (Tabela 5) há somente um valor de tensão para o ângulo de estampagem de $\psi_{1}=65^{\circ}$ e outro valor para o ângulo de estampagem $\psi_{2}=70^{\circ}$. Como visto pelo estudo da redução de espessura, foi na região R2 onde houve a menor redução de espessura.

Para o flange com diâmetro inicial $D_{0}=121 \mathrm{~mm}$ foram estudadas as regiões $\mathrm{R} 1, \mathrm{R} 2$, R3 e R4. A Figura 55 mostra as tensões resultantes para as deformações encontradas nas simulações. 


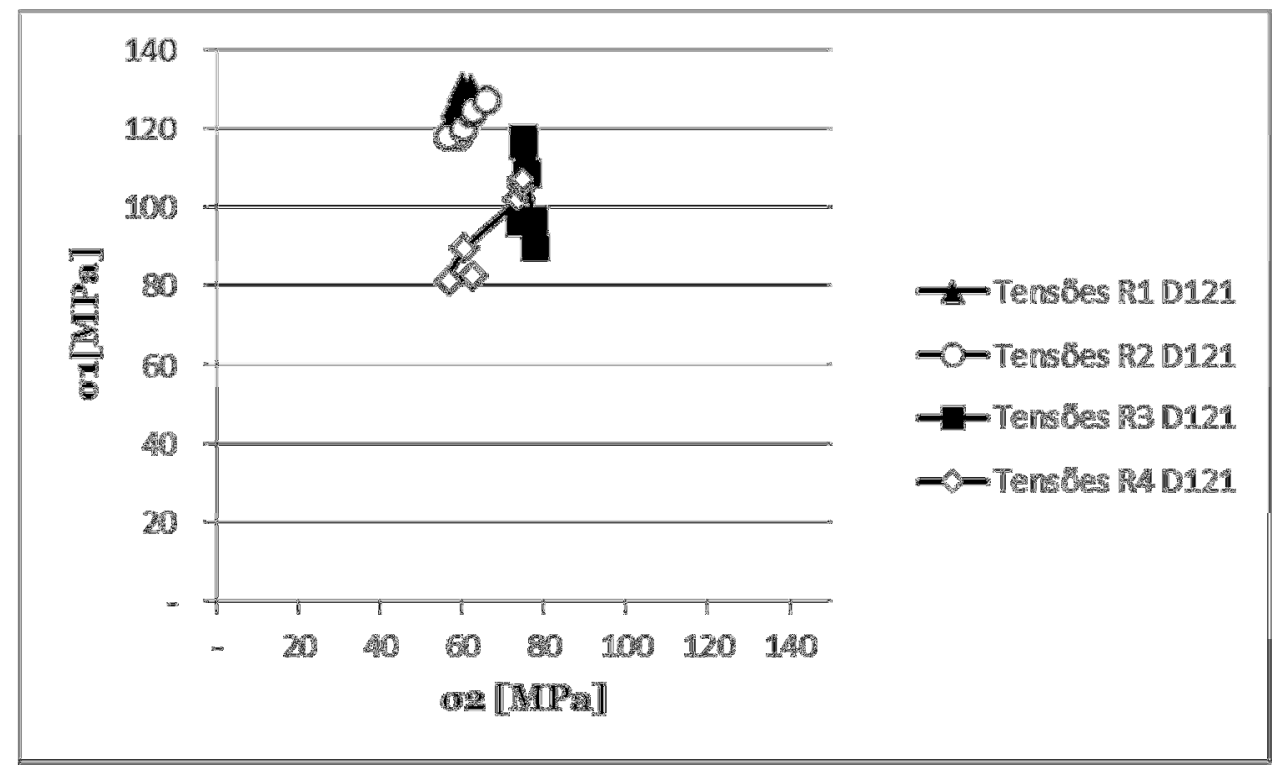

Figura 55 - Tensões atuantes para as deformações encontradas por simulação para o flange com diâmetro inicial $D_{0}=121 \mathrm{~mm}$.

Os maiores níveis de tensão ocorrem nas regiões R1 e R2. Observa-se ainda, pela análise da Figura 55, que há crescimento bem determinado da tensão na região R3 e uma mudança abrupta na região de localização das tensões da região $\mathrm{R} 4$ para o ângulo de estampagem $\psi_{4}=80^{\circ}$.

\subsubsection{Determinação das tensões hidrostáticas}

Para determinar os valores da tensão hidrostáticas $\sigma_{H}$ também foram analisadas as regiões $R 1, R 2$ e $R 3$ para os flanges com diâmetro inicial $D_{0}=102 \mathrm{~mm}$ e $R 1, R 2, R 3$ e R4 para os flanges com diâmetro inicial $D_{0}=121 \mathrm{~mm}$.

A Figura 56 mostra as tensões hidrostáticas atuantes para os flanges com diâmetro inicial $\mathrm{D}_{0}=102 \mathrm{~mm}$. 


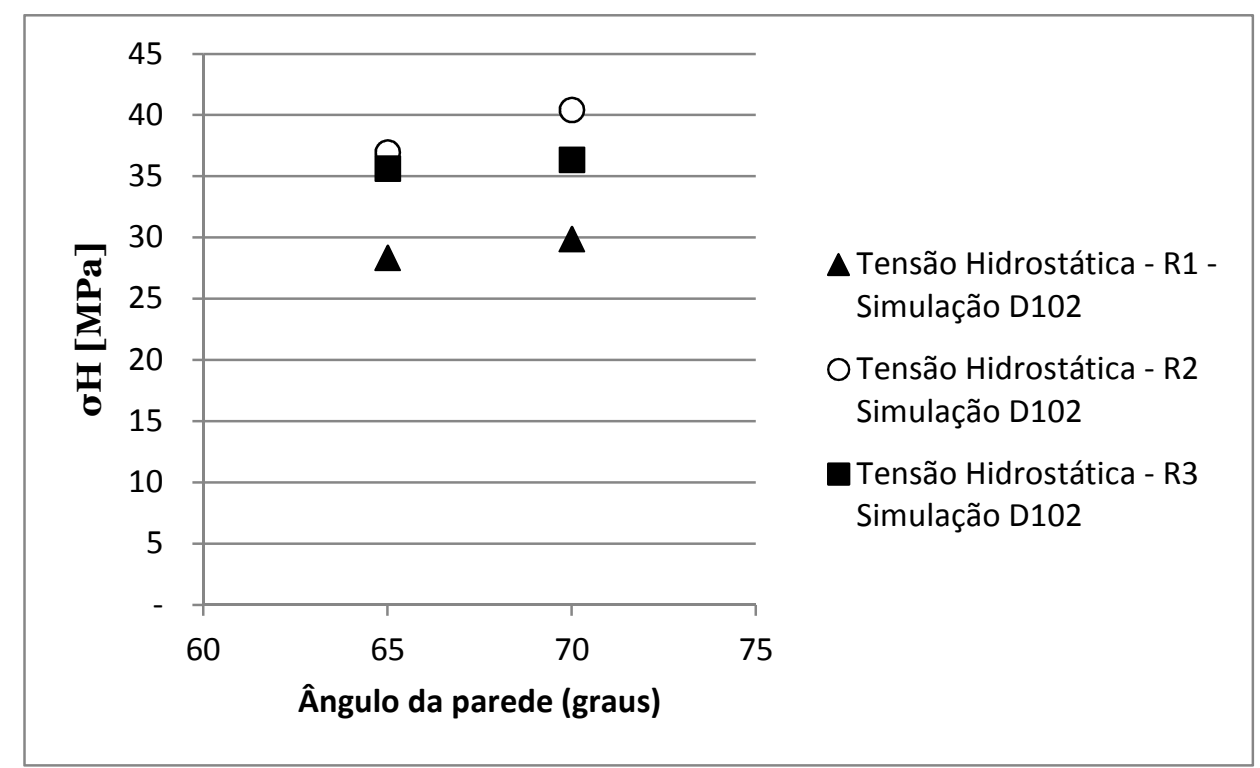

Figura 56 - Tensões hidrostáticas atuantes para as deformações encontradas por simulação para o flange com diâmetro inicial $D_{0}=102 \mathrm{~mm}$.

Observa-se que a tensão hidrostática apresenta os valores mais altos na região R2, seguida da região $\mathrm{R} 3$ e depois da região $\mathrm{R} 1$.

Os resultados para a tensão hidrostática $\sigma_{\mathrm{H}}$ para o flange com diâmetro inicial $\mathrm{D}_{0}=121 \mathrm{~mm}$ são apresentados na Figura 57. 


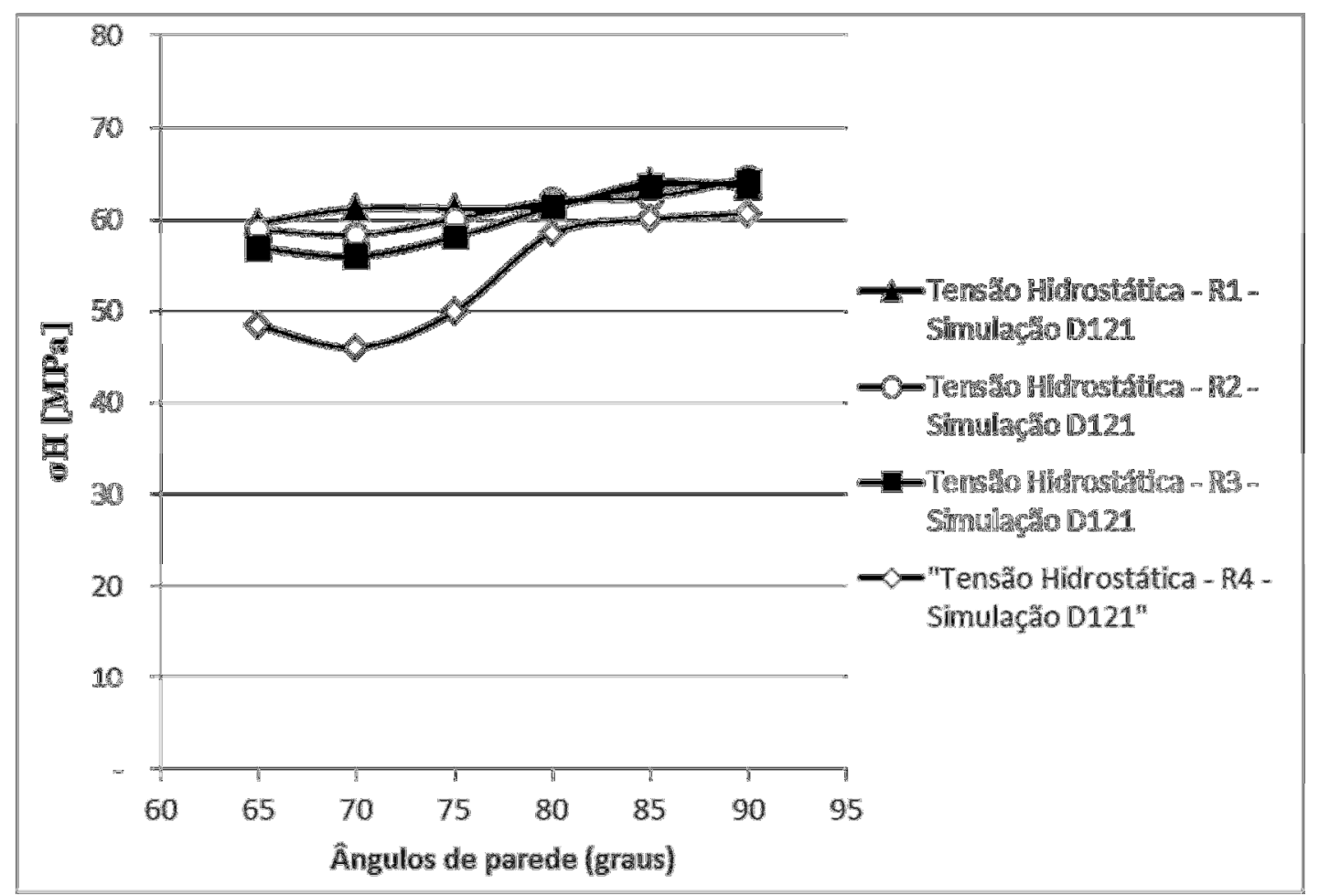

Figura 57 - Tensões hidrostáticas atuantes para as deformações encontradas por simulação para o flange com diâmetro inicial $D_{0}=121 \mathrm{~mm}$.

As tensões hidrostáticas $\sigma_{\mathrm{H}}$ encontradas nas simulações apresentam níveis aproximados para todas as regiões, exceto para a região $\mathrm{R} 4$. Na região $\mathrm{R} 4$ os valores da tensão hidrostática $\sigma_{\mathrm{H}}$ são inferiores quando comparados aos valores das outras regiões ( $R 1, R 2$ e $R 3$ ) e se aproximam quando o ângulo de estampagem é $\psi_{4}=80^{\circ}$. Todas as tensões hidrostáticas máximas para $\psi_{6}=90^{\circ}$ tendem para valores próximos de $60 \mathrm{MPa}$.

\subsubsection{Determinação das tensões equivalentes}

Da mesma forma que foram determinadas as tensões hidrostáticas $\sigma_{\mathrm{H}}$ serão determinadas as tensões equivalentes $\sigma_{\text {eq }}$. Para o flange com diâmetro inicial $D_{0}=102 \mathrm{~mm}$ foram analisadas as regiões $\mathrm{R} 1, \mathrm{R} 2$ e $\mathrm{R} 3$ e os valores das tensões equivalentes $\sigma_{\text {eq }}$ são mostradas na Figura 58. Como nos estudos anteriores, a 
região R2 apresenta valores superiores de tensão equivalente para todos os ângulos de estampagem $\psi_{i}$.

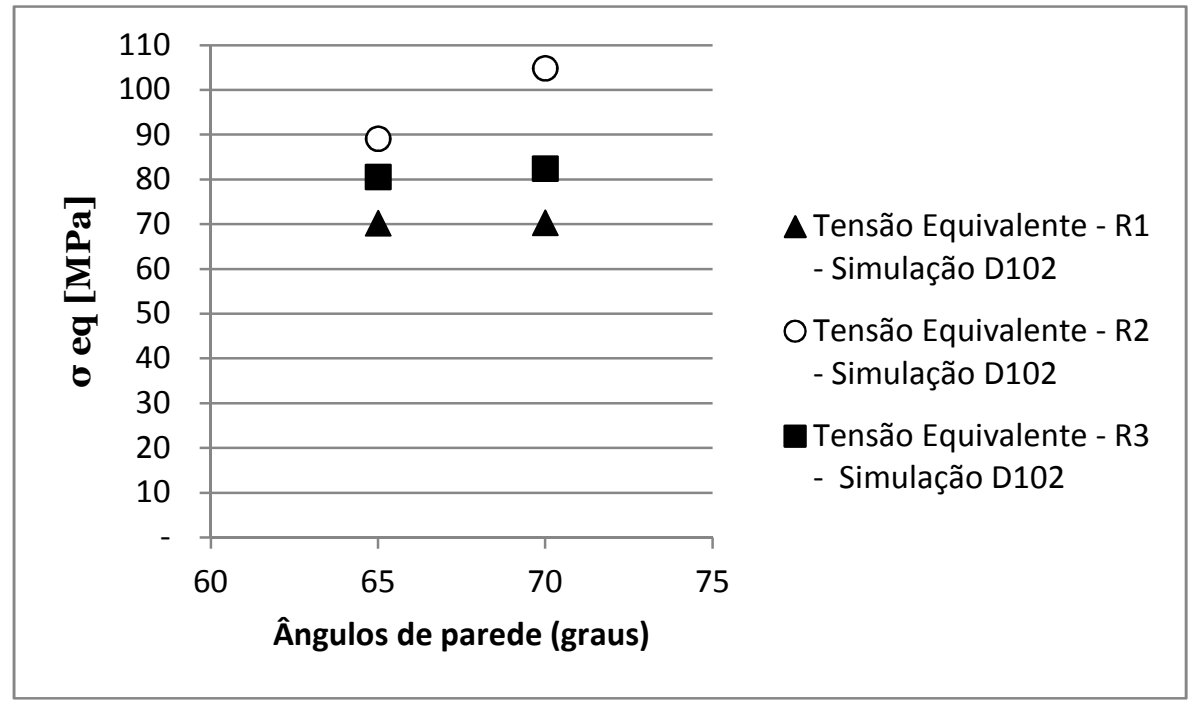

Figura 58 - Tensões equivalentes para as deformações encontradas por simulação para o flange com diâmetro inicial $D_{0}=102 \mathrm{~mm}$.

Para ○ flange com diâmetro inicial $\mathrm{D}_{0}=121 \mathrm{~mm}$ os resultados para a tensão equivalente $\sigma_{\text {eq }}$ são apresentados na Figura 59.

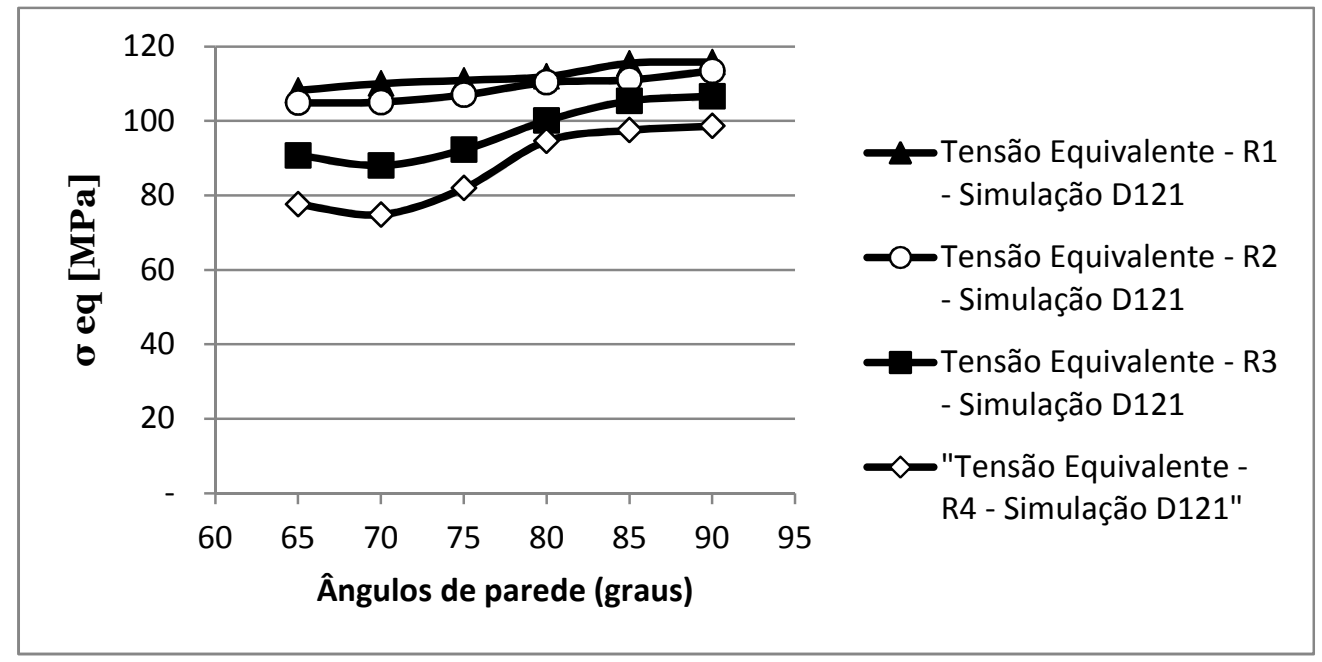

Figura 59 - Tensões equivalentes para as deformações encontradas por simulação para o flange com diâmetro inicial $D_{0}=121 \mathrm{~mm}$. 
As tensões equivalentes $\sigma_{\mathrm{eq}}$ encontradas nas simulações apresentam níveis próximos para as regiões $\mathrm{R} 1$ e $\mathrm{R} 2$, as regiões $\mathrm{R} 2$ e $\mathrm{R} 3$ apresentam valores iniciais inferiores e aproximam-se dos valores das tensões das regiões R1 e R4 para o ângulo de estampagem $\psi_{4}=80^{\circ}$. As tensões máximas para o ângulo máximo de estampagem $\psi_{6}=90^{\circ}$ apresentam valores próximos a $110 \mathrm{MPa}$.

\subsubsection{Dano acumulado}

Como visto na eq. (17), para determinar o valor do dano acumulado, segundo RiceTracey, é necessário determinar os valores da deformação equivalente $\varepsilon_{\text {eq }}$, a tensão equivalente $\sigma_{\mathrm{eq}}$ e a tensão hidrostática $\sigma_{\mathrm{H}}$. Assim, o valor do dano D para o flange com diâmetro inicial $D_{0}=102 \mathrm{~mm}$ pode ser visto na Figura 60 . O dano D é mostrado segundo o ângulo de estampagem $\psi_{i}$.

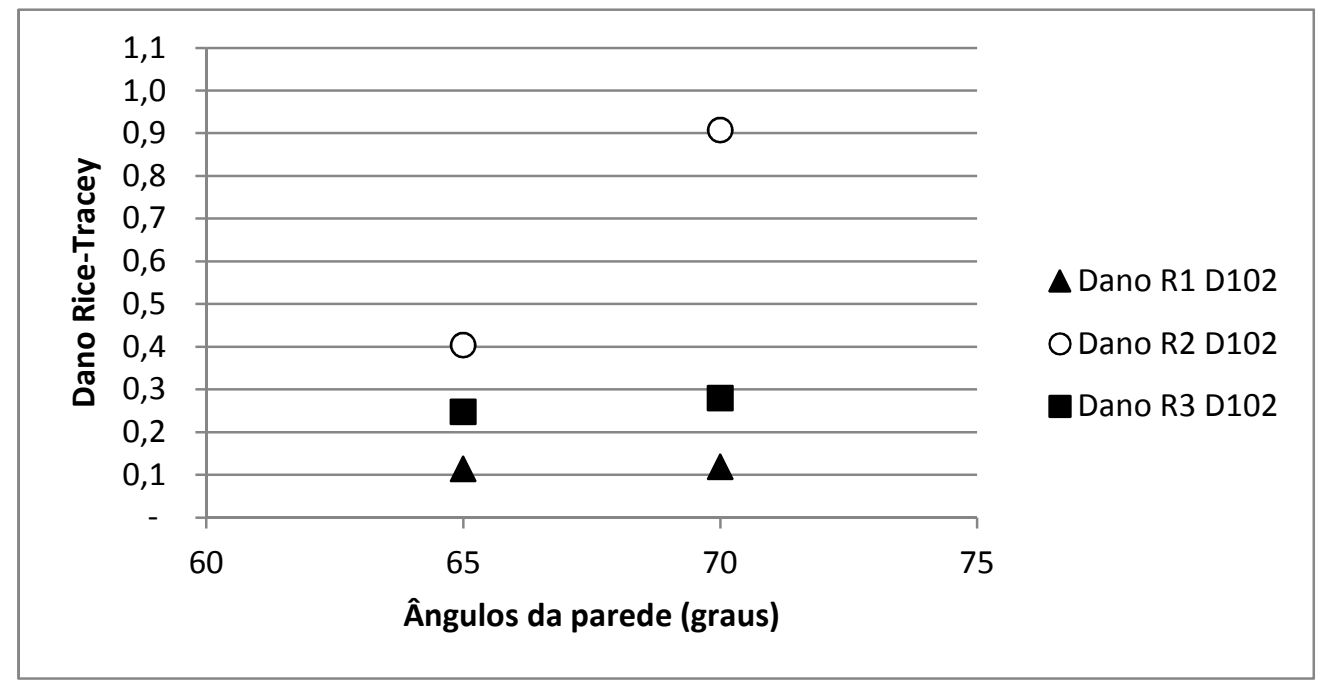

Figura 60 -. Dano acumulado, segundo Rice-Tracey, para as deformações encontradas para o flange com diâmetro inicial $D_{0}=102 \mathrm{~mm}$.

Pela análise da Figura 60 nota-se que o maior valor do dano acumulado ocorreu na região $\mathrm{R} 2$, como era pressuposto e foi analisado anteriormente. 
O valor do dano D para o flange com diâmetro inicial $D_{0}=121 \mathrm{~mm}$ pode ser visto na Figura 61. O dano D é mostrado segundo o ângulo de estampagem $\psi_{i}$. A região onde o valor do dano $\mathrm{D}$ atingiu o maior valor foi na região $\mathrm{R} 2$ com ângulo de estampagem $\psi_{6}=90^{\circ}$.

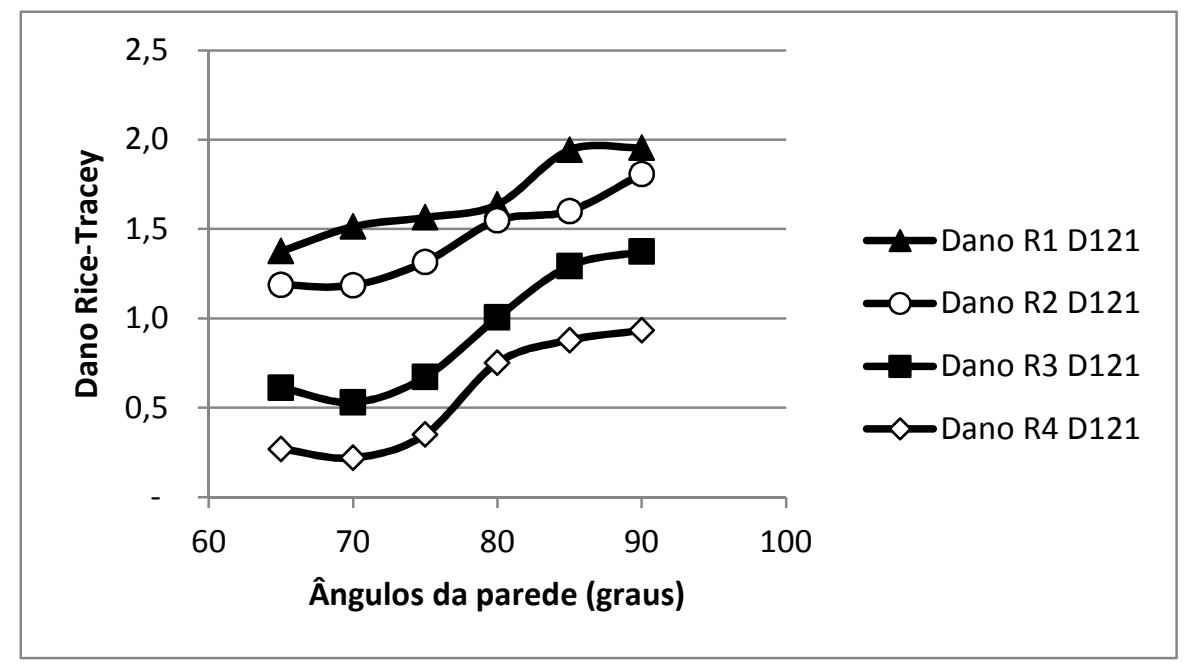

Figura 61 - Dano acumulado, segundo Rice-Tracey, para as deformações encontradas para o flange com diâmetro inicial $D_{0}=121 \mathrm{~mm}$.

De modo geral, foram analisadas as regiões dos flanges com diâmetro inicial $D_{0}=102 m m$ (R1, R2 e R3) e $D_{0}=121 m m$ (R1, R2, R3 e R4) em função das deformações e tensões e, assim, foi possível determinar o dano crítico na parede do flange em função do ângulo de estampagem $\psi_{i}$. Através dos valores das deformações verdadeiras encontrados empregando o método de elementos finitos foi possível obter os valores das tensões atuantes e, por fim, das tensões equivalentes e das tensões hidrostáticas.

Se comparado com os valores encontrados por Cristino et al. (2014) verifica que os valores das tensões atuantes encontrados para o flange com diâmetro inicial $D_{0}=121 \mathrm{~mm}$ estão-dentro do envelope definido.

Para as tensões hidrostáticas apesar de diferença dos valores nota-se comportamento semelhante. 
A análise da tensão equivalente mostra que as todas as regiões apresentam valores próximos de tensão equivalente para todos os ângulos de estampagem $\psi_{i}$. As tensões equivalentes máximas tendem entre valores de 95 a 120 MPa para o ângulo máximo de estampagem $\psi_{6}=90^{\circ}$. A análise do dano para o flange com furo inicial $D_{0}=121 \mathrm{~mm}$ fornece resultados dentro de $20 \%$ de erro para a simulação em relação ao trabalho de Montanari et al. (2013) para as regiões R1, R2 e R3.

Para os flanges com diâmetro inicial $D_{0}=102 \mathrm{~mm}$ os valores não se aproximaram da mesma forma que para os flanges com diâmetro inicial $D_{0}=121 \mathrm{~mm}$. No entanto, pode-se afirmar que o modelo usado é válido para predizer como as trajetórias de deformação se comportam e onde, possivelmente, ocorrerá a falha na estampagem incremental para a fabricação de flanges com furos iniciais. 


\section{CAPÍTULO 4}

\subsection{Projeto do suporte}

O objetivo deste capítulo é estudar e desenvolver um suporte modular aplicável a estampagem incremental, tanto na sua variante sem matriz quanto com matriz. $\mathrm{E}$, dessa forma, aumentar a flexibilidade do processo com relação à geometria da peça a ser deformada. O suporte modular deve ser rígido do ponto de vista estrutural, de fácil instalação e flexível entre suas variantes.

Segundo Ceretti, Giardini e Attanasio (2004), as características ideais do suporte, adaptável ao centro de usinagem, devem ser:

- Capacidade de suportar as forças impostas sobre a chapa;

- Possuir rigidez estrutural e área útil suficientes para a fabricação das peças com geometrias e dimensões diferentes,

- Facilidade de instalação e retirada da máquina, garantindo a flexibilidade do processo.

Outra característica que pode tornar o suporte mais atrativo é a modularidade, atendendo as variantes com matriz e sem matriz na estampagem incremental, de forma a adaptar as chapas com tamanhos iniciais diferentes.

A criação de um suporte modular que atenda as variantes com matriz e sem matriz na estampagem incremental, de forma a adaptar chapas com tamanhos iniciais diferentes e de fácil instalação e retirada confere flexibilidade ao processo e diminui o tempo de set-up.

Segundo Hussain, Hayat e Gao (2008), o aperto dos parafusos de fixação fornecido a chapa deve ser suficiente para que a mesma tenha rigidez suficiente e não se mova durante o processo de deformação, entretanto não figura como parâmetro do processo, ou seja, não deve ser parâmetro de controle, pois não afeta diretamente a qualidade das peças produzidas. 
Quando se inicia um projeto sabe-se relativamente pouco quanto à provável solução final, de modo que nesse estágio há muitas incertezas e corre-se certo risco em supor que a iniciativa seja viável. À medida que o projeto progride, aparecem condicionantes, surgem soluções alternativas, comparam-se possibilidades, e concretizam-se informações. Portanto, o risco de tomar uma solução errada é máximo ao início do processo e decresce com a aparição de novos elementos. Por isso, como forma de auxiliar na tomada de decisão, será utilizado o método de análise de valor, visando obter melhor funcionalidade do suporte modular.

\subsection{Metodologia}

Dedini e Cavalca (2004) definem análise de valor como a aplicação sistemática de um conjunto de técnicas e ferramentas para que as funções necessárias ao produto possam ser identificadas, estabelecendo valores para as funções desejadas. $O$ emprego de ferramentas específicas à análise de tomada de decisões proporciona uma base mais segura para alcançar os objetivos de projeto.

A análise de valor tem como finalidade avaliar dentre as concepções mostradas elaboradas aquela que melhor atende os requisitos de projeto e, consequentemente, que se torna assim a melhor candidata a fabricação. Como metodologia de análise de valor, adota-se aquela formulada por Pahl e Beithz (1996), dada pela eq. (28).

$$
X_{i}=\frac{\sum_{i=1}^{n} w_{i} \cdot v_{i j}}{v_{\max } \cdot \sum_{i=1}^{n} w_{i}}
$$

Onde:

$\mathrm{X}_{\mathrm{i}}$ - valor global

$\mathrm{v}_{\max }$ - valor máximo de todas as variantes

$v_{i j}$ - sub-valor da variante i em relação ao critério j

$\mathrm{w}_{\mathrm{i}}$ - peso i-ésimo do critério $\mathrm{j}$

i - variante

j - critério

n - número de critérios

O método de análise de valor dos tipos construtivos em estudo analisa as variantes técnicas (características) em relação à construção do suporte modular. As variantes 
são comparadas a um conjunto de critérios relacionados à função e são atribuídos pesos a esses critérios. Dentre os vários tipos construtivos abordados, um levantamento das características intrínsecas de cada um permite uma análise técnica detalhada da alternativa de maior viabilidade.

\subsubsection{Requisitos de projeto}

No caso do suporte modular para adaptação ao centro de usinagem que atenda as variantes da estampagem incremental com e sem matriz, são características imprescindíveis:

Rigidez estrutural - o suporte deve apresentar rigidez tão boa quanto a rigidez da máquina onde será instalado.

Facilidade de instalação e remoção - colocar e retirar o suporte da mesa de trabalho de centro de usinagem deve ser facilitado para viabilizar o uso do centro de usinagem para o seu fim específico e para a adaptação da estampagem incremental. É necessário que o suporte não seja demasiadamente pesado, e apresente mecanismos de fácil fixação e remoção.

Flexibilidade do processo de estampagem - o suporte modular deve ser empregado para as variantes com matriz e sem matriz da estampagem incremental. Para tanto, o número de graus de liberdade é diferente. Para a estampagem incremental sem matriz a chapa de base permanece fixa (sem nenhum grau de liberdade). Porém, na variante com matriz há deslocamento no eixo paralelo ao eixoárvore da máquina (um grau de liberdade).

Modularidade - o suporte deve facilitar a utilização de chapas iniciais com tamanhos com a mudança de poucos componentes.

Troca rápida da chapa a ser trabalhada - facilitar a inserção da chapa inicial e a retirada da peça fabricada faz com que seja necessário um mecanismo especial para diminuir o tempo entre as trocas.

Simplicidade construtiva - reduz o tempo e os custos do processo de fabricação do suporte. 
Desse modo, são atribuídos pesos aos requisitos necessários para o funcionamento adequado do suporte modular, como mostra a Tabela 8.

Tabela 8 - Pesos atribuídos aos requisitos

\begin{tabular}{ccc}
\hline Número & Requisito de Projeto & $\mathrm{w}_{\mathrm{i}}$ \\
\hline 1 & Rigidez estrutural & 10 \\
2 & Flexibilidade de instalação e remoção & 7 \\
3 & Flexibilidade de processo & 8 \\
4 & Modularidade & 7 \\
5 & Troca rápida da chapa a ser trabalhada & 5 \\
6 & Simplicidade construtiva & 6 \\
\hline & $\sum_{\mathrm{i}=1}^{\mathrm{n}} \mathrm{w}_{\mathrm{i}}$ & 43 \\
\end{tabular}

\subsection{Etapas do Projeto e suas Características}

A seguir são descritos alguns tipos construtivos de suportes modulares adaptáveis ao centro de usinagem que podem ser usados na estampagem incremental de chapas.

\subsubsection{Primeira concepção}

Inicialmente, considerando o aspecto da rigidez necessária ao suporte, foi encontrada a concepção mostrada na Figura 62. Trata-se de uma estrutura com quatro paredes fixada à mesa do centro de usinagem por meio de parafusos. Além dos parafusos para fixação do suporte à mesa de trabalho, também há outros parafusos para fixação do prensa chapas ao suporte, comprimindo a chapa a ser trabalhada.

Esta concepção apresentou simplicidade construtiva e de fabricação, porém elevado peso e dificuldade de fixação, devido ao grande número de parafusos, já que devem ser retirados por completo sempre que necessária a retirada da chapa trabalhada. 


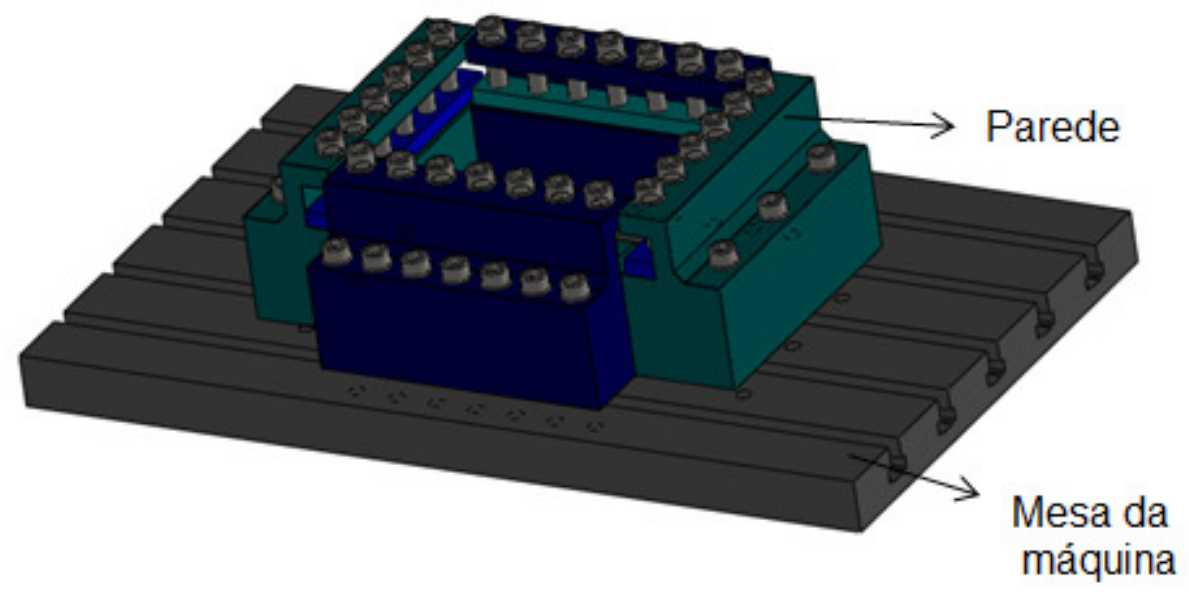

Figura 62 - Primeira concepção.

\subsubsection{Segunda concepção}

Com o intuito de reduzir o peso da estrutura e encontrar uma forma melhor de fixação da chapa foi encontrada a segunda concepção, Figura. 62. Os pilares modulares foram concebidos de maneira a sustentar a mesa superior constituída de uma chapa e de quatro prensa chapas.

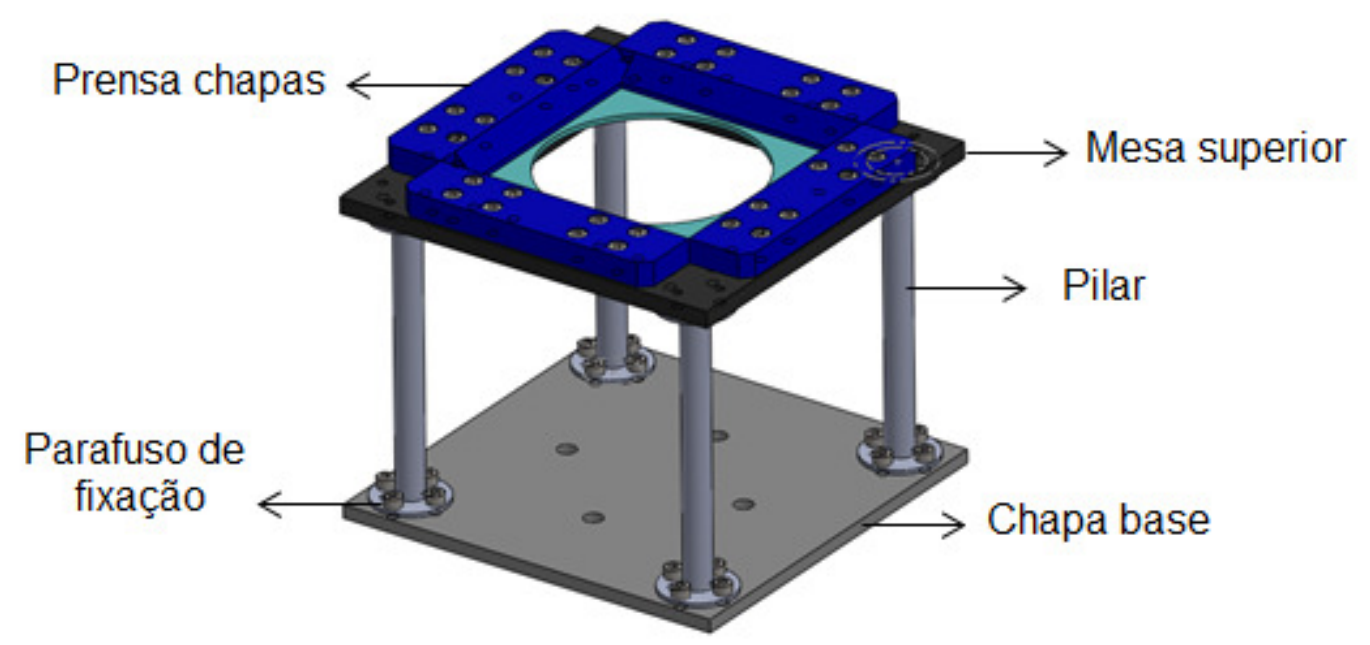

Figura 63 - Segunda concepção.

O conceito apresentou uma construção simples e leve, entretanto sua rigidez foi comprometida, pois a fixação dos pilares por meio de parafusos na chapa base 
limita o diâmetro do tubo utilizado como pilar. Além disso, o projeto não atende ao requisito de permitir o movimento ascendente e descendente na direção do eixoárvore do centro de usinagem, necessário na variante do processo com matriz.

\subsubsection{Terceira concepção}

Uma das características fundamentais para a criação deste suporte para a estampagem incremental é a sua adaptação às variantes com matriz e sem matriz, conferindo flexibilidade ao processo além de, baseado na segunda concepção, melhorar a rigidez do conjunto. Os pilares foram fixados pela parte inferior da chapa e os parafusos foram embutidos na chapa, como mostra a Figura 64.

As buchas superiores foram projetadas para aumentar a área de contato entre a chapa superior e os pilares. Os pilares também funcionam como guias, já que, quando ocorre o movimento da parte superior, as buchas deslizam pelos pilares conferindo o movimento desejado à mesa superior. Para impedir o movimento da parte superior, quando necessário, basta fixar as travas nas buchas superiores através de rosca.

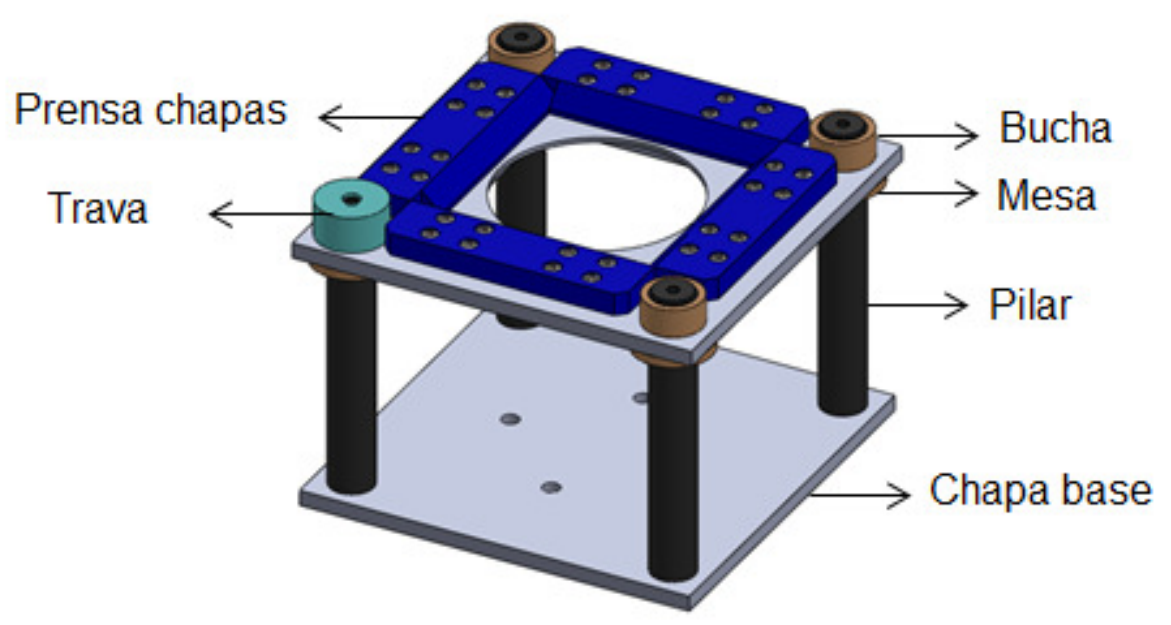

Figura 64 - Terceira concepção.

O suporte modular ainda não atende aos requisitos exigidos pelo projeto, pois ainda é impossível fabricar peças em dimensões diferentes sem alterar o tamanho da chapa de trabalho com a substituição de poucas peças. A cada nova dimensão de 
chapa seria necessário um suporte novo. Desse modo essa concepção não apresenta modularidade.

\subsubsection{Quarta concepção}

A quarta concepção foi criada com o intuito de aumentar a rigidez e conferir modularidade ao projeto. O conceito, apresentado na Figura 65, é composto por travessões superiores que substituem a chapa superior, e apoia o prensa chapas por meio de parafusos. Os pilares extras com ressaltos nas extremidades garantem o alinhamento do suporte. Os travessões possuem como finalidade aumentar o comprimento total do suporte com a inserção de mais peças.

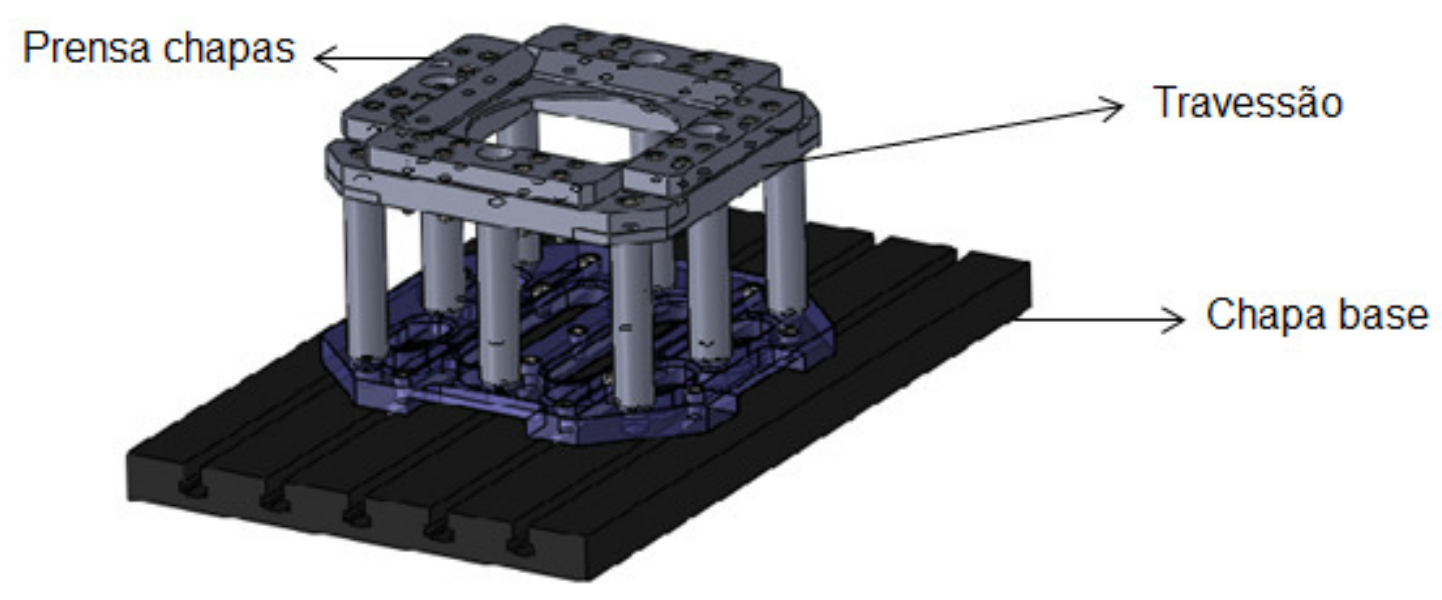

Figura 65 - Quarta concepção.

A quarta concepção apresenta a possibilidade de ser montada com mais travessões superiores e assim ter seu tamanho variado como demonstrado na Figura 65. Entretanto não apresenta flexibilidade entre as variantes do processo (com e sem matriz), como a terceira concepção.

\subsubsection{Quinta concepção}

A quinta concepção, mostrada na Figura 66, é praticamente a junção da terceira e quarta concepções. Apresenta modularidade e flexibilidade. Nesta concepção foi inserido um conjunto de molas (Figura 66(a)), para amenizar as possíveis vibrações 
que venham a ocorrer. Os travessões superiores são unidos por uma porca rosqueada na bucha superior. São mostradas as configurações estendidas no caso da variante sem matriz (Figura 66(d)) e da variante com matriz (Figura 66(c)). Ainda é necessário recuar a fixação dos pilares do travessão de maneira a evitar o contato entre os pilares e o porta-ferramenta quando a estrutura estiver em movimento na direção do eixo-árvore (Figuras 66 (c) e (d)).

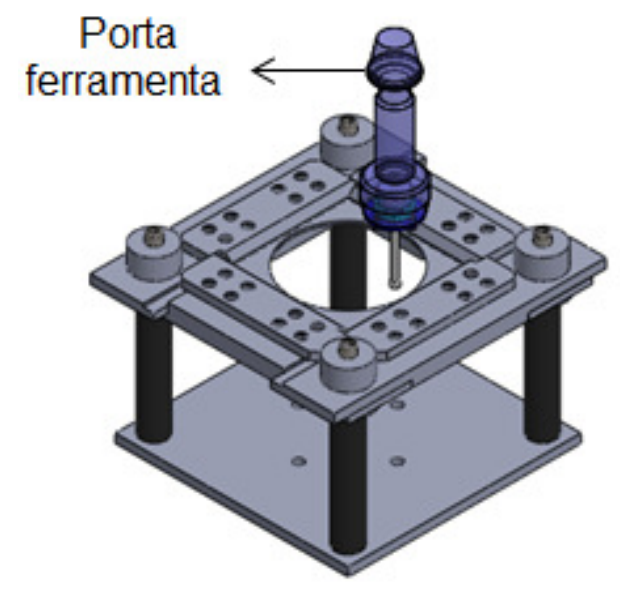

(a)

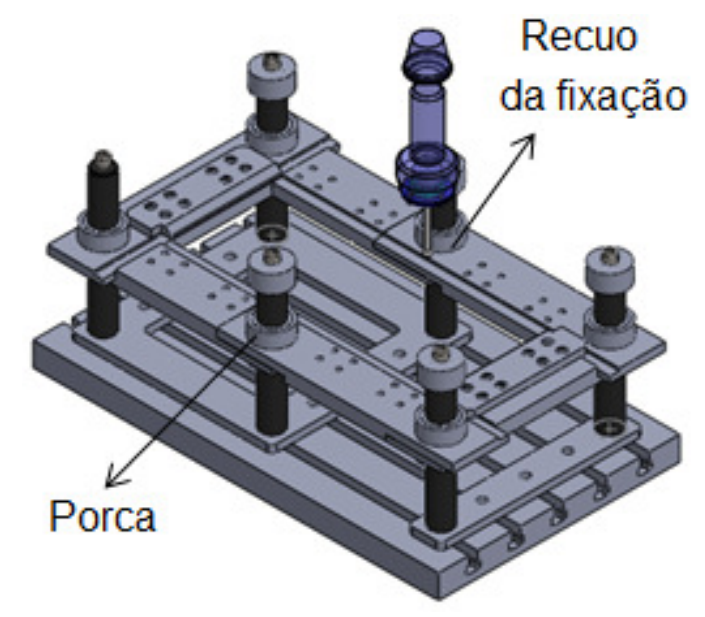

(c)

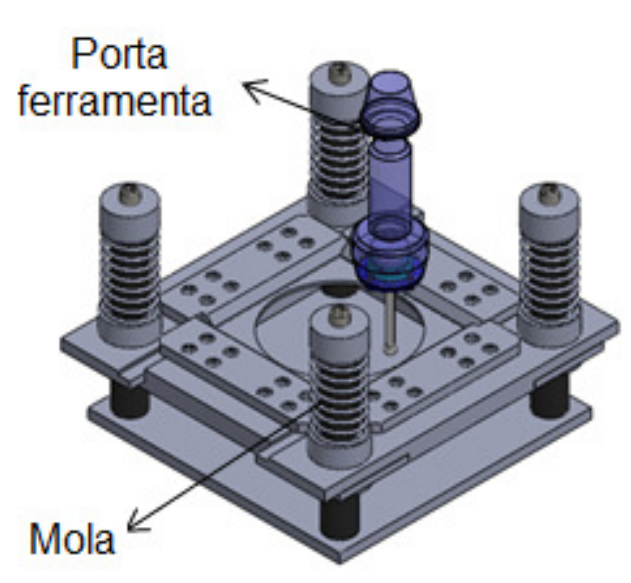

(b)

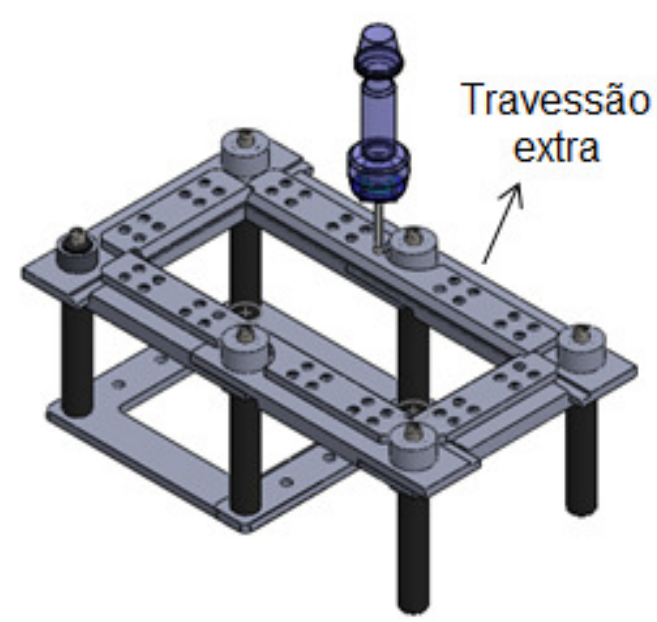

(d)

Figura 66 - Quinta concepção.

Observa-se que, na quinta concepção, ainda não foi atingido o conceito de modularidade, uma vez que o projeto apresenta apenas possibilidades discretas de comprimento. 


\subsubsection{Sexta concepção}

Nessa concepção, Figura 67, é inserida a ideia de utilizar travessões de tamanhos variados e de tornar mais flexível a fixação do suporte à mesa de trabalho da máquina. Para tanto, não serão mais adicionados travessões com o comprimento fixo, o suporte contará com travessões de tamanhos variados. Com isso pode-se variar o comprimento útil de trabalho das chapas com a fabricação de mais dois travessões.
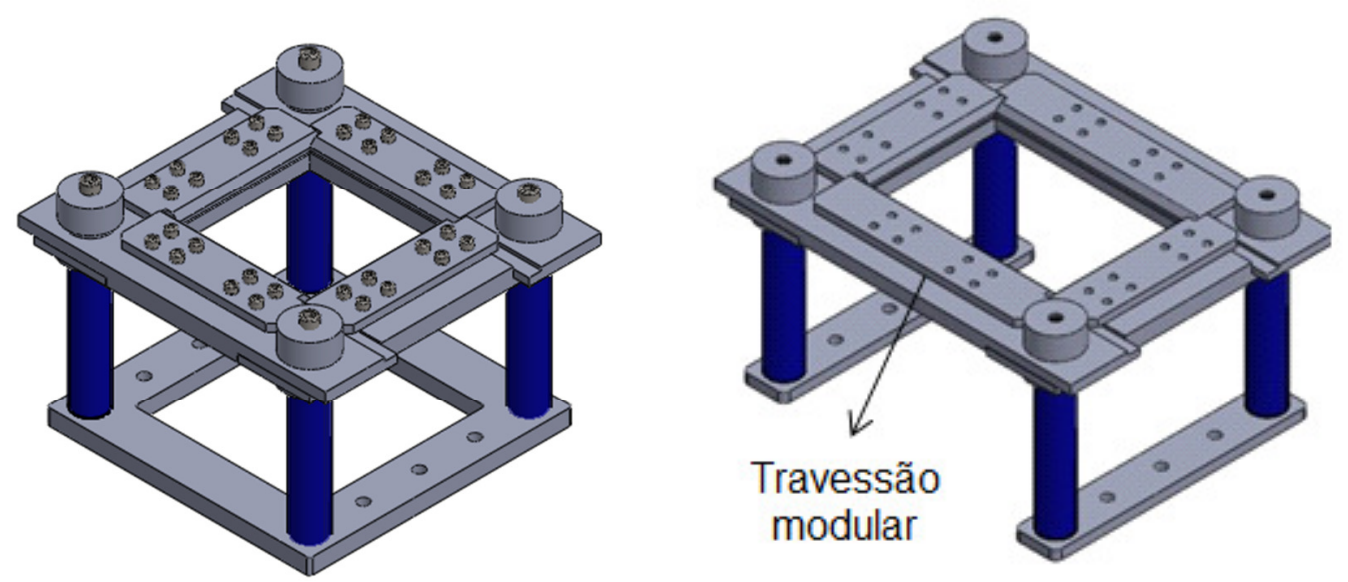

Figura 67 - Sexta concepção.

Desse modo, chegando a uma concepção que engloba todos os requisitos de projeto do suporte modular, é realizada a análise de valor para comprovar a veracidade dos critérios abordados e da solução apresentada.

\subsection{Resultados e discussão}

Dentre os vários tipos construtivos em estudo, através das características (variantes) foi efetuada uma análise de valor, visando obter o sistema com melhor funcionalidade.

A Tabela 9 apresenta os valores atribuídos a cada uma das soluções. 
Tabela 9 - Análise de valor.

\begin{tabular}{|c|c|c|c|c|c|c|c|c|c|c|c|c|}
\hline \multirow[t]{2}{*}{$\mathrm{n}$} & \multicolumn{2}{|c|}{$1^{\underline{a}}$} & \multicolumn{2}{|c|}{$2^{\underline{a}}$} & \multicolumn{2}{|c|}{$3^{a}$} & \multicolumn{2}{|c|}{$4^{\underline{a}}$} & \multicolumn{2}{|c|}{$5^{\mathrm{a}}$} & \multicolumn{2}{|c|}{$6^{\underline{a}}$} \\
\hline & $\mathrm{v}_{\mathrm{i}}$ & $\mathrm{w}_{\mathrm{i}} \cdot \mathrm{v}_{\mathrm{i}}$ & $v_{i}$ & $\mathrm{w}_{\mathrm{i}} \cdot \mathrm{v}_{\mathrm{i}}$ & $v_{i}$ & $\mathrm{w}_{\mathrm{i}} \cdot \mathrm{v}_{\mathrm{i}}$ & $\mathrm{v}_{\mathrm{i}}$ & $\mathrm{w}_{\mathrm{i}} \cdot \mathrm{v}_{\mathrm{i}}$ & $\mathrm{v}_{\mathrm{i}}$ & $\mathrm{w}_{\mathrm{i}} \cdot \mathrm{v}_{\mathrm{i}}$ & $v_{i}$ & $\mathrm{w}_{\mathrm{i}} \cdot \mathrm{v}_{\mathrm{i}}$ \\
\hline 1 & 10 & 100 & 5 & 50 & 8 & 80 & 8 & 80 & 8 & 80 & 8 & 80 \\
\hline 2 & 5 & 35 & 9 & 63 & 9 & 63 & 9 & 63 & 9 & 63 & 9 & 63 \\
\hline 3 & 0 & 0 & 0 & 0 & 10 & 80 & 0 & 0 & 10 & 80 & 10 & 80 \\
\hline 4 & 0 & 0 & 2 & 14 & 2 & 14 & 7 & 49 & 7 & 49 & 9 & 63 \\
\hline 5 & 2 & 10 & 7 & 35 & 7 & 35 & 7 & 35 & 7 & 35 & 7 & 35 \\
\hline 6 & 10 & 60 & 10 & 60 & 10 & 60 & 5 & 30 & 10 & 60 & 10 & 60 \\
\hline$\sum_{i=1}^{n} w_{i} \cdot v_{i j}$ & & 205 & & 222 & & 332 & & 257 & & 367 & & 381 \\
\hline $\mathrm{X}_{\mathrm{i}}$ & & ,48 & & 52 & & 77 & &, 60 & & 85 & & 89 \\
\hline
\end{tabular}

Verifica, através do valor global, observando a Tabela 9, que a alternativa de maior viabilidade do projeto é a sexta concepção. Assim, fica estabelecido que o suporte modular para estampagem incremental nas suas variantes com matriz e sem matriz que atende aos requisitos de rigidez, flexibilidade, modularidade, agilidade na troca da material a ser deformada e simplicidade construtiva. É composto de 4 apoios modulares, 4 pilares, 4 tubos de apoio, uma chapa base, 4 prensa chapas, 32 parafusos M10 de fixação da chapa, 4 buchas roscadas, deslizantes na configuração com matriz e fixas por travas na configuração sem matriz, e 4 parafusos M16 de fixação das buchas, como mostrado na Figura 68.

Ainda durante o projeto do suporte foi desenvolvido o porta ferramentas mostrado na Figura 69. Sua finalidade é garantir que a ferramenta esteja livre para girar. O porta ferramenta não foi considerado na análise de valor e está representado pois completa o ferramental desenvolvido. 


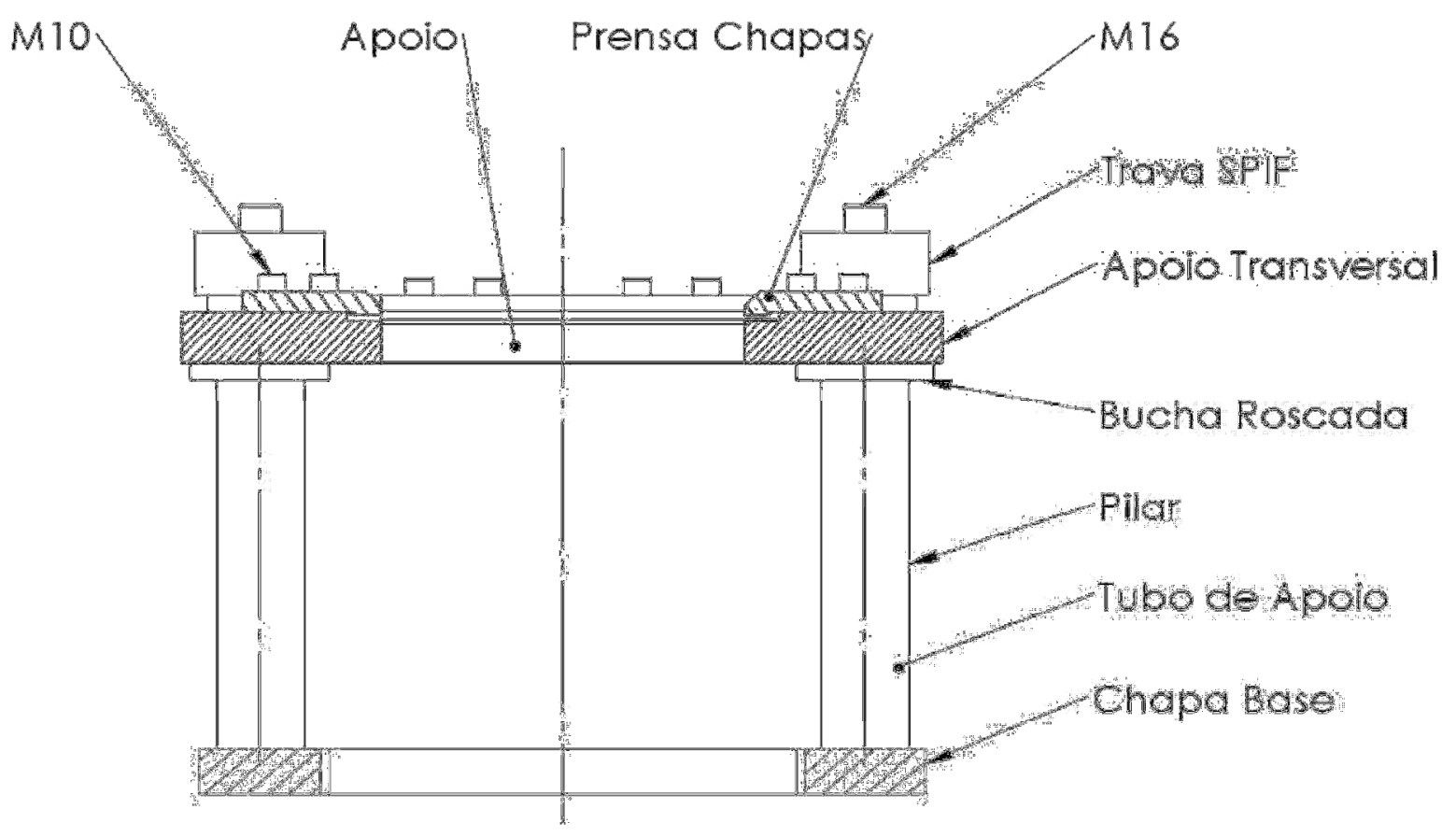

(a)

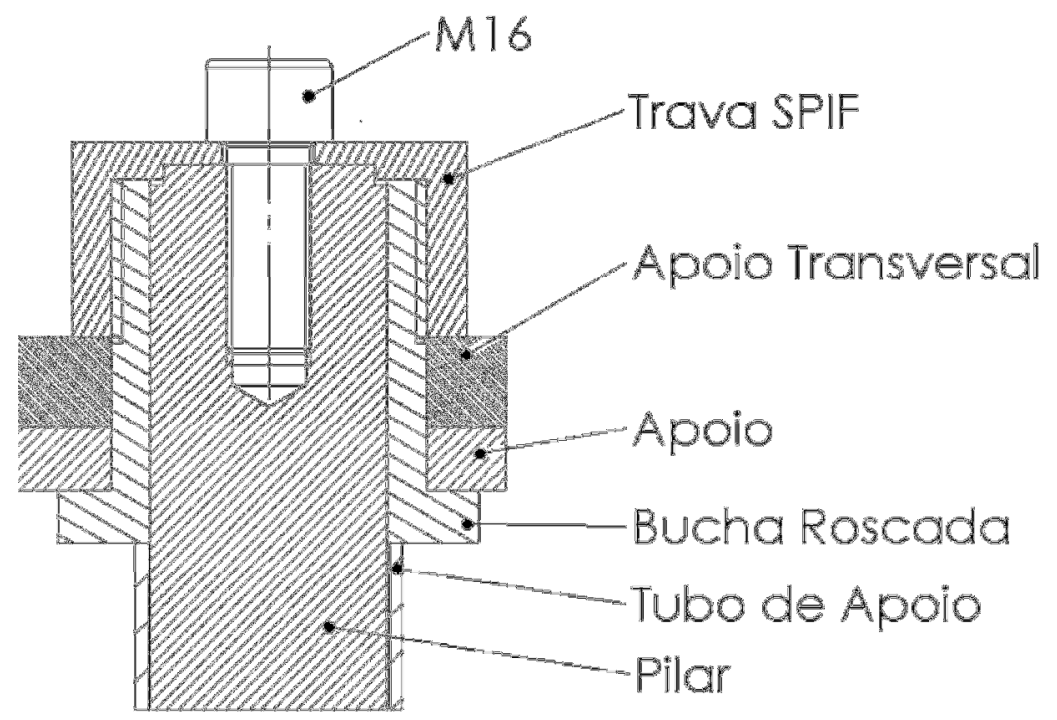

(b)

Figura 68 - (a) Desenho de conjunto da concepção escolhida. (b) Detalhe do dispositivo de travamento dos apoios 


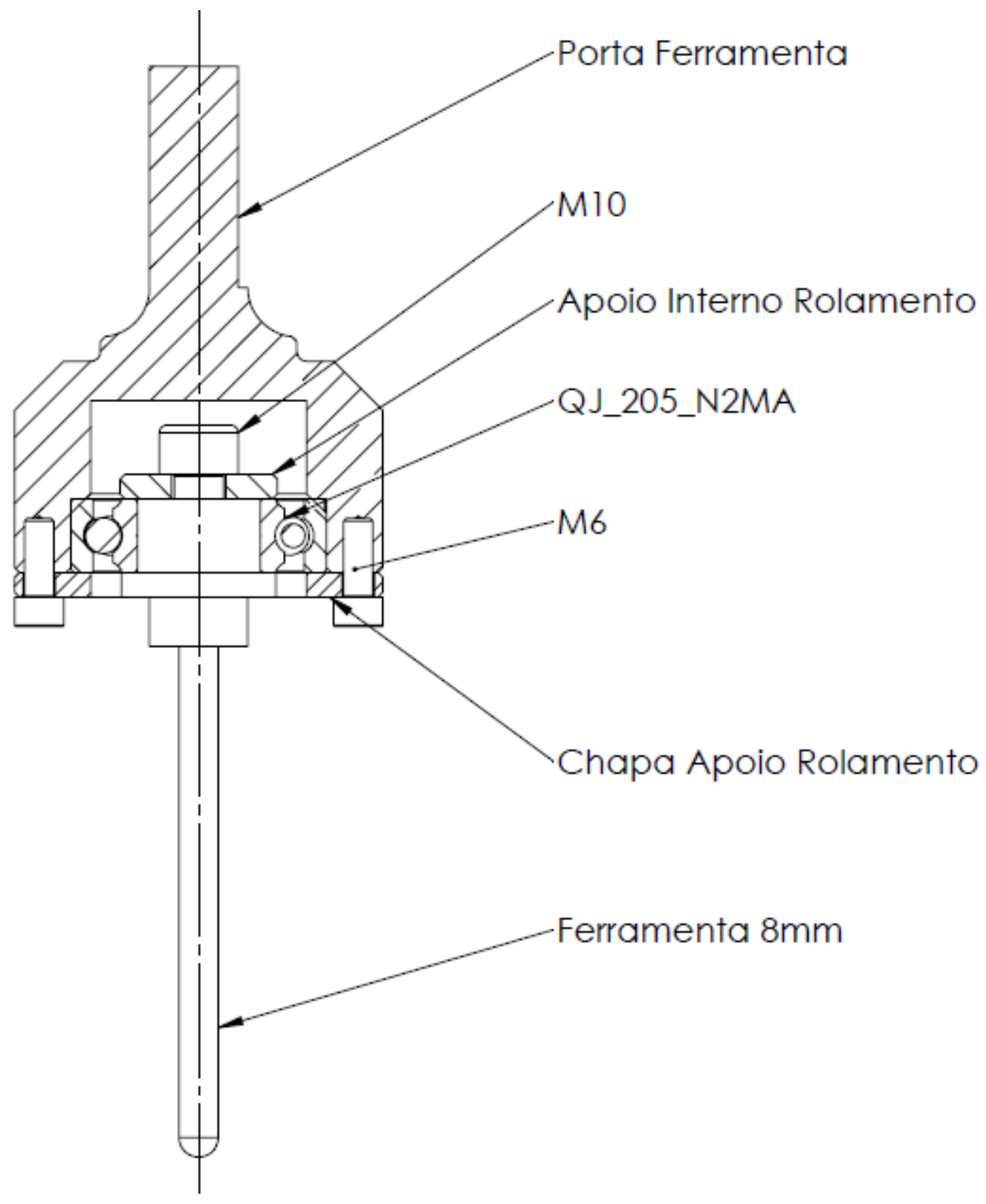

Figura 69 - Porta Ferramentas 


\section{CAPÍTULO 5}

\subsection{Conclusões}

A estampagem incremental de chapas é um processo que cresce em importância à medida que a necessidade por novos processos flexíveis de fabricação aumenta.

Um meio de prever o comportamento de um sistema sob solicitação e de um corpo sob deformação plástica pode ser através de elementos finitos. Neste trabalho foi empregado o software LS-Dyna ${ }^{\mathrm{TM}}$ para prever a trajetória das deformações na estampagem incremental para a fabricação de flanges em chapas previamente furadas.

No que diz respeito à metodologia, foram realizados testes (linha e contato) que visavam otimizar o processo quando do emprego de elementos finitos. Foram realizados os testes de contato e de linha que permitiram definir as condições de contorno da chapa e impediu, por exemplo, acelerar o processo, pois usar este artifício influenciaria nos resultados obtidos. Portanto, é recomendado que antes das simulações façam-se testes como estes.

Foi desenvolvido um programa para simular a trajetória da ferramenta, com e sem a correção pelo seu diâmetro $O$ programa possui duas estratégias de geração de trajetória, uma para incremento em Z variável ao fim de cada volta da ferramenta e outra, cujos incrementos na profundidade são constantes. 
Já as simulações variando o coeficiente de atrito deram ideia de como esse fator influencia nas deformações e para o caso estudados foi usado o coeficiente de atrito de 0,1 .

Com relação ao estudo da trajetória das deformações nos flanges pela estampagem incremental foi possível verificar que as deformações são caracterizadas pelo início na origem e crescimento monotônico até os valores máximos. A parede do flange sofre deformação plana, enquanto na extremidade da aba e no canto há deformação biaxial. Estes resultados corroboram os resultados obtidos por Montanari et al. (2013). O crescimento monotônico também vem ao encontro dos resultados obtidos por Silva et al. (2013) que afirmam que na estampagem incremental de chapas a falha por fratura se dá sem a prévia ocorrência de estricção.

Do mesmo modo, a análise da redução de espessuras permitiu verificar a região onde possivelmente ocorreria a fratura pela redução excessiva de espessura. Para o caso do flange com $D_{0}=102 \mathrm{~mm}$ a maior redução de espessura ocorreu na região R2, no meio da parede do flange.

O modelo de elementos finitos foi usado para determinar o comportamento das trajetórias de deformação. Com esses valores foi possível obter os valores das tensões atuantes e, por fim, o dano crítico.

Portanto é possível afirmar que o emprego do método de elementos finitos para analisar o comportamento das deformações e a região onde ocorrerá a fratura é eficiente do ponto de vista qualitativo, por isso, promissor.

Outro estudo realizado neste trabalho de Mestrado foi o projeto conceitual de um suporte modular adaptável ao centro de usinagem para a estampagem incremental de chapas. Durante a elaboração das diferentes concepções apresentadas, os requisitos de projeto foram gradativamente atingidos, melhorando o projeto a cada nova concepção. Ao final do projeto foi apresentada uma estrutura para a fabricação que melhor atendeu os requisitos de rigidez, flexibilidade, modularidade, agilidade na troca da material e simplicidade construtiva. O resultado foi comprovado utilizandose uma análise de valor, na qual ficou comprovada que a melhor solução, dados os requisitos, foi realmente a última no processo de criação. O suporte modular está 
sendo fabricado e será utilizado em trabalhos experimentais na Escola de Engenharia de São Carlos.

\subsection{Trabalhos futuros}

Modelar o comportamento da chapa, partindo do conhecimento de criação do modelo matemático atual e concomitantemente executar ensaios reais utilizando o suporte modular desenvolvido.

Estudar quais são as condições de contorno realmente necessárias.

Aprimorar o modelo em elementos finitos e a realizar simulações utilizando outros materiais.

Estudar os efeitos de, por exemplo, do deslocamento angular da peça sob deformação.

Por simplificação do modelo, nesse trabalho foi utilizada uma lei isotrópica de endurecimento para o material. No entanto, seria interessante verificar, dentre outras como superfícies de Barlat e encruamento cinemático, qual seria a lei que melhor se adapta ao processo. 


\section{Referências}

ALLWOOD, J. M.; HOUGHTON, N. E.; JACKSON, K. P. The design of an incremental sheet forming machine. Advanced Materials Research, v. 6-8, p. 471 - 478, 2005.

AMBROGIO G., COZZA V., FILICE L., MICARI F. An analytical model for improving precision in single point incremental forming. Journal of Materials Processing Technology, p $92-95,2007$

AMBROGIO, G. et al. Application of incremental forming process for high customised medical product manufacturing. Journal of Materials Processing Technology, p. 156 - 162. 2005.

AMBROGIO, G.; FILICE, L.; GAGLIARDI, F.. Formability of lightweight alloys by hot incremental sheet forming. Materials and Design, p. 501-508, 2012.

AMBROGIO, G.; FILICE, L.; MICARI, F. A force measuring based strategy for failure prevention in incremental forming. Journal of Materials Processing Technology, $p$. $413-416,2006$.

ARAGHI, B. T. et al. Investigation into a new hybrid forming process: Incremental sheet forming combined with stretch forming. CIRP Annals - Manufacturing Technology, p. 225 - 228, 2009.

ARAGHI, B. T. et al. A. Review on the development of a hybrid incremental sheet forming system for small batch sizes and individualized production. Production Engineering. Research and Development, n. 5, p. 393 - 404, 2011.

ARAÚJO, R. et al. Single point incremental forming of a facial implant. Prosthetics and Orthotics International, v. 38, p. $369-378,2014$.

ATKINS, A.G. Fracture in forming. Journal of Materials Processing Technology, $p$. $609-618,1996$.

ATTANASIO, A. et al. Asymmetric two points incremental forming: Improving surface quality and geometric accuracy by tool path optimization. Journal of Materials Processing Technology, v. 197, p. $59-67,2008$.

CÂMARA, J. L. P. B. Single Point Incremental Forming. 2009. 75 f. Dissertação (Mestrado) - Curso de Engenharia Mecânica, Instituto Superior Técnico, Lisboa, 2009.

CENTENO, G. et al. Hole-flanging by incremental sheet forming. International Journal of Machine Tools \& Manufacture, n. 59, p. 46-54, 2012.

CERETTI, E.; GIARDINI, C.; ATTANASIO, A. Experimental and simulative results in sheet incremental forming on CNC machines. Journal of Materials Processing Technology, p. $176-184,2004$.

CHERA, I. et al. FEM researches regarding incremental forming process. Fascicle of Management and Technological Engineering, p. 53-58, 2013.

COFARU, N.; OLEKSIK, V.; PASCU, A. Finite element simulations regard different alternatives of the single point incremental forming process. Proceedings of the 1st 
Wseas International Conference on Visualization, Imaging and Simulation. p. $167-172,2008$.

CRISTINO V. A. M., MARTINS P. A. F., Tecnologia Mecânica, Escolar Editora, 2013.

CRISTINO, V.A. et al. Fracture in hole-flanging produced by single point incremental forming. International Journal of Mechanical Sciences, n. 83, p. 146 - 154, 2014.

CUI, Z. et al. Modeling and validation of deformation process for incremental sheet forming. Journal of Manufacturing Processes, p. 236 - 241, 2013.

CUI, Z.; GAO, L. Studies on hole-flanging process using multistage incremental forming. CIRP Journal of Manufacturing Science and Technology, n. 2, p. 124 128, 2010.

DEDINI, F. G., CAVALCA, K. L. Projeto de sistemas mecânicos. Apostila do curso EM 964 da Faculdade de Engenharia Mecânica da Unicamp, p. 179, 2004.

DEJARDIN, S. et al. Experimental investigations and numerical analysis for improving knowledge of incremental sheet forming process for sheet metal parts. Journal of Materials Processing Technology, p. $263-269,2009$.

DUFLOU, J.R. et al. Experimental study on force measurements for single point incremental forming. Journal of Materials Processing Technology, p. $62-72$, 2007a.

DUFLOU, J.R. et al. Laser Assisted Incremental Forming: Formability and Accuracy Improvement. CIRP Annals - Manufacturing Technology, p. 273 - 276, 2007b.

DUFLOU J. R. et al., Medical application of single point incremental forming: cranial plate manufacturing, Virtual Modelling and Rapid Manufacturing, p 161 - 166, 2005.

ECHRIF S.B.M.; HRAIRI, M. Research and progress in incremental sheet forming processes. Materials and Manufacturing Processes; n. 26, p. $1404-1414$, 2011a.

ECHRIF, S. B. M.; HRAIRI, M. Process simulation and quality evaluation of incremental sheet forming. lium Engineering Journal, Special Issue, Mechanical Engineering, p. $185-196,2011 b$.

EMMENS, W.C.; BOOGAARD, A. H. An overview of stabilizing deformation mechanisms in incremental sheet forming. Journal of Materials Processing Technology, p. $3688-3695,2009$.

FILICE, L.; FRATINI, L.; MICARI, F. Analysis of Material Formability in Incremental Forming. CIRP Annals - Manufacturing Technology, p. 199 - 202, 2002.

FRATINI, L. et al. Influence of mechanical properties of the sheet material on formability in single point incremental forming. CIRP Annals - Manufacturing Technology, p. $207-210,2004$.

HALLQUIST, J. O. LS-DYNA3D Theoretical manual. Livermore, Livemore Software Tecnology Corporation, 1993.

HAM M., JESWIET J. Forming Limit Curves in Single Point Incremental Forming CIRP Annals-Manufacturing Technology, p 277 - 280, 2006 
HAN, F. et al. A Digital Manufacture Technology for Skull Prosthesis using Incremental Sheet Forming Method. Advanced Materials Research, p. $348-352$, 2010.

HENRARD, C. Numerical simulations of the single point incremental forming process. 2009. 224 f., Universidade de Liége, Liège, 2009.

HILL R., A theory of yielding and plastic flow of anisotropic metals, Proceedings of the Royal Society of London (Series A), n. 193, p. 281 - 297, 1948.

HIRT, G. et al. Forming strategies and Process Modelling for CNC Incremental Sheet Forming. CIRP Annals - Manufacturing Technology, p. 203 - 206, 2004.

HUSSAIN, G.; HAYAT, N.; GAO, L. An experimental study on the effect of thinning band on the sheet formability in negative incremental forming. International Journal of Machine Tools \& Manufacture, Nanjing, p. 1170 - 1178, 2008.

JESWIET, J. et al. Asymmetric single point incremental forming of sheet metal. CIRP Annals - Manufacturing Technology, p. 84 - 114, 2005a.

JESWIET, J.; YOUNG, D. Forming limit diagrams for single-point incremental forming of aluminium sheet. Journal of Engineering Manufacture, p. 359-264, 2005b.

KACEM A. et al. Failure prediction in the hole-flanging process of aluminium alloys. Engineering Fracture Mechanics, v. 99, p. 251 - 265, 2013.

KOPAC, J.; KAMPUS, Z. Incremental sheet metal forming on CNC milling machinetool. Journal of Materials Processing Technology, p. $622-628,2005$.

LI, Y. et al. Simulation and experimental observations of incremental sheet forming process. Materials and Manufacturing Processes, n. 29, p. 121 - 128, 2014.

LOPES, A.B. et al. Effect of texture and microstructure on strain hardening anisotropy for aluminum deformed in uniaxial tension and simple shear. International Journal of Plasticity, v. 1, n. 19, p.1 - 22, 2003.

MALHOTRA, R. et al. A new methodology for multi-pass single point incremental forming with mixed toolpaths. CIRP Annals - Manufacturing Technology, Evanston, p. $323-32,2011$.

MEIER, $H$. et al. Increasing the part accuracy in dieless robot-based incremental sheet metal forming. CIRP Annals - Manufacturing Technology, p. 233-328, 2009.

MEIER, $\mathrm{H}$. et al. Two point incremental forming with two moving forming tools. Key Engineering Materials, v. 344, p. 599 - 605, 2007.

MEIER, M., MAGNUS, C., SMUKALA, V. Impact of superimposed pressure on dieless incremental sheet metal forming with two moving tools, Annals of CIRP, $\mathrm{n}$. 60 , p. $327-330,2011$.

MONTANARI, L.; et al. A new approach for deformation history of material elements in hole-flanging produced by single point incremental forming. The International Journal of Advanced Manufacturing Technology, n. 69, p.1175 - 1183, 2013.

OLEKSIK, V.; BREAZ, R. E.; PASCU, A. M. Finite element method simulation for rectangular parts obtained by incremental sheet metal forming process. Proceedings of the 15th International Conference on Manufacturing Systems - Icmas, p. 407 - 410, 2006. 
PAHL, G.; BEITZ, W., Engineering design: A systematic approach. Great Britain, Springer-Verlag London Limited, 1996.

PARK, J.; KIM, Y. Fundamental studies on the incremental sheet metal forming technique. Journal of Materials Processing Technology, p. 447 - 453, 2003.

PETEK, A.; KUZMAN, K.; SUHAC, B.. Autonomous on-line system for fracture identification at incremental sheet forming. CIRP Annals - Manufacturing Technology, p. $283-286,2009$.

PETEK, A.; KUZMAN. K.; FIJAVŽ, R. Backward drawing of necks using incremental approach. Key Engineering Materials; v. 473, p. 105 - 112, 2011.

PETEK, A.; KUZMAN. K. Backward hole-flanging technology using an incremental approach. Journal of Mechanical Engineering, v. 58, n. 2, p. $73-80,2012$.

POWELL, N. N.; ANDREW, C. Incremental forming of flanged sheet metal components without dedicated dies. Proceedings of the Institution of Mechanical Engineers, Part B: Journal of Engineering Manufacture, v. 206, p. 41-47, 1992.

QIN, Q. et al. Numerical simulation on the effect of process parameters for incremental sheet forming. Advanced Materials Research. Beijing, p. $158-161$, 2010.

RICE J. R., TRACEY D.M. On the ductile enlargement of voids in triaxial stress fields. Journal of the Mechanics and Physics of Solids, 1969.

RODRIGUES, J.; MARTINS, P. Tecnologia Mecânica - Tecnologia da deformação plástica - Fundamentos teóricos, v. 1. Escolar Editora, Lisboa, 695p, 2010.

SILVA, M. B. et al. Revisiting the fundamentals of single point incremental forming by means of membrane analysis. International Journal of Machine Tools \& Manufacture, n. 48, p. $73-83,2008 a$.

SILVA M.B.; et al. Single point incremental forming and formability-failure diagrams. Journal Strain Analysis in Engineering Design, n. 43, p. 15 - 36, 2008b.

SILVA M.B., NIELSEN P.S.; BAY N.; MARTINS P.A.F. Failure mechanisms in singlepoint incremental forming of metals, The International Journal of Advanced Manufacturing Technology, n. 56, p. 893 - 903, 2011.

SILVA M.B.; et al. On the formability of hole-flanging by incremental sheet forming. Journal of Materials Design and Applications, n. 227, p. $91-99,2013$.

SILVA M. B., MARTINS P. A. F., Incremental Sheet Forming in Comprehensive Materials Processing, v. 3; p. 7 - 26, 2014. Editado por Hashmi, S.

SKJOEDT, M.; HANCOCK, M. H.; BAY, N. Creating Helical Tool Paths for Single Point Incremental Forming. Key Engineering Materials, p. 583 - 590, 2007.

TEIS, H. E. Handbook of Metal Forming Processes. Editora Marcel Dekker, Inc., New York, 1999.

THIBAUD, S. et al. A fully parametric toolbox for the simulation of single point incremental sheet forming process: Numerical feasibility and experimental validation. Simulation Modelling Practice and Theory, p. 32 - 43, 2012. 
THIPPRAKMAS, S.; JIN, M., MURAKAWA, M. Study on flanged shapes in fine blanked-hole flanging process (FB-hole flanging process) using finite element method (FEM). Journal of Materials Processing Technology, n. 19 - 193, p. 128 133, 2007.

VOSWINCKEL H.; BAMBACH M.; HIRT G. Improving geometrical accuracy for flanging by incremental sheet metal forming. International Journal of Material Forming, p. 1-9, 2014

YAMADA Y.; KOIDE M. Analysis of the bore-expanding test by the incremental theory of plasticity. International Journal of Mechanical Sciences, v. 10, p. $1-14$, 1968.

YAMASHITA, M.; GOTOH, M.; ATSUMI, S. Numerical simulation of incremental forming of sheet metal. Journal of Materials Processing Technology, p. 163 172, 2007. 